\title{
Would you work with me?
}

Citation for published version (APA):

van Schelven, F. (2022). Would you work with me? The process and impact of involving young people with a chronic condition in research and innovation. [Doctoral Thesis, Maastricht University]. Ridderprint. https://doi.org/10.26481/dis.20220218fs

Document status and date:

Published: 01/01/2022

DOI:

$10.26481 /$ dis.20220218fs

Document Version:

Publisher's PDF, also known as Version of record

\section{Please check the document version of this publication:}

- A submitted manuscript is the version of the article upon submission and before peer-review. There can be important differences between the submitted version and the official published version of record.

People interested in the research are advised to contact the author for the final version of the publication, or visit the DOI to the publisher's website.

- The final author version and the galley proof are versions of the publication after peer review.

- The final published version features the final layout of the paper including the volume, issue and page numbers.

Link to publication

\footnotetext{
General rights rights.

- You may freely distribute the URL identifying the publication in the public portal. please follow below link for the End User Agreement:

www.umlib.nl/taverne-license

Take down policy

If you believe that this document breaches copyright please contact us at:

repository@maastrichtuniversity.nl

providing details and we will investigate your claim.
}

Copyright and moral rights for the publications made accessible in the public portal are retained by the authors and/or other copyright owners and it is a condition of accessing publications that users recognise and abide by the legal requirements associated with these

- Users may download and print one copy of any publication from the public portal for the purpose of private study or research.

- You may not further distribute the material or use it for any profit-making activity or commercial gain

If the publication is distributed under the terms of Article $25 \mathrm{fa}$ of the Dutch Copyright Act, indicated by the "Taverne" license above, 


\section{Would you work with me?}

The process and impact of involving young

people with a chronic condition

in research and innovation

Femke van Schelven 
The research presented in this thesis was conducted at Nivel, Netherlands Institute for Health Services Research, and CAPHRI, Care and Public Health Research Institute, Maastricht University. Nivel and CAPHRI participate in the Netherlands School of Public Health and Care Research (CaRe).

$978-94-6122-713-3$

www.nivel.nl

Postbus 1568

3500 BN Utrecht

Tel: 030-27 29700

E-mail: receptie@nivel.nl

Cover design: Studio van Schelven

Word processing: Debora Groothedde

Printing: Ridderprint

All rights reserved. No part of this publication may be reprinted or reproduced or utilized in any form or any electronic, mechanical, or other means, now known or hereafter invented, including photocopying and recording, or any information storage or retrieval. Exceptions are allowed in respect of any fair dealing for the purpose of research, private study, or review. 


\title{
Would you work with me?
}

The process and impact of involving young people with a chronic condition in research and innovation

\author{
DISSERTATION
}

To obtain the degree of Doctor at the Maastricht University, on the authority of the Rector Magnificus, Prof. Dr. Pamela Habibović,

in accordance with the decision of the Board of Deans,

to be defended in public

on Friday 18 February 2022, at 13.00 hours

by

Femke van Schelven 


\section{Supervisor}

Prof. dr. J.J.D.J.M. Rademakers

\section{Co-supervisor}

Dr. H.R. Boeije (Nivel)

\section{Assessment Committee}

Prof. dr. A.J.H.M. Beurskens (chair)

Dr. H.M. van de Bovenkamp (Erasmus University Rotterdam)

Dr. C. Dedding (Amsterdam University Medical Centers)

Prof. dr. G.E. Nagelhout 


\section{Table of contents}

Chapter $1 . \quad$ General introduction

\section{Part I: The evidence base}

Chapter 2. Developments since the ratification of the United

Nations Convention on the Rights of the Child:

a scoping review

\section{Part II: PPI in practice}

Chapter 3. Experiences with PPI through a panel: a focus group

study among young people with a chronic condition

Chapter 4. Lessons learned and practical tips from over thirty projects involving young people with a chronic condition: a mixed methods study

\section{Part III: Meaningful impact}

Chapter 5. An exploration of the relation between the way PPI with young people with a chronic condition is organized and its impact: a multilevel study

Chapter 6. Perspectives of young people with a chronic condition and professionals on meaningful impact:

a Q methodology study

Chapter $7 . \quad$ General discussion

Impact paragraph

Summary

Nederlandse samenvatting

Dankwoord

About the author 



\title{
Chapter 1
}

\author{
General introduction
}

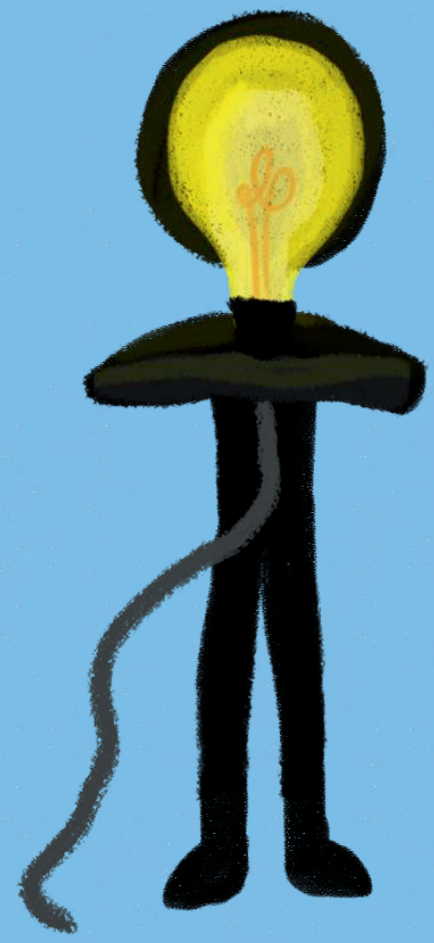




\section{'You can't work for a group without involving them. That is the biggest mistake that is always made. That young people are talked about and not with.'}

This statement was made by a 25-year old girl with a chronic condition who is an active member of a Dutch participatory youth panel. Her remark illustrates an important reason why Patient and Public Involvement (PPI) of young people with a chronic condition is receiving increasing attention. After the ratification of the United Nations on the Convention of the Rights of the Child (UNCRC) in $1989,{ }^{1}$ the awareness that young people have a right to have a say in matters that affect them accelerated. From that time onwards, research and innovation in the field of health and social care has increasingly been carried out with young people with a chronic condition, rather than solely for them. The UNCRC is now ratified by almost all countries in the world, with the Netherlands being among one of the first.

Despite this, the girl's statement also shows that PPI of young people with a chronic condition is not yet common practice. Most research and innovation in health and social care is still carried out by academic researchers, health care professionals and policymakers (hereafter referred to as "professionals"). Questions continue to exist on the right ways of involving young people with a chronic condition and the impact of PPI. These questions led to the research presented in this thesis.

\section{Patient and Public Involvement}

PPI in health and social care has its roots in the second half of the 20th century. This period is characterized by individualization in Western society, in which freedom of choice and self-determination were more and more valued. ${ }^{2}$ The authority of medical institutions was increasingly questioned, due to disappointment over health care decisions that failed to include the views of its users. ${ }^{3}$ During the 1960 s and 1970s, groups of health service users developed a collective voice and formed emancipatory groups that actively campaigned for the right to have a say in matters that affect them. An influential example is the Disability Rights Movement, which advocated against the medical model that reduced them to a disability, label or diagnosis. ${ }^{4}$ Their slogan 'Nothing about us, without us' is now frequently quoted in relation to PPI.

The past decades, PPI gained increasing momentum in health and social care. PPI is becoming increasingly mandatory when applying for research and innovation funding. For example, ZonMw, an important funder of health research in the Netherlands, has adopted PPI as a general criterion in assessing research proposals. ${ }^{5}$ The Dutch organization FNO promotes PPI of young people with a chronic condition in programs that concern them. ${ }^{6}$ 
An abundance of arguments have been put forward in the literature as to why PPI is so important. Generally, they can be divided into three groups: moral, methodological and educational. ${ }^{7-10}$

Moral arguments for PPI suggest that involvement in decisions that will (eventually) affect people's lives is a fundamental right.7,8 These arguments are about democracy and empowerment and often refer to the slogan of the Disability Rights Movement ${ }^{11}$ and - in the case of young people with a chronic condition - to basic rights as described in the UNCRC. ${ }^{1}$ Related to these arguments are policies that emphasize the need for PPI. ${ }^{7,8}$

Methodological arguments suggest that PPI leads to better research and innovation. ${ }^{7,8}$ In the past, research and innovation in health and social care has been criticized for not always matching the needs and values of health service users, as it insufficiently recognized the complexity and contextuality of having an illness and its treatment. Studies on agenda setting have shown that both younger and older health service users value different priorities in research and innovation compared to professionals. ${ }^{12-17}$ It is now generally acknowledged that PPI can improve the relevance and quality of research and innovation, since health service users are able to provide insights from their lived experience. ${ }^{18-23}$

Educational arguments focus on the benefits for the people involved in the PPI process. ${ }^{10}$ Jurrius has described this argument in more detail in her research on participatory research with young people. She argues that PPI can provide (young) health service users with opportunities for personal development. Indeed, many studies have suggested that PPI can contribute to the knowledge and skills, network, independence and confidence of both younger and older health service users. ${ }^{18,19,23}$ Educational arguments can also pertain to professionals. Studies have suggested that professionals benefit from PPI through improving their knowledge and understanding of the area they work in, increasing their awareness of different opinions and viewpoints and challenging them to find innovative ways of working together. ${ }^{23,24}$

\section{Young people with a chronic condition}

The arguments for PPI suggest that both younger and older health service users can and should be involved in research and innovation that concerns them. However, most research on PPI focuses on adults. Relatively little is known about PPI of younger health service user groups, such as young people with a chronic condition.

Although estimations vary, the number of young people with a chronic condition is substantial in the Netherlands. In 2018, it was estimated that over 1,3 million young people aged 0 to 25 were diagnosed with a chronic condition (Box 1). ${ }^{25}$ This is 26 percent of all young people in this age group. Variation in what conditions are classified as chronic makes it difficult to determine exact numbers of young people with a chronic condition. It is, 
however, certain that the number is growing and will continue to grow for the next decades. ${ }^{25-27}$

\section{Box 1. Definition of chronic condition}

Chronic conditions can be physical, such as diabetes, rheumatism and cystic fibrosis, or mental, such as anxiety disorders and depression. They are defined as conditions that 1) are diagnosed based on medical scientific knowledge and made with reproducible and valid methods or instruments that meet professional standards, 2) last at least three to six months or recur at least three times per year and 3) result in the ongoing need for medication, treatment or medical devices. ${ }^{25,27}$

Having a chronic condition can have an enormous impact on young people's lives. Between the age of 16 to 25 years, they are transitioning from adolescence towards adulthood. They become increasingly independent from their families, start building their own social life and focus on school and career choices. ${ }^{28-30}$ These pursuits are challenging for young people in general, but even more for those with a chronic condition. Many studies have shown that young people with a chronic condition are lagging behind in achieving developmental milestones. ${ }^{29,31-34}$ For example, they experience worse outcomes at school, are less likely to have paid jobs and are older when they have their first romantic relationship. Waldboth and colleagues noted that young people with a chronic condition are trying to 'live a normal life in an extraordinary way'. ${ }^{28}$ On the one hand, they have similar interests, pursuits and challenges compared to their peers without a chronic condition. On the other hand, a chronic condition and its treatment impede both their physical and socio-emotional development. $^{34,35}$ Consequently, it requires additional effort to pursuit similar goals compared to their peers without a chronic condition. ${ }^{28}$

In health and social care, many research and innovation projects are conducted that address these topics. However, PPI in these projects received little attention. The tendency to underestimate the competence of young people as decision-makers is most likely an important reason for this. ${ }^{36,37}$ Young people are considered to be less experienced in speaking on behalf of others and less familiar with the way organizations and decisionmaking processes work. This is even more the case for young people with a chronic condition, who are less likely than their healthy peers to have obtained experience in, for example, a side job. ${ }^{31}$ Moreover, sometimes adults' (over)protection limits the possibilities for their PPI, especially when young people have an additional vulnerability, such as a chronic condition. ${ }^{18,38}$

In recent years, however, these perceptions appear to be changing. It is increasingly recognized that young people with a chronic condition can and should be involved in research and innovation projects that concern them. ${ }^{38,39}$ In 1989, the UNCRC established 
this as their fundamental right. Also, an increasing number of studies are showing that young people with a chronic condition are able to contribute to research and innovation projects. Examples are available of them being involved in the preparation of projects (e.g. during grant application ${ }^{40}$ ), in the execution (e.g. in conducting questionnaires and interviews and designing a training ${ }^{40,41}$ ) and in the implementation and dissemination of project results and products (e.g. in writing articles and reports ${ }^{19}$ ).

\section{Terms and definitions of PPI}

Internationally, there is discussion about what PPI exactly entails. Variation exists in both the terminology and its definition. Different words are used to refer to PPI. In the literature, the terms PPI or 'involvement' are used interchangeably with terms such as 'participation' or 'engagement'. These three terms often refer to various definitions. ${ }^{36,42}$ Consequently, the concept has been used in a breadth of ways, making it rather vague and unclear. ${ }^{43,44}$

An influential definition of PPI has been formulated by INVOLVE. ${ }^{42}$ This former advisory group of the British National Institute for Health Research (now replaced by the Centre for Engagement and Dissemination) defined PPI as 'research [or innovation] being carried out with or by members of the public rather than to, about or for them'. Members of the public include (potential) patients, carers, people who use health and social care services and people from organizations that represent people who use services. INVOLVE has not solely provided a definition for PPI, but also for engagement and participation. This helps to clearly distinguish between PPI and these two terms. According to INVOLVE, participation is about people taking part in a research study. They are, for example, taking part in a clinical trial, completing a questionnaire or participating in a focus group. Engagement is about providing access to and disseminating information and knowledge. Examples are sharing study findings with research participants or members of the public and raising awareness of research through media such as television, newspapers and social media. 
Box 2. Hart as the founding father of young people's PPI

Influential work in the field of young people's PPI has been conducted by Hart. In the essay 'Children's participation: From tokenism to citizenship', he describes the Ladder of Involvement to illustrate shared decision-making and associated power relations between young people and adults. ${ }^{36}$ Based on the work of Arnstein on citizen involvement, ${ }^{45}$ he distinguishes eight roles that provide young people with different degrees of agency when working together with adults in projects in the public domain (Figure 1). ${ }^{36}$

Figure 1. Levels of young people's involvement, based on Hart's Ladder of Involvement 8. Child-initiated, shared decisions with adults: Young people invite adults to share decision-making in a project they come up with and design.

7. Child-initiated and directed: Initial project ideas come from young people. They also decide how a project will be executed.

6. Adult-initiated, shared decisions with young people: Adults initiate the initial ideas for a project, but young people are involved in every stage of a project. Challenges in the project and disagreements between young people and adults are openly discussed.

5. Consulted and informed: Young people are informed and consulted about projects developed and led by adults.

4. Assigned but informed: Young people are consciously performing tasks assigned to them by adults.

3. Tokenism: Young people are asked to share their opinions, but in fact have little or no influence on the project.

2. Decoration: Young people are involved in a project organised by adults, with little understanding of their involvement. Adults do no pretend the project is inspired by young people.

1. Manipulation: Adults use the voice of young people to communicate their own message.

Over the years, Hart's Ladder of Involvement has been criticised. ${ }^{37,46-48}$ The most common criticisms focus on the ladder metaphor. According to Tritter and McCallum, a ladder is an oversimplification of reality. ${ }^{47} \mathrm{~A}$ ladder does not do justice to the complexities associated with PPI. It does not take into account the variety of young people that can be involved, the methods adopted to involve them and the projects they are involved in. Other criticisms address the hierarchy the ladder implies. ${ }^{37,46,47}$ Many have interpreted this as if the higher rungs are superior to the lower rungs. Hart's Ladder of Involvement has also been criticized for taking adults' view as a starting point. ${ }^{37,48}$ The 
rungs of the ladder describe the decision making power adults have and how they share it with young people. A model that departs from the perspective of young people may be more preferred, when thinking about PPI. Some have even argued a top rung should be added to the ladder, representing young people making decisions without adults. ${ }^{46}$

In 2008, Hart wrote a book chapter called 'Stepping Back from The Ladder' in which he responded to the criticism. ${ }^{46} \mathrm{He}$ stated that the ladder may have been 'unfortunate'. He borrowed the metaphor from the work of Arnstein, ${ }^{45}$ as he considered it a useful metaphor to organize his thinking about PPI. It was, however, not his intention to suggest a hierarchy. Hart acknowledges that the opportunities for PPI depend on the young people and the context in which PPI takes place. Young people should not always try to (or feel like they have to) be involved as co-deciders and adults do not always have to support shared decision making. Hart also addresses the desire to add a top rung to the ladder on which young people are making decisions without adults. ${ }^{46} \mathrm{Here}$, he makes an important point about PPI. He argues that PPI is about inviting others to be involved and recognizing that others have a voice too. In other words, adults should respect and listen to young people's views, but it should also be the other way around. However, as Hart comments on the United Nations Convent on the Rights of the Child (UNCRC): 'Children's rights to have their perspective taken into account "in all matters that concern them" are often wrongly understood to mean that children should have the last word.'

\section{From theory to practice}

The theoretical underpinning of PPI raises great expectations about its moral, methodological and educational impact. However, translating the theory of PPI into practice is not without challenges. Young people with a chronic condition and professionals are struggling how to shape their collaboration. Substantive issues include, for example, how to achieve the impact they desire and how to handle differences in ideas and opinions. ${ }^{20,49}$ There are more practical challenges as well, since PPI of young people with a chronic condition requires additional time and resources. ${ }^{50,51}$ The health issues, fatigue and sudden hospital stays young people with a chronic condition have to cope with can make PPI processes even more challenging.

An important reason for these challenges is the context-dependency of PPI. PPI is not a single, simple intervention and there is no blueprint for doing it right. ${ }^{37,52}$ It can take many forms. As illustrated by Hart's Ladder of Involvement (Box 2), young people with a chronic condition can play various roles in projects. They can also be involved in different stages of projects, e.g. preparation, execution or implementation. For many, it is unclear what roles young people with a chronic condition should play in what stages of projects to achieve 
the desired impact. ${ }^{40,41,50}$ This depends on numerous factors, such as the persons involved and the aim and content of the research or innovation project they are involved in.

The organization of PPI processes is further complicated by power relations between young people with a chronic condition and professionals. ${ }^{53-56}$ PPI is about inviting others to be involved and recognizing voices of others, thus both young people with a chronic condition and professionals should be able to influence decision making. This requires a change in traditional thinking about power relations. For a long time, decision making power has been the domain of professionals. Young people with a chronic condition - and health service users in general - were receivers of care provided by medical professionals, participants in research conducted by academic researchers and subjects to choices of policy makers. In PPI, these traditional power relationships are shifting and professional boundaries are blurred as young people with a chronic condition become peers and members of project teams. ${ }^{18,57}$ Professionals have to let go some of the control in order to give them the opportunity to make a difference. It has been shown that this can cause discomfort in PPI of health service users in general. ${ }^{56}$ In PPI of young people with a chronic condition, this discomfort may be even more present, due to their age and perceived vulnerability. Professionals might be hesitant to choose for PPI, as they fear that providing young people with a chronic condition with too much decision making power might come at the expense of the quality and professionality of research and innovation, rather than improving it.

To address the challenges in organizing PPI processes, more insight is needed into the way young people with a chronic condition can be involved in research and innovation projects in health and social care and what factors hinder or facilitate the achievement of impact that is meaningful to themselves and professionals. Sharing lessons learned from PPI practice can provide valuable examples of what works in specific contexts, provide professionals with more confidence to share decision making power and motivate young people with a chronic condition to be involved.

\section{Evaluation in PPI}

Robust evaluations are a valuable means to obtain more insight into what works in PPI of young people with a chronic condition. They can help answering two relevant questions. ${ }^{52}$ First, what difference does PPI make? Information about impact provides insights in the achievement of PPI aims. And second, what PPI approaches are successful in achieving its aims? In the words of Staniszewska and colleagues: 'it requires evidence to inform best practice' $^{58}$

It is sometimes suggested that impact evaluations are not useful in PPI. Especially those who do PPI based on moral arguments have stated that PPI is a right and therefore always of value, irrespective of its impact. ${ }^{52}$ However, Staley rightly argued that robust impact evaluations can always provide relevant feedback on the success of a PPI approach and the 
achievement of its aims. She emphasized that understanding PPI as a right can give patients 'a seat at the table', whereas impact evaluations can improve PPI approaches to ensure they can actually exercise their rights. ${ }^{52}$

Unfortunately, impact evaluations in PPI of young people with a chronic condition are still in its infancy. The current evidence for its impact is scarce and lacking quality. The authors of a literature review published in 2004 concluded this was due to the novelty of the topic..$^{59}$ A literature review conducted ten years later showed little progress. ${ }^{51}$ The authors of this review suggested this is the result of inconsistencies in defining and reporting PPI and a lack of robust methods to evaluate it. However, little detail is provided on what exactly is reported and what methods are currently used.

Measuring PPI impact appears to be as complex and context-dependent as its process. Impact can come in different shapes and sizes. ${ }^{52}$ In a literature review on PPI in research, no less than nine types of impact were identified: on the research agenda, design and delivery, ethics, the people involved, researchers, participants, the wider community, community organizations and implementation and change. This impact may not solely occur at the end of PPI, but also during. ${ }^{60}$ This makes it difficult to determine what impact should be expected and monitored and when.

There is a need for improved evaluation of PPI of young people with a chronic condition to obtain more insight in how and whether its expectations are met. This starts with a better understanding of the aspects that should be addressed to improve the quality of evaluation studies. Mapping the developments that took place in research on PPI of young people with a chronic condition can provide valuable insights in the origins of the standstill in this field and identify ways to move forward. Moreover, more insight is needed in what forms of impact should be addressed in evaluations.

\section{Research objectives and questions}

Worldwide, young people with a chronic condition are increasingly involved in research and innovation that concerns them. Moral, methodological and educational arguments have raised great expectations about the impact of this PPI. However, it is unclear how and whether these expectations are actually met. Therefore, the main objectives of this thesis are to:

1. Gain insight into the concept of PPI of young people with a chronic condition and possible shifts herein over time; and

2. Strengthen the evidence base on how young people with a chronic condition can be involved in research and innovation projects in health and social care to achieve impact that is meaningful to them and to others. 
Based on these objectives, the following research questions have been formulated:

1. What developments in PPI of young people with a chronic condition can be seen in the existing literature over the past decades?

2. What factors hinder or facilitate (1) the process of PPI of young people with a chronic condition in research and innovation projects and (2) the impact of their PPI?

3. What is meaningful impact in the context of PPI of young people with a chronic condition in research and innovation projects, and how can this be evaluated?

\section{Content}

This thesis starts with five chapters describing studies that address the research questions presented in the previous subsection. The thesis is divided into three parts. Part $\mathbf{1}$ focuses on the developments in the literature on PPI with young people with a chronic condition. It contains one chapter (chapter 2) that presents the results of a scoping review of the literature since the ratification of the UNCRC in 1989. A systematic overview is provided of the definitions, goals, activities, experiences and impact that were reported from then up and until 2018. Part 2 contains two chapters and addresses examples of how young people with a chronic condition can be involved and the lessons that were learned about hindering and facilitating factors for PPI and its impact. Chapter 3 describes the experiences of young people with a chronic condition with PPI through a participatory panel. Then, chapter 4 presents the lessons learned from a large program that funded over thirty projects in which young people with a chronic condition were involved. Part $\mathbf{3}$ of this thesis contains two chapters and focuses on defining and evaluating meaningful impact of PPI. It starts with a quantitative exploration of the relation between how PPI is organized and its outcomes (chapter 5). Chapter 6 provides insight into the different perspectives of young people with a chronic condition and researchers on meaningful PPI and its implications for evaluating impact.

In chapter 7, the overall discussion and conclusions are presented. The implications for practice and recommendations for future research are addressed here as well. 


\section{References}

1. United Nations General Assembly. Convention on the Rights of Child, 1989.

2. Rademakers J. De actieve patiënt als utopie. Utrecht: Nivel; 2016.

3. Wilson P, Mathie E, Keenan J, et al. ReseArch with Patient and Public invOlvement: a RealisT evaluation: The RAPPORT study. Health Services and Delivery Research. 2015;3(38). doi: $10.3310 /$ hsdr03380

4. Trigt $P$ van. A Blind Spot of a Guiding Country? Human Rights and Dutch Disability Groups Since 1981. Disability Movements: National Policies and Transnational Perspectives. 2015;53:87-102. doi:10.13154/mts.53.2015.87-102

5. ZonMw. Relevantiecriteria ZonMw. Published 2017. Accessed June 22, 2020. https://www.zonmw.nl/nl/subsidies/relevantiecriteria/.

6. FNO Zorg voor Kansen. Jongeren INC: Programmatekst 2020-2023. Published 2020. Accessed October 30, 2020. https://www.fnozorgvoorkansen.nl/wp-content/ uploads/ 2020/01/Publieksversie-Programmatekst-Jongeren-INC-26-nov.pdf.

7. Morris $C$, Shilling $V$, McHugh $C$, Wyatt $K$. Why it is crucial to involve families in all stages of childhood disability research. Dev Med Child Neurol. 2011;53(8):769-771. doi:10.1111/j.14698749.2011.03984.x

8. van der Scheer $\mathrm{L}$, Boenink M. The benefits of patient involvement for translational research. Health Care Anal. 2017;25(3):225-241. doi:10.1007/s10728-014-0289-0

9. Boote J, Ward PR, Thompson J, et al. Critical perspectives on 'consumer involvement' in health research: Epistemological dissonance and the know-do gap. J Sociol. 2009;46(1):63-82. doi:10.1177/1440783309351771

10. Jurrius K. Uit de spagaat! Naar een kwaliteitsraamwerk voor participatief jongeren onderzoek. [PhD thesis]. Utrecht: Utrecht University; 2012.

11. Charlton J. Nothing about us without us: Disability oppression and empowerment. University of California Press; 1998.

12. Tallon D, Chard J, Dieppe P. Relation between agendas of the research community and the research consumer. Lancet. 2000;355(9220):2037-2040. doi:10.1016/S0140-6736(00)02351-5

13. Broerse JEW, Zweekhorst MBM, van Rensen AJML, de Haan MJM. Involving burn survivors in agenda setting on burn research: An added value? Burns. 2010;36(2):217-231. doi:10.1016/j.burns.2009.04.004

14. Nierse CJ, Abma TJ. Developing voice and empowerment: The first step towards a broad consultation in research agenda setting. J Intell Disabil Res. 2011;55(4):411-421. doi:10.1111/j.1365-2788.2011.01388.x

15. Crowe $S$, Fenton $M$, Hall $M$, Cowan $K$, Chalmers I. Patients', clinicians' and the research communities' priorities for treatment research: There is an important mismatch. Res Involv Engagem. 2015;1(1):1-10. doi:10.1186/s40900-015-0003-x

16. Tunnicliffe DJ, Singh-Grewal D, Craig JC, et al. Healthcare and research priorities of adolescents and young adults with systemic lupus erythematosus: A mixed-methods study. Journal Rheumatol. 2017;44(4):444-451. doi:10.3899/jrheum.160720

17. Odgers $\mathrm{HL}$, Tong $\mathrm{A}$, Lopez-Vargas $\mathrm{P}$, et al. Research priority setting in childhood chronic disease: A systematic review. Arch Dis Child. 2018;103(10):942-951. doi:10.1136/archdischild-2017-314631 
18. Chappell $P$, Rule $P$, Dlamini M, Nkala N. Troubling power dynamics: Youth with disabilities as coresearchers in sexuality research in South Africa. Childhood. 2014;21(3):385-399. doi:10.1177/0907568214525427

19. Flicker $\mathrm{S}$. Who benefits from community-based participatory research? A case study of the positive youth project. Health Educ Behav. 2006;35(1):70-86. doi:10.1177/1090198105285927

20. Graham N, Mandy A, Clarke C, Morriss-Roberts C. Using children and young people as advocates to inform research design. Brit J Occup Ther. 2017;80(11):684-688. doi:10.1177/0308022617725491

21. Stevenson M. Participatory data analysis alongside co-researchers who have Down syndrome. J App/ Res Intellect Disabil. 2014;27(1):23-33. doi:10.1111/jar.12080

22. Powers LE, Garner T, Valnes B, et al. Building a successful adult life: Findings from youth-directed research. Exceptionality. 2007;15(1):45-56. doi:10.1080/09362830709336925

23. Brett J, Staniszewska S, Mockford C, et al. A systematic review of the impact of patient and public involvement on service users, researchers and communities. Patient. 2014;7(4):387-395. doi:10.1007/s40271-014-0065-0

24. Staley K. Exploring impact: Public involvement in NHS, public health and social care research. Eastleigh: INVOLVE; 2009.

25. van Hal L, Tierolf B, van Rooijen M, van der Hoff M. Een actuee/ perspectief op kinderen en jongeren met Een chronische aandoening in Nederland. Utrecht: Verwey-Jonker Instituut; 2019.

26. Sawyer SM, Drew S, Yeo MS, Britto MT. Adolescents with a chronic condition: Challenges living, challenges treating. Lancet. 2007;369(9571):1481-1489. doi:10.1016/S0140

27. Mokkink LB, Van der Lee JH, Grootenhuis MA, Offringa M, Van Praag BMS, Heymans HSA. Omvang en gevolgen van chronische aandoeningen bij kinderen. Tijdschrift voor kindergeneeskunde. 2007;75(4):154-158.

28. Waldboth V, Patch C, Mahrer-Imhof R, Metcalfe A. Living a normal life in an extraordinary way: A systematic review investigating experiences of families of young people's transition into adulthood when affected by a genetic and chronic childhood condition. Int I Nurs Stud. 2016;62:44-59. doi:10.1016/j.ijnurstu.2016.07.007

29. Taylor RM, Gibson F, Franck LS. The experience of living with a chronic illness during adolescence: A critical review of the literature. J Clin Nurs. 2008;17(23):3083-3091. doi:10.1111/j.13652702.2008.02629.x

30. Sattoe J. Growing up with a chronic condition: Challenges for self-management and selfmanagement support. [PhD thesis]. Rotterdam: Erasmus University; 2015.

31. Maurice-Stam H, Nijhof SL, Monninkhof AS, Heymans HSA, Grootenhuis MA. Review about the impact of growing up with a chronic disease showed delays achieving psychosocial milestones. Acta Paediatr. 2019;108(12):2157-2169. doi:10.1111/apa.14918

32. Stam H, Hartman EE, Deurloo JA, Groothoff J, Grootenhuis MA. Young adult patients with a history of pediatric disease: Impact on course of life and transition into adulthood. $J$ Adolescent Health. 2006;39(1):4-13. doi:10.1016/j.jadohealth.2005.03.011

33. Lum A, Wakefield CE, Donnan B, et al. Understanding the school experiences of children and adolescents with serious chronic illness: A systematic meta-review. Child Care Health Dev. 2017;43(5):645-662. doi:10.1111/cch.12475

34. Sattoe JNT, Hilberink SR, Van Staa A, Bal R. Lagging behind or not? Four distinctive social participation patterns among young adults with chronic conditions. I Adolescent Health. 2014;54(4):397-403. doi:10.1016/j.jadohealth.2013.09.017 
35. Harries T, Rettie R, Gabe J. Shedding new light on the (in)compatibility of chronic disease management with everyday life: Social practice theory, mobile technologies and the interwoven time-spaces of teenage life. Sociol Health III. 2019;41(7):1396-1409. doi:10.1111/1467-9566.12952

36. Hart R. Children's participation: From tokenism to citizenship. Florence: UNICEF; 1992.

37. Dedding C. Delen in macht en onmacht: Kindparticipatie in de (alledaagse) diabeteszorg. [PhD thesis]. Amsterdam: University of Amsterdam; 2009.

38. Brady LM, Preston J. How do we know what works? Evaluating data on the extent and impact of young people's involvement in English health research. Research for All. 2020;4(2):194-206. doi:10.14324/RFA.04.2.05

39. Allsop MJ, Holt RJ, Levesley MC, Bhakta B. The engagement of children with disabilities in healthrelated technology design processes: Identifying methodology. Disabil Rehabil Assist Technol. 2010;5(1):1-13. doi:10.3109/17483100903323267

40. Rosen-Reynoso M, Kusminsky M, Gragoudas S, et al. Youth-based participatory research: Lessons learned from a transition research study. Pediatrics. 2010;126(S3):S177-S182. doi:10.1542/peds.2010-1466N

41. Kramer J, Barth Y, Curtis K, et al. Involving youth with disabilities in the development and evaluation of a new advocacy training: Project TEAM. Disabil Rehabil. 2013;35(7):614-622. doi:10.3109/09638288.2012.705218

42. INVOLVE. What is public involvement in research? Accessed July 23, 2020. https://www.invo.org.uk/find-out-more/what-is-public-involvement-in-research-2/

43. Blunt C, Blyth C, Chapman R, et al. Editorial. Brit J Learn Disabil. 2012;40(2):83-84. doi:10.1111/j.1468-3156.2012.00748.x

44. Cook T, Boote J, Buckley N, Vougioukalou S, Wright M. Accessing participatory research impact and legacy: Developing the evidence base for participatory approaches in health research. Educ Action Res. 2017;25(4):473-488. doi:10.1080/09650792.2017.1326964

45. Arnstein S. A ladder of citizen participation. J Am I Planners. 1969;35(4):216-224. doi:10.1080/01944366908977225

46. Hart R. Stepping back from "the ladder": Reflections on a model of participatory work with children. In: Reid A, Bruun B, Nikel J, Simovska V, eds. Participation and Learning: Perspectives on Education and the Environment, Health and Sustainability. Springer; 2008:19-31.

47. Tritter JQ, McCallum A. The snakes and ladders of user involvement: Moving beyond Arnstein. Health Policy. 2006;76(2):156-168. doi:10.1016/j.healthpol.2005.05.008

48. Reddy N, Ratna K. A journey in children's participation. Bangalore: The Concerned For Working Children; 2002.

49. Murray R. Sixth Sense: The disabled children and young people's participation project. Child Soc. 2012;26(3):262-267. doi:10.1111/j.1099-0860.2012.00439.x

50. Van Staa A, Jedeloo S, Latour JM, Trappenburg MJ. Exciting but exhausting: Experiences with participatory research with chronically ill adolescents. Health Expect. 2010;13(1):95-107. doi:10.1111/j.1369-7625.2009.00574.x

51. Bailey $S$, Boddy $K$, Briscoe $S$, Morris $C$. Involving disabled children and young people as partners in research: A systematic review. Child Care Health Dev. 2015;41(4):505-514. doi:10.1111/cch. 12197

52. Staley K. 'Is it worth doing?' Measuring the impact of patient and public involvement in research. Res Involv Engagem. 2015;1(1):1-10. doi:10.1186/s40900-015-0008-5 
53. Locock L, Boylan A-M, Snow R, Staniszewska S. The power of symbolic capital in patient and public involvement in health research. Health Expect. 2017;20(5):836-844. doi:10.1111/hex.12519

54. Baur V, van Elteren A, Abma TA. Dealing with distrust and power dynamics: Asymmetric relations among stakeholders in responsive evaluation. Evaluation. 2010;16(3):233-248. doi:10.1177/1356389010370251

55. Tritter JQ. Revolution or evolution: The challenges of conceptualizing patient and public involvement in a consumerist world. Health Expect. 2009;12(3):275-287. doi:10.1111/j.13697625.2009.00564.x

56. Woelders S. Power-full patient participation: Opening spaces for silenced knowledge. [PhD thesis]. Amsterdam: Vrije Universiteit Amsterdam; 2009.

57. Rich C, Goncalves A, Guardiani M, O'Donnell E, Strzelecki J. Teen advisory committee: Lessons learned by adolescents, facilitators and hospital staff. Pediatr Nurs. 2014;40(6):289-296.

58. Staniszewska S, Herron-Marx S, Mockford C. Measuring the impact of patient and public involvement: The need for an evidence base. Int J Qual Health C. 2008;20(6):373-374. doi:10.1093/intqhc/mzn044

59. Cavet J, Sloper P. Participation of disabled children in individual decisions about their lives and in public decisions about service development. Child Soc. 2004;18(4):278-290. doi:10.1002/CHI.803

60. Springett J. Impact in participatory health research: What can we learn from research on participatory evaluation? Educ Action Res. 2017;25(4):560-574. doi:10.1080/09650792.2017.1342554 




\section{Chapter 2}

\section{Developments since the ratification of the United Nations Convention on the Rights of the Child: a scoping review}

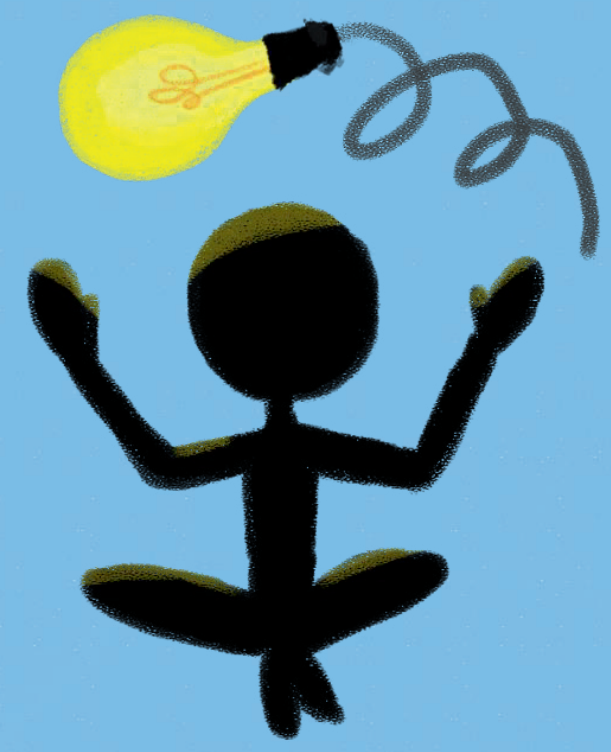

Published as: Schelven F van, Boeije H, Mariën V, Rademakers J. Patient and Public Involvement of young people with a chronic condition in projects in health and social care: A scoping review. Health Expectations. 2020;23(4):789-801. doi:10.1111/hex.13069 


\section{Abstract}

Background. The involvement of young people with a chronic condition in research and implementation projects in health and social care receives growing attention. Yet, there is a lack of conceptual clarity of this so-called 'Patient and Public Involvement' (PPI) and methods to systematically evaluate it are absent. This scoping review aimed to gain insight into developments in the existing literature on PPI of young people with a chronic condition by mapping reported definitions, goals, activities, experiences and impact.

Methods. We conducted searches in Cinahl, Embase, PsycINFO, PubMed and Scopus. Included articles described involvement of young people with a chronic condition in research and implementation projects, contained empirical data, were written in English and were published after 1990. Two researchers independently carried out the data extraction.

Results. Twenty-three studies out of 4993 initial hits met the inclusion criteria. We found great variation in definitions and operationalizations of PPI. Reflections of authors on the process of PPI and its impact were similar and did not change over the years.

Discussion and conclusion. Limited progress in the evidence base of the impact of PPI with young people with a chronic condition was found. Over the years, studies continue to report similar experiences and challenges. In order to move forward, we suggest future research to make connections to existing work instead, to include thorough descriptions of what is understood by PPI and how this is translated into activities, and to use systematic and objective, but also flexible, methods to measure its impact. 


\section{Introduction}

Internationally, there is growing attention for the involvement of young people with a chronic condition (YPCC). ${ }^{1,2}$ Researchers and policy makers increasingly aim to carry out research projects (eg scientific projects aimed at increasing knowledge) and implementation projects (eg practice-oriented projects aimed at developing, for example, tools and interventions) together with rather than about or for them. ${ }^{3}$ This is often referred to as 'Patient and Public Involvement' (PPI) and is associated with the ratification of the United Nations Convention on the Rights of the Child (UNCRC) in 1989. ${ }^{4}$ According to this convention, all young people have a right to have a say in matters that affect them, without discrimination and irrespective of disabilities.

Young people with a chronic condition's involvement in research and implementation projects in health and social care is also motivated by the expected benefits. Researchers have argued that PPI improves the relevance and quality of projects ${ }^{1,5,6}$ and contributes to the personal development of YPCC. ${ }^{1,6-9}$ Consequently, there appears to be a general consensus that YPCC's involvement should become an integral and standard element of projects that affect them. ${ }^{2,8,10}$

However, two systematic reviews have found remarkably little (high quality) evidence concerning the impact of PPI with YPCC. 1,2 The authors of the first review, published in 2004, have suggested that this was due to the novelty of the research area. ${ }^{2}$ Ten years later, the authors of another review concluded that evidence was still limited. ${ }^{1}$ According to them, this can be related to inadequate reporting and the absence of methods to assess PPI processes and outcomes.

Highly relevant in the discussion about reporting and assessing the impact of PPI is the lack of clarity about the concept. ${ }^{11-14}$ A well-known definition of young people's involvement in projects has been formulated by Hart: the process of sharing decisions which affect one's life and the life of the community in which one lives. ${ }^{15}$ This definition, and other definitions that have frequently been referred to, 3,16 are rather broad. It has been suggested that these umbrella definitions create space for diverse interpretations and meanings of the concept. ${ }^{11,13}$ Consequently, researchers and policy makers have used it in a breadth of ways, ${ }^{13,14}$ making the concept rather unclear.

There is a dearth of research addressing the conceptualization of PPI with YPCC. In 2017, Educational Action Research has dedicated a special issue to conceptualizing impact of $\mathrm{PPI}_{1}{ }^{17}$ but the studies in this issue have focused on other or broader populations (eg adults or young people in general). It is suggested that the concept of PPI with YPCC can be somewhat different. ${ }^{18}$ 
Conceptual clarity about PPI with YPCC is needed to generate more and higher quality evidence concerning its impact. ${ }^{11}$ The current lack of clarity has resulted in the use of different definitions for the same terms, leading to confusion in what exactly is measured. ${ }^{12} \mathrm{~A}$ more general consensus of what is understood by PPI and what outcomes can be expected is essential in developing methods to systematically assess its impact.

The aim of this review was to gain insight into how PPI with YPCC in projects in health and social care is conceptualized in the existing literature and possible shifts herein. We have mapped reported definitions and goals, activities, experiences and impact. The following research questions were studied:

1. What definitions and goals of PPI with YPCC are described in the existing literature?

2. How are these definitions and goals operationalized in involvement activities?

3. What are the experiences with and impact of these involvement activities?

4. What developments in PPI with YPCC can be seen in the existing literature after the UNCRC was ratified in 1989 ?

Since this is an emerging field in research, a scoping review design was chosen for the study. ${ }^{19,20}$ This design allows for a flexible and broad approach in mapping research activity, that is summarizing the range of evidence to gain insight in its breadth and depth. From this, conclusions can be drawn regarding the overall state of the literature and research gaps can be identified.

\section{Methods}

A scoping review was conducted following the stages of the methodological framework developed by Arksey and O'Malley, ${ }^{19}$ refined by Levac, Colquhoun and O'Brien. ${ }^{20}$

\section{Stage 1: Identifying research questions and aim}

The questions and aim that guided the review are specified in the introduction. A wide approach was chosen to generate breadth of coverage in this area of research. Important parameters were: young people, that is people aged 12-25; chronic conditions, that is conditions 'that last or are expected to last twelve or more months and result in functional limitations and/or the need for ongoing medical care', ${ }^{21}$ and PPI.

\section{Stages 2 and 3: Identifying studies and study selection}

The search strategy was developed by the first author with the help of a librarian. It employed variations and Boolean connections (AND, OR) of the following terms: young people, chronic conditions and PPI. Searches were conducted in five databases: Cinahl, Embase, PsycINFO, PubMed and Scopus. Table 1 shows the search string used in PubMed as an example. The last search was performed 23 January 2019. 
Table 1. Search string in PubMed

\begin{tabular}{|c|c|}
\hline Search & Query \\
\hline \#5 & $\begin{array}{l}\text { Search (((\#1 AND \#2 AND \#3))) AND ("1990"[Date - Publication] : "3000"[Date } \\
\text { - Publication]) }\end{array}$ \\
\hline \#4 & Search (\#1 AND \#2 AND \#3) \\
\hline \#3 & $\begin{array}{l}\text { Search ("Stakeholder Participation"[Mesh] OR } \\
\text { Participation"[Mesh] OR "Patient participation"[Mesh] OR "Community-Based } \\
\text { Participatory Research"[Mesh] OR research particip*[tiab] OR participatory } \\
\text { research[tiab] OR participatory action research[tiab] OR project particip*[tiab] } \\
\text { OR program particip*[tiab] OR policy participat*[tiab] OR meaningful } \\
\text { particip*[tiab] OR research involv*[tiab] OR patient participation[tiab] OR user } \\
\text { involvement[tiab] OR participative[tiab] OR participatory[tiab] OR } \\
\text { engagement[tiab] OR collaborative[tiab] OR advocacy[tiab]) }\end{array}$ \\
\hline$\# 2$ & $\begin{array}{l}\text { Search ("Chronic Disease"[Mesh] OR "Disabled Persons"[Mesh] OR chronic } \\
\text { disease*[tiab] OR chronic ill*[tiab] OR chronically ill[tiab] OR chronic } \\
\text { condition[tiab] OR chronic disab*[tiab] OR disabled person[tiab] OR physical } \\
\text { disab*[tiab] OR physically handicapped[tiab] OR physically challenged[tiab] } \\
\text { OR disablilit*[tiab] OR handicapped[tiab] OR physically disabled[tiab] OR } \\
\text { mentally disabled[tiab]) }\end{array}$ \\
\hline$\# 1$ & $\begin{array}{l}\text { Search ("Adolescent"[Mesh] OR "Young Adult"[Mesh] OR adolescen*[tiab] OR } \\
\text { young adult*[tiab] OR young people[tiab] OR young person*[tiab] OR } \\
\text { youth[tiab] OR teen*[tiab] OR youth[tiab]) }\end{array}$ \\
\hline
\end{tabular}

\section{Inclusion and exclusion criteria}

Studies were included in the review, if they:

1. ... addressed YPCC;

a. Young people being defined as people aged 12-25;

b. Chronic condition being defined as conditions 'that last or are expected to last twelve or more months and result in functional limitations and/or the need for ongoing medical care'. ${ }^{21}$

2. ... reported on PPI in research or implementation projects.

3. ... contained empirical data.

4. ... were written in English.

5. ... were published after 1990 (the year after the ratification of the UNCRC). 
Studies that reported on involvement of representatives of YPCC, such as caregivers or care providers, or did not clearly distinguish YPCC as a subgroup were excluded. Studies containing non-empirical data (eg editorials), literature reviews, meta-analyses and conference papers were also excluded.

\section{Study selection}

One researcher (FS) performed the search and removal of duplicates. She also conducted the initial screening of titles and abstracts and discarded obviously irrelevant studies. Two reviewers (FS and VM) independently screened the remaining titles and abstracts, and subsequently the full texts. Discrepancies were resolved and if necessary a third reviewer (HB) was consulted to make a final decision. The researchers regularly met to discuss challenges and uncertainties in study selection.

The reference lists of included studies were screened to identify additional relevant studies.

\section{Stage 4: Charting the data}

A data charting form was developed to extract relevant data from the included studies. The form was piloted on three studies and adapted to ensure it was comprehensive. Two researchers (FS and VM) extracted data on: the study (study aim); the project in which YPCC were involved (project aim); and PPI (definitions and goals, YPCC involved, activities, and outcomes and reflections on PPI processes).

\section{Quality assessment}

Arksey and $\mathrm{O}^{\prime}$ Malley ${ }^{19}$ have argued that quality assessment is not part of a scoping review. However, according to Levac et $\mathrm{al}_{1}{ }^{20}$ this is debatable. Assessing the quality of the vast range of studies in a scoping review helps to put the results in context and facilitates interpretation. Therefore, we decided to report on the quality of the included studies.

Qualitative studies were assessed using the Critical Appraisal Skills Program (CASP), ${ }^{22}$ which contains ten criteria on study design, recruitment strategy, data collection and analysis, the relationship between researcher and participants, ethical considerations, description of the findings and the value of the overall study. Quantitative studies were assessed using the NIH Quality Assessment Tool for Observational Cohort and Cross-Sectional Studies. ${ }^{23}$ This checklist covers fourteen criteria concerning study participants, power analysis, timing between exposure and outcome, definition of exposure and outcome measures and presence of bias. Mixed methods studies were screened using the Mixed Methods Appraisal Tool (MMAT), ${ }^{24}$ which contains five specific criteria for qualitative, randomized controlled trial, non-randomized trial, descriptive and mixed methods designs. 


\section{Stage 5: Collating, summarizing and reporting results}

Extracted data were analysed using quantitative analysis and qualitative analysis. The quantitative analysis focused on characteristics of the included studies. The majority of the results were analysed qualitatively and focused on descriptions and operationalizations of PPI, outcomes and reflections on PPI processes. The first author developed initial themes based on discussions with all members of the research team.

\section{Results}

\section{Included studies}

A total of 4993 studies were retrieved through database searching. After the removal of duplicates and screening of records, twenty-three studies were included in the review (Figure 1). Nineteen were qualitative, $, 5,9,25-40$ two quantitative 41,42 and two mixed methods. ${ }^{43,44}$ In fifteen studies, PPI with YPCC was the outcome of interest. 5,7,9,25,28-32,35,3740,42 In eight studies, it was applied as study method. $26,27,33,34,36,41,43,44$ None of the studies were published before 2000, eight between 2001 and 2010,5,7,25,29,30,39,41,42 and fifteen between 2011 and 2018. 9,26-28,31-38,40,43,44

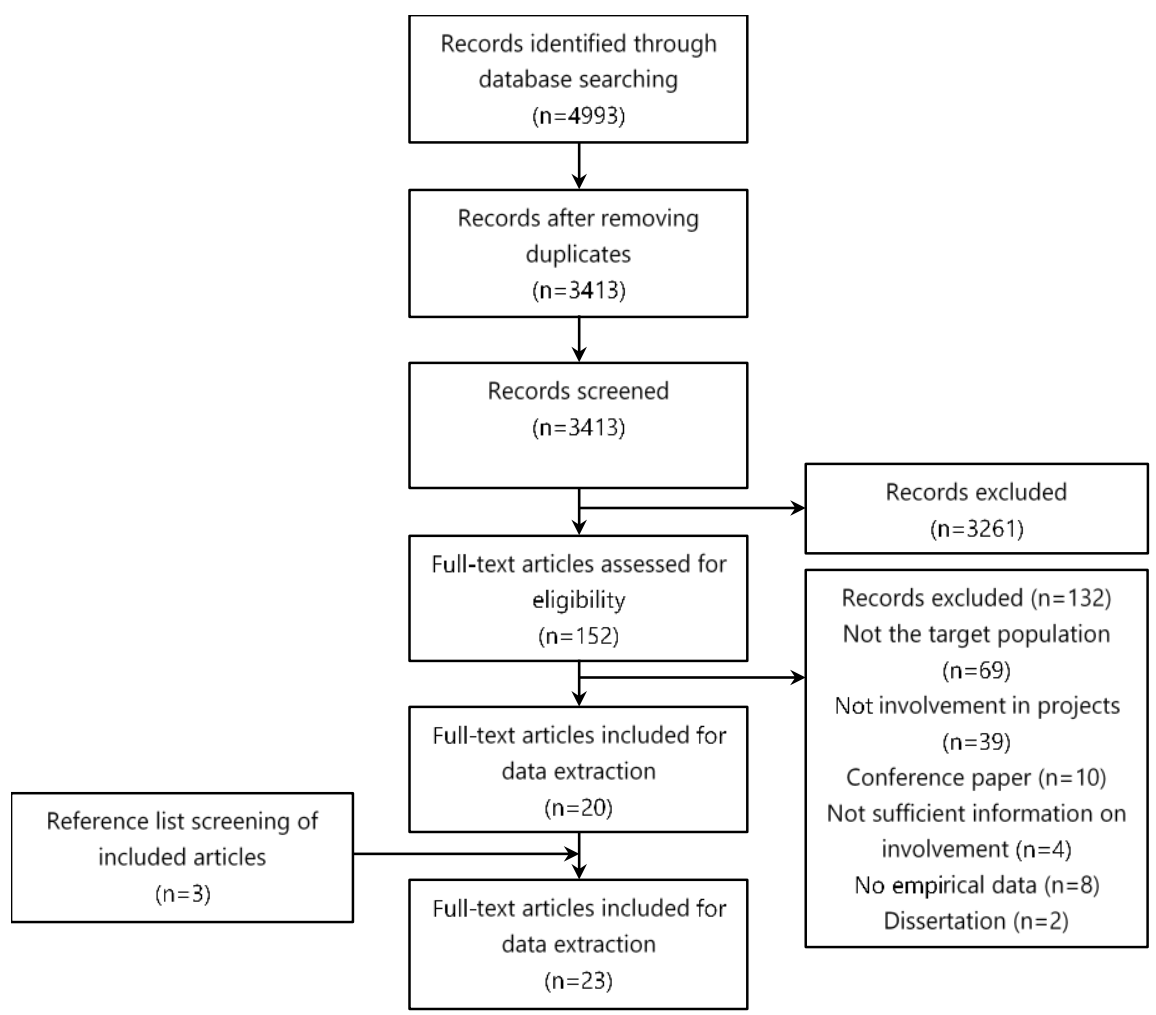

Figure 1. Flow diagram of the article selection process 
Table 2 provides an overview of the content of the projects in the included studies and the YPCC involved. The studies reported on nineteen unique projects. One project was addressed in two studies, ${ }^{27,28}$ and three studies described findings from multiple projects. ${ }^{7,30,42}$ Of the nineteen unique projects, nine were research projects, ${ }^{27-29,31}$ $33,36,38,39,41$ six were implementation projects, $25,26,35,37,40,43$ and four combined elements of both research and implementation. 5,9,34,44 The studies addressing multiple projects provided results on involvement in implementation projects. ${ }^{7,30,42}$

Table 2. Participatory projects in the included studies and the YPCC involved

\begin{tabular}{|c|c|c|c|}
\hline Reference & $\begin{array}{l}\text { Research or } \\
\text { implementation }\end{array}$ & Participatory project & $\begin{array}{l}\text { Young people (YP) } \\
\text { involved }\end{array}$ \\
\hline $\begin{array}{l}\text { Brown et al. } \\
\text { (2005) }\end{array}$ & Implementation & $\begin{array}{l}\text { Designing a switch- } \\
\text { based device to provide } \\
\text { control of a Virtual } \\
\text { Learning Environment }\end{array}$ & $\begin{array}{l}6 \text { YP (age 16-19) with } \\
\text { physical disabilities }\end{array}$ \\
\hline $\begin{array}{l}\text { Bruce \& } \\
\text { Parker } \\
\text { (2012) }\end{array}$ & $\begin{array}{l}\text { Research \& } \\
\text { implementation }\end{array}$ & $\begin{array}{l}\text { Preparing advocates to } \\
\text { shape the future for } \\
\text { themselves and for } \\
\text { others }\end{array}$ & $\begin{array}{l}6 \text { YP (age 18+) who } \\
\text { are deafblind }\end{array}$ \\
\hline $\begin{array}{l}\text { Castensoe- } \\
\text { Seidenfaden } \\
\text { et al. (2017) }\end{array}$ & Implementation & $\begin{array}{l}\text { Developing an app to } \\
\text { support self- } \\
\text { management }\end{array}$ & $\begin{array}{l}37 \text { YP (age 16-26) with } \\
\text { diabetes }\end{array}$ \\
\hline $\begin{array}{l}\text { Chappell et } \\
\text { al. (2014) }\end{array}$ & Research & $\begin{array}{l}\text { Studying how issues as } \\
\text { love, relationships, sex } \\
\text { and HIV/AIDS are } \\
\text { discussed in the } \\
\text { construction of the } \\
\text { sexual sense of self }\end{array}$ & $\begin{array}{l}3 \text { YP (age 15-20) with } \\
\text { physical impairments }\end{array}$ \\
\hline $\begin{array}{l}\text { Chappell } \\
(2014)\end{array}$ & \multicolumn{3}{|c|}{ See Chappell et al. (2014) } \\
\hline $\begin{array}{l}\text { Coyne et al. } \\
(2016)\end{array}$ & Implementation & $\begin{array}{l}\text { Co-developing an e- } \\
\text { health intervention to } \\
\text { support transition to } \\
\text { adult healthcare }\end{array}$ & $\begin{array}{l}17 \text { YP (age 15-23) with } \\
\text { CHD, cystic fibrosis } \\
\text { and diabetes }\end{array}$ \\
\hline $\begin{array}{l}\text { Flicker } \\
(2008)\end{array}$ & Research & $\begin{array}{l}\text { Improving living } \\
\text { conditions }\end{array}$ & $\begin{array}{l}27 \text { YP (age unknown) } \\
\text { living with HIV }\end{array}$ \\
\hline
\end{tabular}




\begin{tabular}{|c|c|c|c|}
\hline $\begin{array}{l}\text { Franklin \& } \\
\text { Sloper } \\
(2009)\end{array}$ & Implementation & $\begin{array}{l}\text { Not provided (study } \\
\text { addresses multiple } \\
\text { participatory projects) }\end{array}$ & $\begin{array}{l}\text { YP (age 5-18) with } \\
\text { disabilities }\end{array}$ \\
\hline $\begin{array}{l}\text { Graham et } \\
\text { al. (2007) }\end{array}$ & Research & $\begin{array}{l}\text { Studying experiences of } \\
\text { play }\end{array}$ & $\begin{array}{l}1 \text { YP (age 19) with } \\
\text { cerebral palsy }\end{array}$ \\
\hline $\begin{array}{l}\text { Kramer et al. } \\
(2003)\end{array}$ & $\begin{array}{l}\text { Research \& } \\
\text { implementation }\end{array}$ & $\begin{array}{l}\text { Evaluating the extent to } \\
\text { which a project was } \\
\text { useful and enjoyable }\end{array}$ & $\begin{array}{l}6 \text { YP (age 12-17) with } \\
\text { disabilities }\end{array}$ \\
\hline $\begin{array}{l}\text { Lightfoot \& } \\
\text { Sloper } \\
\text { (2003) }\end{array}$ & Implementation & $\begin{array}{l}\text { Not provided (study } \\
\text { addresses multiple } \\
\text { participatory projects) }\end{array}$ & $\begin{array}{l}\text { YP (age 13-20) with } \\
\text { arthritis, asthma, } \\
\text { cancer, chronic pain, } \\
\text { cystic fibrosis, } \\
\text { diabetes, eczema, renal } \\
\text { failure and spina bifida }\end{array}$ \\
\hline $\begin{array}{l}\text { Marshall et } \\
\text { al. (2012) }\end{array}$ & Research & $\begin{array}{l}\text { Exploring attitudes and } \\
\text { practices in relation to } \\
\text { sexual health }\end{array}$ & $\begin{array}{l}7 \text { YP (age 17-26) with } \\
\text { intellectual disabilities }\end{array}$ \\
\hline $\begin{array}{l}\text { McAnuff et } \\
\text { al. (2016) }\end{array}$ & Research & $\begin{array}{l}\text { Designing feasible and } \\
\text { practicable research in } \\
\text { participation outcomes } \\
\text { and interventions }\end{array}$ & $\begin{array}{l}6 \text { YP (age 11-18) with } \\
\text { neurodisabilities }\end{array}$ \\
\hline $\begin{array}{l}\text { Moreau \& } \\
\text { Eady (2017) }\end{array}$ & $\begin{array}{l}\text { Research \& } \\
\text { implementation }\end{array}$ & $\begin{array}{l}\text { Exploring involvement } \\
\text { in medical education }\end{array}$ & $\begin{array}{l}17 \text { YP (age and chronic } \\
\text { condition unknown) } \\
\text { were interviewed } \\
\text { about (desired) } \\
\text { involvement in medical } \\
\text { education + } 12 \text { young } \\
\text { people (age and } \\
\text { chronic condition } \\
\text { unknown) were } \\
\text { involved in conducting } \\
\text { the study }\end{array}$ \\
\hline $\begin{array}{l}\text { Murray } \\
\text { (2012) }\end{array}$ & Implementation & $\begin{array}{l}\text { Facilitating involvement } \\
\text { in high level, strategic } \\
\text { Children Service's } \\
\text { Planning }\end{array}$ & $\begin{array}{l}27 \text { YP (age 5-25) with } \\
\text { learning and physical } \\
\text { disabilities and sensory } \\
\text { impairments }\end{array}$ \\
\hline
\end{tabular}




\begin{tabular}{|c|c|c|c|}
\hline $\begin{array}{l}\text { Powers et al. } \\
(2007)\end{array}$ & Research & $\begin{array}{l}\text { Obtaining information } \\
\text { about transition } \\
\text { experiences considered } \\
\text { effective and } \\
\text { opportunities to } \\
\text { participate in them }\end{array}$ & $\begin{array}{l}\text { YP (age 16-28) with } \\
\text { deafness, learning } \\
\text { disability, traumatic } \\
\text { brain injury, cerebral } \\
\text { palsy, epilepsy, } \\
\text { blindness, spinal cord } \\
\text { injury, bipolar disorder, } \\
\text { autism, down } \\
\text { syndrome, spinal } \\
\text { muscular atrophy, } \\
\text { spina bifida and } \\
\text { dwarfism (number } \\
\text { unknown) }\end{array}$ \\
\hline $\begin{array}{l}\text { Rahi et al. } \\
\text { (2011) }\end{array}$ & Research & $\begin{array}{l}\text { Identifying content and } \\
\text { generating items for a } \\
\text { self-report instrument } \\
\text { assessing quality of life }\end{array}$ & $\begin{array}{l}18 \text { YP (age 10-16) with } \\
\text { visual impairments }\end{array}$ \\
\hline $\begin{array}{l}\text { Rich et al. } \\
\text { (2014) }\end{array}$ & Implementation & $\begin{array}{l}\text { Creating a forum to } \\
\text { explore areas of interest; } \\
\text { making } \\
\text { recommendations to } \\
\text { enhance quality and } \\
\text { quantity of practice; } \\
\text { informing hospital } \\
\text { employees; and } \\
\text { providing advocacy } \\
\text { opportunities and } \\
\text { experience. }\end{array}$ & $\begin{array}{l}18 \text { YP (age 14-21) } \\
\text { (chronic condition } \\
\text { unknown) }\end{array}$ \\
\hline $\begin{array}{l}\text { Rosen- } \\
\text { Reynoso et } \\
\text { al. (2010) }\end{array}$ & $\begin{array}{l}\text { Research \& } \\
\text { implementation }\end{array}$ & $\begin{array}{l}\text { Providing } \\
\text { postsecondary } \\
\text { education transition } \\
\text { support }\end{array}$ & $\begin{array}{l}\text { 15+ YP (age 16+) } \\
\text { (exact number and } \\
\text { chronic condition } \\
\text { unknown) }\end{array}$ \\
\hline
\end{tabular}




\begin{tabular}{|c|c|c|c|}
\hline $\begin{array}{l}\text { Sloper \& } \\
\text { Lightfoot } \\
(2002)\end{array}$ & Implementation & $\begin{array}{l}\text { Not provided (study } \\
\text { addresses multiple } \\
\text { participatory projects) }\end{array}$ & $\begin{array}{l}\text { YP (age 4-21, most } \\
\text { were 12-18) with } \\
\text { single condition (e.g. } \\
\text { asthma, autistic } \\
\text { spectrum disorders, } \\
\text { cancer, cystic fibrosis, } \\
\text { diabetes, renal failure } \\
\text { and sickle cell disease) } \\
\text { or multiple conditions }\end{array}$ \\
\hline $\begin{array}{l}\text { Stevenson } \\
(2013)\end{array}$ & Research & $\begin{array}{l}\text { Assisting in achieving } \\
\text { life goals and greater } \\
\text { social connection }\end{array}$ & $\begin{array}{l}3 \text { YP (age 18-25) with } \\
\text { Down Syndrome }\end{array}$ \\
\hline $\begin{array}{l}\text { Van Staa et } \\
\text { al. (2009) }\end{array}$ & Research & $\begin{array}{l}\text { Exploring self-care } \\
\text { competencies and } \\
\text { preferences }\end{array}$ & $\begin{array}{l}9 \text { YP (age 15+) with } \\
\text { dermatologic } \\
\text { disorders, blood } \\
\text { disorders, } \\
\text { neuromuscular } \\
\text { diseases, renal failure } \\
\text { and diabetes mellitus }\end{array}$ \\
\hline $\begin{array}{l}\text { Vindrola- } \\
\text { Padros } \\
(2016)\end{array}$ & Implementation & $\begin{array}{l}\text { Distilling key findings } \\
\text { from a study into an } \\
\text { information leaflet }\end{array}$ & $\begin{array}{l}23 \text { YP (age } 7-14 \text { ) with } \\
\text { long term conditions }\end{array}$ \\
\hline
\end{tabular}

The included studies reported on PPI of one to over 50 YPCC. YPCC were aged 4-28 years; five studies (also) included data on YPCC younger than 1230,35,36,40,42 and three on YPCC older than 25.26,32,41 Six studies focused on young people with one specific condition, 9,26,29,31,36,38 such as diabetes, renal failure and cystic fibrosis, but most addressed several conditions or a general group of conditions, $7,2,5,7,2,2,3,3,32,3,3,3,3,39-44$ such as physical impairments or learning disabilities. In some studies, YPCC were included based on additional criteria, other than age and chronic condition, such as previous participatory experiences, educational level and skills and abilities. 


\section{Quality assessment}

Looking at the quality of the qualitative studies, only three articles met all criteria of the CASP $^{7,29,34}$ and one study met all but one criterion. ${ }^{9}$ The other qualitative studies mostly provided limited or no information on study design and/or methods. In some articles, a section on study methodology or a clear description of methods were absent. Also, they rarely provided a critical reflection on the author's own role in the study, even when YPCC and professionals had a double role of being both the researcher and the researched and were investigating a participatory process they were part of themselves.

The two quantitative studies provided descriptive statistics. Consequently, only the first five criteria concerning the statement of the research aim and the (selection of) study participants of the NIH Quality Assessment Tool were applicable. One study met all applicable criteria. ${ }^{42}$ The other study met all but one, due to convenience sampling of study participants. $^{41}$

The two mixed methods studies did not meet the criteria of the MMAT on representativeness of the quantitative sample and nonresponse bias. ${ }^{43,44}$ Information about the recruitment of participants was missing or a convenience sample was used. One study also lacked methodological information about the qualitative component of the study. ${ }^{44}$ In this study, criteria on deriving and interpreting the qualitative findings were not met, but the small qualitative component had minimal bearing on the overall findings.

\section{The concept of PPI}

\section{Terms and definitions}

In most studies, the terms participatory research (eg participatory action research, community-based participatory research, youth-based participatory research), 5,9,27$29,32,34,38,39,41$ participative or participatory design, ${ }^{25,26}$ or user involvement (eg service-user

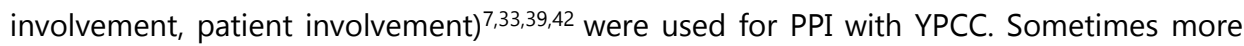
general terms were applied, such as participation, ${ }^{30,35,44}$ participatory approach ${ }^{40,43}$ or advocacy. ${ }^{31}$ One study reported on child-centred methods, ${ }^{36}$ and one on emancipatory disability research. ${ }^{38}$

An explicit definition of PPI was provided in twelve studies (Table 3). 5,9,28-32,38,39,41-43 In the other studies, PPI was not defined, but two studies described a framework ${ }^{44}$ or key principles. ${ }^{40}$ None of the studies reporting on participative or participatory design explained these terms, the other terms were defined in various ways. The definitions provided did not depend on the terms used, and no differences were found in older or more recent publications. 
Table 3. Definitions of involvement in the included studies

\begin{tabular}{ll} 
Reference & Definition \\
$\begin{array}{l}\text { Brown et al. } \\
\text { (2005) }\end{array}$ & $\begin{array}{l}\text { The term participative design processes is used, but no definition is } \\
\text { provided. }\end{array}$ \\
\hline $\begin{array}{l}\text { Bruce \& } \\
\text { Parker }\end{array}$ & $\begin{array}{l}\text { Participatory action research involves participants for the purpose of } \\
\text { addressing a problem that is of sincere concern to them. Integral are } \\
\text { (2012) }\end{array}$ \\
& $\begin{array}{l}\text { self-determination and advocacy. Four elements are essential: 1) } \\
\text { participants identify issues to be studied, 2) participants are directly } \\
\text { involved in research, 3) involvement supports individuals in identifying } \\
\text { strengths and resources and 4) goal of the research is to improve quality } \\
\text { of life. }\end{array}$
\end{tabular}

Castensoe- Participatory design promotes user participation in technology design.

Seidenfaden

et al. (2017)

Chappell et Participatory research marks a shift from viewing young people just as

al. (2014) 'objects'. Instead of being bystanders, young people are, to varying levels, engaged in research design, data collection and analysis. Empowerment should be understood as producing 'alternative power saturated knowledge' rather than being seen as a commodity to be seized by those perceived as powerless.

Chappell The term participatory research design is used, but no definition is (2014) provided.

Coyne et al. In a participatory approach young people's input is viewed as a central (2016) element in design and development. It involves co-learning and reciprocal transfer of expertise, shared decision-making and mutual ownership of processes and products. Four key principles: 1) consultation and cooperation with relevant stakeholders, 2) experimentation with alternative designs, 3) contextualisation and 4) iterative development.

Flicker Community-based participatory research is a collaborative approach
(2008) that equitably involves all partners in research and recognizes everyone's unique strengths. It begins with a research topic of importance to the community with the aim of combining knowledge and action for social change. It is rooted in communities, builds on local knowledge and strengths, directly serves community interests, and encourages participation at all levels. It challenges notions of objectivity and the idea that science is apolitical by adopting a set of underlying beliefs and principles that embrace subjectivity. 


\begin{tabular}{|c|c|}
\hline $\begin{array}{l}\text { Franklin \& } \\
\text { Sloper } \\
\text { (2009) }\end{array}$ & $\begin{array}{l}\text { Participation is a continuum along which the type of participation } \\
\text { activity should be determined according to the circumstances and the } \\
\text { participating children. Levels are being informed, expressing a view, } \\
\text { influencing the decision-making process and being the main decider. }\end{array}$ \\
\hline $\begin{array}{l}\text { Graham et } \\
\text { al. (2007) }\end{array}$ & $\begin{array}{l}\text { The term advocate is defined as 'a person who puts a case forward on } \\
\text { someone else's behalf'. In this research, it is used to refer to those } \\
\text { involved in contributing to research projects. }\end{array}$ \\
\hline $\begin{array}{l}\text { Kramer et al. } \\
\text { (2003) }\end{array}$ & $\begin{array}{l}\text { The project was informed by Lundy's framework that outlines four } \\
\text { elements for participation in research: (1) ensuring a safe and inclusive } \\
\text { space to express views, (2) providing accessible methods to express } \\
\text { views, (3) provide an audience and (4) allowing youth to influence } \\
\text { decisions. }\end{array}$ \\
\hline $\begin{array}{l}\text { Lightfoot \& } \\
\text { Sloper } \\
\text { (2003) }\end{array}$ & The term involvement is used, but no definition is provided. \\
\hline $\begin{array}{l}\text { Marshall et } \\
\text { al. (2012) }\end{array}$ & $\begin{array}{l}\text { Participatory research seeks to share power between researchers and } \\
\text { community participants. }\end{array}$ \\
\hline $\begin{array}{l}\text { McAnuff et } \\
\text { al. (2016) }\end{array}$ & $\begin{array}{l}\text { The terms service user involvement project and of co-design are used, } \\
\text { but no definition is provided. }\end{array}$ \\
\hline $\begin{array}{l}\text { Moreau \& } \\
\text { Eady (2017) }\end{array}$ & $\begin{array}{l}\text { The term community-based participatory research is used, but no } \\
\text { definition is provided. }\end{array}$ \\
\hline $\begin{array}{l}\text { Murray } \\
\text { (2012) }\end{array}$ & The term participation is used, but no definition is provided. \\
\hline $\begin{array}{l}\text { Powers et al. } \\
\text { (2007) }\end{array}$ & $\begin{array}{l}\text { Participatory action research is aimed at involving constituents of } \\
\text { research at all levels. It is an approach for bolstering the quality and } \\
\text { relevance of research. }\end{array}$ \\
\hline $\begin{array}{l}\text { Rahi et al. } \\
\text { (2011) }\end{array}$ & The term child-centred methods is used, but no definition is provided. \\
\hline $\begin{array}{l}\text { Rich et al. } \\
\text { (2014) }\end{array}$ & No terms and definitions provided. \\
\hline $\begin{array}{l}\text { Rosen- } \\
\text { Reynoso et } \\
\text { al. (2010) }\end{array}$ & $\begin{array}{l}\text { Youth-based participatory research is defined as a collaborative } \\
\text { partnership between researchers and youth, to help achieve the project's } \\
\text { goals. Similar to community-based participatory research, it focuses on } \\
\text { engaging the youth in all phases of the research, including design, } \\
\text { implementation, analysis and dissemination of results. }\end{array}$ \\
\hline $\begin{array}{l}\text { Sloper \& } \\
\text { Lightfoot } \\
\text { (2002) }\end{array}$ & $\begin{array}{l}\text { The term involvement can encompass a number of different levels of } \\
\text { participation from tokenism to children holding increasing power over } \\
\text { the content and process of the consultation initiative. }\end{array}$ \\
\hline
\end{tabular}




\begin{tabular}{ll}
\hline Stevenson & Emancipatory Disability Research principles indicate that co-researchers \\
(2013) & should be involved in data analysis in a way which is meaningful to them; \\
that the data analysis is conducted in a transparent, logical and rigorous & manner and aims to produce findings which can be used for the tangible \\
& benefit of disabled people. Participatory Action Research provided an \\
& authentic way in which data can be generated from cycles of planning, \\
& acting, observing and reflecting. \\
\hline Van Staa et & Patient or user involvement entails consultation and involvement of \\
al. (2009) & patients in all health-care decisions on the individual and collective level; \\
& in the development and evaluation of services; and also in health \\
& research. Participatory research is a collaborative undertaking aimed at \\
& more involvement of the community being studied in all aspects of the \\
& research process. It is carried out with and by the research subjects rather \\
& than on them. Core elements are co-learning and reciprocal transfer of \\
& expertise, shared decision-making power and mutual ownership of \\
& process and products of the research enterprise. \\
\hline Vindrola- & The participatory approach was guided by four key principles: \\
Padros & consultation and cooperation with relevant stakeholders, \\
(2016) & experimentation with alternative designs, contextualisation, and iterative \\
& development. Inclusion of visual methods in research design does not \\
& automatically make it 'participatory' as young people's voices might be \\
& relegated to the voice of the researcher or other adults or they might \\
& not have avenues or the 'tools' for shaping the research process. \\
\hline
\end{tabular}

In the definitions, five recurring elements were identified. First, PPI is a collaborative approach, $, 29,39,43$ meaning that projects are carried out with or by YPCC (not on them). ${ }^{28,39}$ Another element is that participatory projects address topics that matter to YPCC. ${ }^{9,29}$ The third element is that PPI is a continuum of activities in which YPCC have different levels of influence, ${ }^{28-30,42}$ varying from being informed to being the main decider. ${ }^{30}$ Allowing YPCC to play a role in various stages of a project is the fourth element we identified. 5,28,39,41 The last element is that PPI is meaningful to both the YPCC involved and YPCC in general. $5,31,38,41$

We discovered three key principles on which PPI is built. A prominent one is sharing power. ${ }^{28,29,32,43}$ Participatory processes depend on shared decision making, co-learning and mutual ownership of project products. ${ }^{39,43}$ Another principle is iterative development. ${ }^{38,40,43}$ PPI requires repeated cycles of planning, acting, observing and reflecting. ${ }^{38}$ The third key principle is that participatory processes focus on YPCC's strengths and resources. ${ }^{9,29}$ 


\section{Goals}

Improving relevance and quality of projects were reported as important goals of PPI. 5,7,9,26,29,33,34,36,39-42,44 Other goals of participation are providing YPCC with opportunities for learning and personal development ${ }^{26,34,41}$ and recognizing them as social agents with a unique perspective. $27,28,32,34$ Finally, several studies cited the UNCRC, 7,27,28,30,35,39,42 suggesting that YPCC's rights were also a reason for involvement.

\section{Operationalizations of PPI}

\section{Recruitment}

Several studies have described YPCC's involvement in the recruitment of other young people. YPCC participated in establishing recruitment processes, ${ }^{32,34}$ designing recruitment materials ${ }^{7,29,31}$ and identifying and recruiting YPCC. 5,27,41 They advised, for example, on recruitment strategies, ${ }^{7,32}$ chose incentives for research participation, ${ }^{32}$ commented on information sheets for research participants, ${ }^{31}$ distributed flyers ${ }^{5}$ and recruited YPCC from their network. 5,41

\section{Design}

YPCC played a role in designing research, 5,7,29,31-34,41 and tools and interventions. 5,25,26,33,40,43,44 In research projects, they were involved, for example, in drafting research questions ${ }^{29}$ and protocols. ${ }^{29,31}$ In implementation projects, they co-designed an app for self-management, ${ }^{26}$ an online curriculum to improve transition to postsecondary education, ${ }^{5}$ and an information leaflet on shared decision making in care. ${ }^{40}$

Studies have reported several design activities with YPCC. Most activities were group consultations, such as participatory workshops ${ }^{25,26,29,40,43}$ or group or panel meetings. $5,7,32-$ 34,41,44 Design activities were seldom individual. ${ }^{31,40}$ Also, virtually all consultations were face-to-face. ${ }^{5,7,25,29,34,40,41,43,44}$ One study consulted a mail panel for feedback on a selfmanagement app. ${ }^{26}$ During consultations, YPCC provided feedback on research designs or prototypes of practical tools or interventions developed by adult professionals, $5,25,26,32,33,40,43,44$ or they developed (parts of) research designs or prototypes themselves. ${ }^{7,26,41,44}$ In some cases, creative techniques were applied, such as an 'interactive storyboarding process', ${ }^{25} \mathrm{a}$ 'diamond ranking exercise with images and sorting cards', $^{40}$ sketching prototypes ${ }^{26}$ and creating video self-portraits. ${ }^{26}$

\section{Collecting and analysing data}

During data collection, YPCC were involved in establishing data collection protocols, 29,32 and developing surveys and topic guides for interviews and focus groups. $5,7,27,28,34,36,37,39,41,44$ YPCC developed data collection tools themselves (supported by adult researchers), $7,37,39,41,44$ or reviewed and revised materials developed by adult researchers.32,36 They also (co-)conducted surveys, interviews and focus 
groups. ${ }^{7,27,28,37,38}$ They did this mostly by themselves (supported by adult researchers). $7,27,28,37-39,41$ One study mentioned the use of 'Participatory Rural Appraisal techniques, such as drawing and timelines', to help YPCC to initiate interview and focus group conversations. ${ }^{27}$

During data analysis, YPCC were involved in performing analyses $27-29,38$ and interpreting findings. 5,7,31,32,34,38,39,41 They were predominantly involved in qualitative analyses, through member checking sessions ${ }^{31,32,34,38,41}$ and meetings in which they discussed and coded interview transcripts. $27-29,38$ Other activities included keeping reflexive journals that helped to reflect on other YPCC's views ${ }^{27,28}$ and a workshop to translate findings into practical guidelines. ${ }^{7}$ In two studies, YPCC were involved in quantitative analyses: they entered responses in a database, calculated average ratings and analysed bar graphs and frequencies, ${ }^{44}$ and reviewed and interpreted findings. ${ }^{41}$

\section{Dissemination}

During dissemination, YPCC were involved in writing (research) reports, for example, as coauthors of a scientific article, ${ }^{28,44}$ or reviewers of articles written by adult researchers. ${ }^{9,29,39}$ Furthermore, YPCC commented on dissemination strategies, ${ }^{32}$ (co-)presented at, for example, conferences, ${ }^{7,29,32,35,38,39,41}$ launched a website, ${ }^{43}$ created magazines and newsletters ${ }^{29}$ and videos, ${ }^{5,7}$ participated in media activities ${ }^{39}$ and developed a research brief and agenda. ${ }^{41}$

\section{Support}

YPCC are provided with different types of support. They participated in trainings on research methods $27,28,39,44$ and advocacy. ${ }^{9}$ Professionals also aided YPCC by providing them with feedback and by discussing solutions for possible issues they experienced. ${ }^{28,41,42}$ Payment ${ }^{7,29,42}$ and gift cards $^{37,43}$ were used to acknowledge them for their time and efforts, and pizza parties and informal meals were organized to create an informal and comfortable atmosphere. ${ }^{5,29,37}$ Funding and support were also provided for transport. ${ }^{29,32,37,42}$

In some cases, professionals working with YPCC also received support, in the form of training or information and additional time. ${ }^{42}$ Some studies reported structural support for youth participation by hiring a person with designated responsibility for $\mathrm{PPI}^{37,42}$ or by providing all new personnel with an introduction course on PPI. ${ }^{30}$

\section{Impact of PPI}

\section{Note on outcome measures}

Patient and Public Involvement was the outcome of interest in some studies and a study method in other studies. In studies in which PPI was the outcome of interest, involvement 
was the focus of the study. Consequently, these studies have paid extensive attention to its process and impact, and generally have studied and described this more systematically than studies that applied PPI as a study method. In the studies that applied PPI as a study method, authors mostly made a short statement in the discussion about their experiences concerning the process and impact.

\section{Impact on projects}

Over the years, mainly positive outcomes of PPI were reported. In general, studies stated that YPCC were able to provide new insights from their lived experience $7,28,35,37,42,44$ and that their involvement positively influenced at least some aspects of projects. ${ }^{5,9,26,28-}$ $32,34,36,38,39,41,42$ Especially data collection and analysis ${ }^{28,29,31,34,36,41}$ and dissemination of project results seem to benefit from YPCC's involvement, 5,29,32,39,41,42 but improvements were also reported for research design, $5,29,41$ recruitment ${ }^{5,29}$ and project products, such as an intervention or an article. ${ }^{9,26}$ Limited specific examples were provided contributions of YPCC to projects. PPI increased the relevance of research questions ${ }^{5}$ and usability of practical tools. ${ }^{26}$ Other examples included improved accessibility of consent forms and questionnaires, $^{32}$ better questions in questionnaires ${ }^{36,41}$ and increased media attention. ${ }^{39}$

In some articles, the benefits were somewhat nuanced. Interviews and focus groups conducted by YPCC can lack depth, due to limited skills of asking follow-up questions. ${ }^{27,39}$ In data collection, YPCC tend to interpret findings assertively, adding their own experiences. ${ }^{38}$ Also, PPI does not necessarily facilitate the recruitment of other YPCC.

\section{Impact on stakeholders}

Both older and more recent studies have reported that PPI can also benefit the YPCC involved. Reported benefits included learning new knowledge and skills, 5,28$30,37,38,41$ developing confidence, ${ }^{9,30,37,42}$ building new relationships, ${ }^{7,30,35}$ feeling valued $^{7,29,30}$ and learning about themselves..$^{27,28}$ One study reported about PPI as an 'intensive community development interventions with a strong dose-response effect', because it provides YPCC with an opportunity to actively engage in society. ${ }^{29}$

Given the reported benefits, it is not surprising that studies have reported commitment and enthusiasm among YPCC regarding their PPI. YPCC felt proud ${ }^{32}$ and privileged, $^{38}$ and expressed the wish to continue to advocate for their peers in the future. ${ }^{9,30,38}$ Two studies have reported similar feelings among professionals; it increased the commitment of researchers to their research project ${ }^{39}$ and contributed to feelings of inspiration and pride. ${ }^{29}$ 


\section{Reflections on PPI}

YPCC's motivations

A variety of YPCC's motivations for PPI were reported, including the wishes to help others and contribute to society, ${ }^{7,9,29,37}$ share their perspectives, ${ }^{7,34,39}$ meet others, ${ }^{29,39}$ learn new skills, $^{39}$ have fun ${ }^{39}$ and do something new. ${ }^{7}$

\section{Time and funding}

Both older and more recent studies have shown that participatory projects require additional resources compared with non-participatory projects, since they develop at a relatively slow pace and are time-consuming for YPCC and professionals. 5,9,26,29,30,32,37,39,40,42 Additional funding is also a key enabler of PPI. $7,26,29,30,35$ Lack of time and funding can hinder an ongoing and detailed dialogue between both parties, ${ }_{1}^{7,26,30,35,38}$ and result in feelings of frustration and lack of control. ${ }^{5,9,29}$

\section{Representativeness}

Over the years, several studies have raised concerns about the representativeness and diversity of the YPCC's involved in projects. Most participatory projects only include a small number of YPCC. ${ }^{30}$ Also, PPI may require specific qualities and capabilities..$^{9,30,31}$ Studies have suggested that the YPCC involved are more outgoing, critical and self-confident than their non-involved peers $34,37,39$ and that 'hard-to-reach' YPCC are provided with less opportunities for PPI. ${ }^{30}$ Some studies have described a risk of dropping out, due to the process being too strenuous, ${ }^{9,39}$ YPCC losing interest ${ }^{39}$ or being afraid of stigmatizing or losing respect from peer groups. ${ }^{29}$ Consequently, only a 'core group ${ }^{29}$ or 'elite' ${ }^{39}$ may remain involved. For two studies, representativeness was not necessarily the aim of PPI in their project, ${ }^{33} 39$ but 'to work with service users as a part of a team'. ${ }^{33}$

\section{What activities work?}

Studies have reported that YPCC should be involved in all phases of a project, ${ }^{26,44}$ and especially during the first project phases., 26,32 This enables YPCC to participate before research questions or tool design are set in stone. ${ }^{26,33}$

It is suggested that there is 'not one right method for involvement'. ${ }^{7}$ Appropriate activities vary according to the needs and interests of the YPCC involved and the purposes of PPI. $7,30,32,38$ However, authors have documented several activities they considered successful, including creative and fun methods (eg visual methods), ${ }^{30,40}$ group work (eg participatory workshops, working groups, group advocacy), ${ }^{7,35,37,40}$ regular meetings, ${ }^{26,35}$ designing products (eg videos, books, tool prototypes), ${ }^{26,34}$ a mail panel, ${ }^{26}$ one-to-one discussions, ${ }^{7,37}$ face-to-face presentations ${ }^{34}$ and shadowing and mentoring. ${ }^{34}$ It is recommended to formulate goals that can be accomplished in the short term ${ }^{37}$ and to conduct group work separately from adult participants. ${ }^{26}$ 


\section{Support}

Studies have reported the importance of supporting the YPCC involved. YPCC have to learn about, for example, the topic addressed by the project, ${ }^{9,35}$ research methods, ${ }^{28,34,38}$ structures of policy and decision making, ${ }^{30,35}$ and advocacy and communication. ${ }^{9,35}$ Also, they need to be informed about what PPI entails ${ }^{7,30}$ and develop the confidence to share their views..$^{30}$

As such, authors have recommended several ways to support PPI they considered rewarding, including training $\mathrm{YPCC}_{1}^{38}$ providing them with feedback ${ }^{7,30,37}$ and appointing experienced facilitators who can inform and support individual YPCC's. ${ }^{7,34,37,40}$ Creating a comfortable atmosphere in which YPCC feel free to share their experiences ${ }^{7,37}$ and (financially) rewarding them for their involvement ${ }^{7,29,34}$ are also important. Some studies suggested to train professionals in supporting PPI. ${ }^{7,32}$

\section{Power dynamics}

In participatory projects, power dynamics are different compared to non-participatory projects. ${ }^{28,29,32,38}$ Professionals are no longer seen as care provider and project facilitator only, but also as peer. ${ }^{28,37}$ They need to work as a team, with a shared understanding of aims and team members who learn with and from each other. ${ }^{9,30}$

It is, therefore, important that YPCC are respected and taken seriously. ${ }^{7,35,37,42}$ Studies stressed the importance of reassuring YPCC their ideas are valid and important, ${ }^{7,35,37}$ and listening to them and acting on their input. ${ }^{29,30}$ 'Involvement is more than just listening; it requires follow-up action'. ${ }^{30}$ This can be challenging, especially when preferences of YPCC, professionals or other stakeholders differ. ${ }^{35,42,43}$ Clear feedback is vital for YPCC to accept that not all their ideas can be taken forward. ${ }^{7}$

\section{Flexibility}

PPI requires flexibility and an open mind from professionals., ${ }^{5,43}$ 'Letting go of controlling the process', can contribute to the meaningfulness of PPI. ${ }^{28}$ Professionals need to be open to iterative revisions of projects and project materials, ${ }^{5,40,43}$ and, in some cases, to be prepared to go back to square one. ${ }^{5}$ Also, participatory methods need to be flexible, so they can be adapted to the YPCC involved. ${ }^{38}$ This 'loss of control' can cause discomfort, when names and reputations are associated with the project. ${ }^{29}$

\section{Discussion}

The aim of this scoping review was to gain insight into the developments in the existing literature on PPI with YPCC in research and implementation projects in health and social care, from the ratification of the UNCRC in 1989. We have mapped reported definitions and goals, activities, experiences and impact. 
Studies included in the review were published between 2002 and 2017. Most studies were from the last decade, suggesting an increased interest in PPI with YPCC. However, we also found limited progress of the evidence base: definitions continue to be broad and diverse, studies providing high-quality evidence of the impact are still scarce, and topics addressed remain largely the same. As such, Mayo' $\mathrm{s}^{45}$ statement that PPI entered the mainstream vocabulary but the practice lagged behind the rhetoric, may-after two decades-still be applicable to the involvement of YPCC.

The challenges of PPI with YPCC are probably an important reason for the limited progress we found in this review. Involvement comes with issues of obtaining additional project resources, representativeness, finding ways to involve YPCC and to support them, dealing with (changing) power dynamics and letting go of controlling the process. Over the years, these challenges continued to exist, with studies reporting similar experiences.

Overcoming challenges related to, for example, changing power dynamics and letting go of the process is fundamental to improving PPI; when professionals resist to share some of their authority and power with YPCC, their involvement will be mostly tokenistic. ${ }^{18}$ This is not easy, as PPI processes are complex and highly dependent on the context they take place in. However, reporting on the same challenges time and again will not help overcome them, but turn them into some impenetrable wall we keep hitting. Therefore, to break down this wall and address the identified challenges, future research should use existing knowledge as a starting point rather than reinvent the wheel. ${ }^{46}$

In line with Bailey et al, ${ }^{1}$ our synthesis has revealed variation in definitions of PPI with YPCC. Studies provide varying definitions-addressing different aspects—for the same terms. Half of the included studies did not provide a definition. Consequently, it is difficult to determine to what extent studies are addressing the same concept. ${ }^{46}$ We have experienced this ourselves during the screening phase of the review, in which we observed that purely qualitative research was sometimes termed 'participatory'.

Despite the variation in definitions, we also discovered some overlap. We identified five recurring elements, which correspond to elements addressed by Hart's description of young people's involvement. ${ }^{15}$ That is to say, PPI is collaborative (a) and it addresses topics that matter to YPCC (b). It is a continuum of activities providing YPCC with different levels of influence $(c)$ in various stages of a project (d). Finally, PPI is meaningful to both the YPCC involved and YPCC in general (e).

In defining PPI, a trade-off needs to be made between finding a common definition and allowing for flexibility. When studies use the same words meaning different things-and the other way around - their results become hard to compare. Studies involving YPCC as advisors probably describe different experiences and impact compared with studies 
involving them as decision-making partners. At the same time, there may be similarities in experiences and impact, as both studies have involved YPCC in a certain way. Neglecting and poorly defining these differences and similarities causes difficulties in comparing studies and experiences, and in learning about what works for whom and under what circumstances.

However, as Tritter and McCallum have argued, breadth in defining and operationalizing YPCC's involvement is also desirable, to allow for flexibility in determining PPI processes. ${ }^{47}$ The variety in projects and the way YPCC are involved make formulating one clear and concise definition of PPI difficult. Therefore, we do not promote the use of a strict definition for PPI, but we do urge researchers to include thorough descriptions of what is understood by PPI and how this is translated into activities in future studies, for example, by following the GRIPP-checklist for reporting PPI. ${ }^{46}$

As in previous reviews, ${ }^{1,2}$ we found few studies providing high-quality evidence on the impact of PPI. Information on methods and measurements are commonly lacking, and in many cases it is unclear how findings were derived. Also, findings are often based on experiences from those involved in the PPI process themselves, which may have contributed to the predominantly positive experiences in the studies. Also, striking is the shortage of perspectives of YPCC in the reflections on PPI processes. Most findings are based on observations and reflections of professionals. This is remarkable, as PPI by its very nature is about including young people in matters that affect them. ${ }^{15}$

More robust evaluation of PPI with YPCC is needed to convince a broader public of its validity and relevance. ${ }^{46}$ Future research using objective measurements could therefore benefit the evidence base of the impact of PPI and contribute to a more critical discussion. Conducting these measurements is not easy, as PPI is a complex process. ${ }^{48,49}$ Consequently, there is no single method for measuring impact. Studies in which ad hoc consultations were conducted with YPCC should probably adopt different impact assessment criteria and evaluation methods than studies that have extensively collaborated with YPCC as decisionmaking partners. One PPI approach may be best evaluated conducting interviews focusing on the benefits for the people involved, while another PPI approach requires observations or questionnaires focusing on the benefits for the project quality. Therefore, we recommend the use of a range of flexible evaluation methods that can be adapted to the project and young people involved. ${ }^{48}$ The authors of a recent literature review have created a useful overview of frameworks for evaluating and reporting PPI that can be applied in different contexts, such as the $\mathrm{PiiAF}^{49}$ and the Quality Involvement Framework. ${ }^{50}$

\section{Strengths and limitations}

This is the first review to gain insight into the developments in the existing literature on PPI with YPCC by extensively mapping definitions and goals, activities, experiences and impact. 
We assessed articles published over a broad time period; from the ratification of the UNCRC in 1989 to 2018.

One limitation of this review may be the broad search string on chronic conditions. We may have missed studies focusing on one specific condition. In addition, due to inconsistencies in how involvement is defined and reported, some studies may have been overlooked here as well. To reduce this to a minimum, reference lists of included articles were screened for relevant studies. Another limitation is that we did not include grey literature in the review. These sources may also include relevant information, as it is likely that not all involvement efforts are described in scientific articles.

\section{Conclusion}

Based on this review, we recommend conducting more well-reported research that uses systematic and objective evaluation methods and builds on previous studies to improve the evidence base on PPI with YPCC. There already appears to be a general consensus that YPCC's involvement should be an integral and standard elements of projects. An improved evidence base can contribute to the validity and reliability of PPI by teaching us about what works for whom and under what circumstances. We also urge YPCC and professionals to just do PPI, despite its challenges. The challenges and complexity of PPI can cause insecurity and a fear of doing it wrong. However, this review has shown that there is not one right method to do it. Moreover, as Lundy has argued, PPI is seldom perfect; 'there could always be more time, more resources and more children involved'. ${ }^{51}$ When the principles reported in this review are applied (learn from previous work, define and thoroughly report what is meant by PPI, and systematically evaluate its progress and outcomes) valuable lessons can be learned from doing PPI to improve its practice and impact.

\section{Conflict of interest}

No potential conflict of interest was reported by the authors. 


\section{References}

1. Bailey S, Boddy K, Briscoe S, Morris C. Involving disabled children and young people as partners in research: A systematic review. Child Care Health Dev. 2015;41(4):505-514. doi:10.1111/cch.12197

2. Cavet J, Sloper P. Participation of disabled children in individual decisions about their lives and in public decisions about service development. Child Soc. 2004;18(4):278-290. doi:10.1002/CHI.803

3. INVOLVE. Approaches to public involvement Research. Published 2013. Accessed April 30, 2018. http://www.invo.org.uk/posttyperesource/approaches-to-public-involvement/.

4. United Nations General Assembly. Convention on the Rights of Child, 1989.

5. Rosen-Reynoso M, Kusminsky M, Gragoudas S, et al. Youth-based participatory research: Lessons learned from a transition research study. Pediatrics. 2010;126(S3):S177-S182. doi:10.1542/peds.2010-1466N

6. Hackett $\mathrm{CL}$, Mulvale G, Miatello A. Co-designing for quality: Creating a user-driven tool to improve quality in youth mental health services. Health Expect.2018;21(6):1013-1023. doi:10.1111/hex.12694

7. Lightfoot J, Sloper P. Having a say in health: Involving young people with a chronic illness or physical disability in local health services development. Child Soc. 2003;17(4):277-290. doi:10.1002/CHI.748

8. Dedding C. Delen in macht en onmacht: Kindparticipatie in de (alledaagse) diabeteszorg. [PhD thesis]. Amsterdam: University of Amsterdam; 2009.

9. Bruce SM, Parker AT. Young deafblind adults in action: Becoming self-determined change agents through advocacy. Am Ann Deaf. 2012;157(1):16- 26. doi:10.1353/aad.2012.1607

10. Tuffrey-Wijne I, Butler G. Co-researching with people with learning disabilities: An experience of involvement in qualitative data analysis. Health Expect. 2010;13(2):174-184. doi:10.1111/j.13697625.2009.00576.x

11. Bigby $C$, Frawley $P$, Ramcharan $P$. Conceptualizing inclusive research with people with intellectual disability. J App/ Res Intellect Disabil. 2014;27(1):3-12. doi:10.1111/jar.12083

12. Gallivan J, Burns KK, Bellows $M$, Eigenseher $C$. The many faces of patient engagement. J Participat Med. 2012;4:e32.

13. Blunt C, Blyth C, Chapman R, et al. Editorial. Brit J Learn Disabil. 2012;40(2):83-84. doi:10.1111/j.1468-3156.2012.00748.x

14. Cook T, Boote J, Buckley N, Vougioukalou S, Wright M. Accessing participatory research impact and legacy: Developing the evidence base for participatory approaches in health research. Educ Action Res. 2017;25(4):473-488. doi:10.1080/09650792.2017.1326964

15. Hart R. Children's participation: From tokenism to citizenship. Florence: UNICEF; 1992.

16. Shier H. Pathways to participation: Openings, opportunities and obligations. Child Soc. 2001;15(2):107-117. doi:10.1002/chi.617

17. Special themed issue: The conceptualisation and articulation of impact: Hopes, expectations and challenges for the participatory paradigm. In: Roche TC B eds. Vol. 25. New York: Routledge; 2017.

18. Skelton T. Children, young people, UNICEF and participation. Child Geograp. 2007;5(1-2):165181. doi: $10.1080 / 14733280601108338$

19. Arksey H, O'Malley L. Scoping studies: Towards a methodological framework. Int J Soc Res Methodol. 2005;8(1):19-32. doi:10.1080/1364557032000119616 
20. Levac D, Colquhoun $\mathrm{H}, \mathrm{O}$ 'Brien KK. Scoping studies: Advancing the methodology. Implement Sci. 2010;5(69):1-9. doi:10.1186/1748-5908-5-69

21. Hwang W, Weller W, Ireys $H$, Anderson G. Out-of-pocket medical spending for care of chronic conditions. Health Aff. 2001;20(6): 267-278. doi:10.1377/hlthaff.20.6.267

22. CASP. CASP Checklist: 10 questions to help you make sense of qualitative research. Published 2018. Accessed July 11, 2019. https://casp-uk.net/wp-content/uploads/2018/01/CASPQualitative-Checklist-2018.pdf.

23. NIH. Quality assessment tool for observational cohort and cross-sectional studies. Accessed July 11, 2019. https://www.nhlbi.nih.gov/health-topics/study-quality-assessment-tools.

24. Pace R, Pluye P, Bartlett $G$ et al. Testing the reliability and efficiency of the pilot Mixed Methods Appraisal Tool (MMAT) for systematic mixed studies review. Int J Nurs Stud. 2012;49:47-53. doi:10.1016/j.jijnurstu.2011.07.002

25. Brown DJ, Battersby S, Standen $P$, Anderton N, Harrison M. Inclusive design for disability: A prototype switch for use in virtual learning environments. Int J Disabil Hum Dev. 2005;4(2): 103119. doi:10.1515/IJDHD.2005.4.2.103

26. Castensoe-Seidenfaden P, Reventlov Husted G, Teilmann G, Hommel E, Olsen BS, Kensing F. Designing a self-management app for young people with type 1 diabetes: Methodological challenges, experiences, and recommendations. JMIR Mhealth Uhealth. 2017;5(10):e124. doi:10.2196/mhealth.8137

27. Chappell P. How Zulu-speaking youth with physical and visual disabilities understand love and relationships in constructing their sexual identities. Cult Health Sex. 2014;16(9):1156-1168. doi:10.1080/13691058.2014.933878

28. Chappell P, Rule P, Dlamini M, Nkala N. Troubling power dynamics: Youth with disabilities as coresearchers in sexuality research in South Africa. Childhood. 2014;21(3):385-399. doi:10.1177/0907568214525427.

29. Flicker $S$. Who benefits from community-based participatory research? A case study of the positive youth project. Health Educ Behav. 2006;35(1):70-86. doi:10.1177/1090198105285927

30. Franklin A, Sloper P. Supporting the participation of disabled children and young people in decision-making. Child Soc. 2009;23:3-15. doi:10.1111/j.1099-0860.2007.00131.x

31. Graham N, Mandy M, Clarke C, Morriss-Roberts C. Using children and young people as advocates to inform research design. BrJ Occup Ther. 2017;80(11):684-688. doi:10.1177/0308022617725491

32. Marshall Z, Nixon S, Nepveux D, et al. Navigating risks and professional roles: Research with lesbian, gay, bisexual, trans, and queer young people with intellectual disabilities. $J$ Empir Res Hum Res Ethics. 2012;7(4):20-33. doi:10.1525/jer.2012.7.4.20

33. McAnuff J, Brooks R, Duff C, Quinn M, Marshall J, Kolehmainen N. Improving participation outcomes and interventions in neurodisability: Co-designing future research. Child Care Health Dev. 2017;43(2):298-306. doi:10.1111/cch.12414

34. Moreau KA, Eady K. The involvement of adolescents with chronic health conditions in medical education: An exploratory qualitative study. Hosp Pediatr.2017;7(11):668-674. doi:10.1542/hpeds.2017-0010

35. Murray R. Sixth Sense: The disabled children and young people's participation project. Child Soc. 2012;26(3):262-267. doi:10.1111/j.1099-0860.2012.00439.x

36. Rahi JS, Tadic V, Keeley S, Lewando-Hundt G. Capturing children and young people's perspectives to identify the content for a novel vision-related quality of life instrument. Ophthalmology. 2011;118(5):819-824. doi:10.1016/j.ophtha.2010.08.034 
37. Rich C, Goncalves A, Guardiani M, O'Donnell E, Strzelecki J. Teen advisory committee: Lessons learned by adolescents, facilitators and hospital staff. Pediatr Nurs. 2014;40(6):289-296.

38. Stevenson M. Participatory data analysis alongside co-researchers who have Down syndrome. J App/ Res Intellect Disabil. 2014;27(1):23-33. doi:10.1111/jar.12080

39. Van Staa A, Jedeloo S, Latour JM, Trappenburg MJ. Exciting but exhausting: Experiences with participatory research with chronically ill adolescents. Health Expect. 2010;13(1):95-107. doi:10.1111/j.1369-7625.2009.00574.x

40. Vindrola-Padros C, Martins A, Coyne I, Bryan G, Gibson F. From informed consent to dissemination: Using participatory visual methods with young people with long-term conditions at different stages of research. Glob Public Health. 2016;11(5-6):636- 650. doi:10.1080/17441692.2016.1165718

41. Powers $L E$, Garner $T$, Valnes B, et al. Building a successful adult life: Findings from youth-directed research. Exceptionality. 2007;15(1):45-56. doi:10.1080/09362830709336925

42. Sloper P, Lightfoot J. Involving disabled and chronically ill children and young people in health service development. Child Care Health Dev. 2003;29(1):15-20. doi:10.1046/j.13652214.2003.00315.x

43. Coyne I, Prizeman G, Sheehan A, Malone H, While AE. An e-health intervention to support the transition of young people with long-term illnesses to adult healthcare services: Design and early use. Patient Educ Couns. 2016;99(9):1496-1504. doi:10.1016/j.pec.2016.06.005

44. Kramer J, Barth Y, Curtis K, et al. Involving youth with disabilities in the development and evaluation of a new advocacy training: Project TEAM. Disabil Rehabil. 2013;35(7):614-622. doi:10.3109/09638288.2012.705218.

45. Mayo M. Children's and young people's participation in development in the South and in urban regeneration in the North. Prog Dev Stud. 2001;1(4):279-293. doi:10.1177/146499340100100401

46. Staniszewska S, Brett J, Mockford C, Barber R. The GRIPP-checklist: Strengthening the quality of patient and public involvement reporting in research. Int I Technol Assess Health Care. 2011;27(4):391-399. doi:10.1017/S0266462311000481

47. Tritter JQ, McCallum A. The snakes and ladders of user involvement: Moving beyond Arnstein. Health Policy. 2006;76(2):156-168. doi:10.1016/j.healthpol.2005.05.008

48. Greenhalgh $T$, Hinton $L$, Finlay $T$ et al. Frameworks for supporting patient and public involvement in research: Systematic review and co-design pilot. Health Expect. 2019;22(4):785-801. doi:10.1111/hex.12888

49. Collins M, Long R, Page A, Popay J, Lobban F. Using the Public Involvement Impact Assessment Framework to assess the impact of public involvement in a mental health research context: $A$ reflective case study. Health Expect. 2018;21(6):950-963. doi:10.1111/hex.12688

50. Morrow $E$, Ross $F$, Grocott $P$, Bennett J. A model and measure for quality service user involvement in health research. Int J Consum Stud. 2010;34(5):532-539. doi:10.1111/j.1470-6431.2010.00901.x

51. Lundy L. In defence of tokenism? Implementing children's right to participate in collective decision-making. Childhood. 2018;25(3):340-354. doi:10.1177/0907568218777292 




\section{Chapter 3}

Experiences with PPI through a panel: a focus group study among young people with a chronic condition

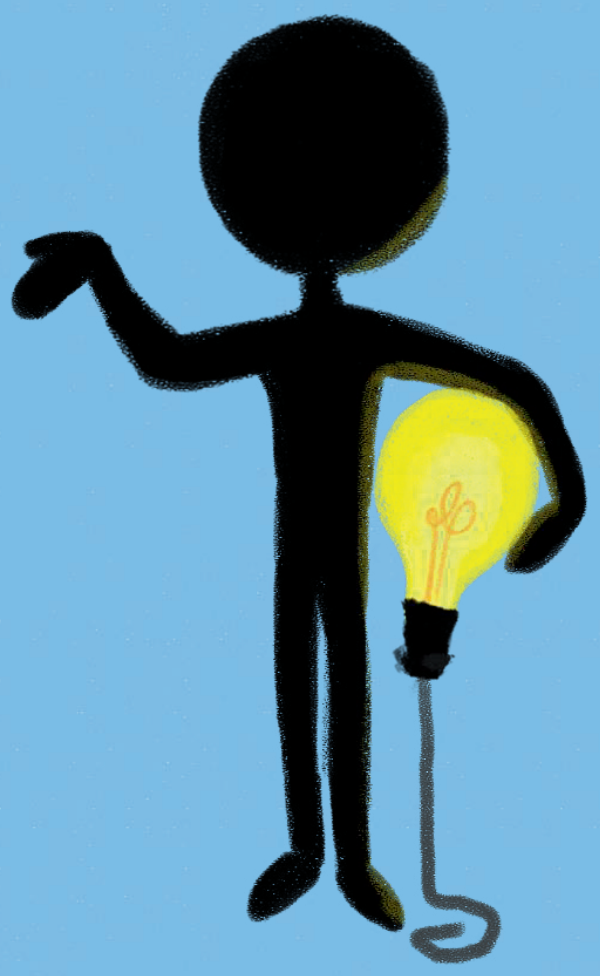

Published as: Schelven F van, Boeije H, Inhulsen MB, Sattoe JNT, Rademakers J. "We know what we are talking about": Experiences of young people with a chronic condition involved in a participatory youth panel and their perceived impact. Child Care in Practice. 2019;27(2):191-207. doi:10.1080/13575279.2019.1680529 


\begin{abstract}
There is a growing recognition that research and implementation projects should be carried out "with" or "by" young people with chronic conditions, instead of "about" or "for" them. The current study aimed to explore how young people with chronic conditions experience their involvement in a participatory youth panel. This panel was a structural part of a threeyear program addressing the social position of young people with chronic conditions in the Netherlands. It hosted 45 research and implementation projects to improve the social position of young people with chronic conditions in five areas: care, school, work, sport, and personal strength.

Output from these projects were, for example, a tool to improve self-management, an evidence-based method to facilitate the transition to adult-care, and a digital platform about performing physical activity with a disability. During the program, six focus groups consisting of four to eleven panel members were conducted. The transcripts were analysed using the principles of thematic analysis. The results show panel members took part in multiple projects and activities, such as assessing project applications, evaluating the progress of projects and organizing a political lobby. They were enthusiastic about their role in the panel. The structural nature of the panel enabled them to achieve personal growth and professionalization of their participation. Consequently, panel members experienced an increasing impact on the program and separate projects, and on national politics.
\end{abstract}

Therefore, it is suggested that a structural form of participation, such as a participatory panel, is suitable to facilitate meaningful participation of young people with chronic conditions. 


\section{Introduction}

It is widely recognized that young people with chronic conditions experience social disadvantages compared to their peers. Studies have reported that having a chronic condition complicates, for example, performing at school, ${ }^{1}$ achieving developmental milestones $^{2}$ and social participation. ${ }^{3,4}$ Therefore, considerable research has investigated ways to improve opportunities of these young people and has targeted different areas, such as health care ${ }^{5}$, sport ${ }^{6}$ and school. ${ }^{7}$

To resolve social disadvantages, research projects (e.g. scientific projects aimed at increasing knowledge on how young people's opportunities can be improved) and implementation projects (e.g. practice-oriented projects aimed at developing, for example, tools and interventions to enhance their social position) have been developed. Traditionally, researchers and policy makers have focused on carrying out these types of projects "about" or "for" young people with chronic conditions. ${ }^{8}$ In more recent years, there has been growing recognition that projects should be carried out "with" or even "by" them. It is emphasized that these young people have the right to participate in decision making that concerns them. Hart defined this type of participation as "the process of sharing decisions which affect one's life and the life of the community in which one lives". 9

Researchers stress the importance of participation, since it benefits both young people, and research and implementation projects. Participation contributes to the personal and social development of chronically ill young people by providing them with opportunities to gain new knowledge and skills, ${ }^{10-13}$ to build a social network ${ }^{10,11}$ and to increase their independence, confidence and self-esteem. ${ }^{7,10,11}$ Furthermore, several studies have pointed out that youth participation increases the relevance and quality of research. ${ }^{10,14}$

There are, however, some practical limitations to involving young people with chronic conditions in projects. For example, projects in which their participation is part of the design are usually less efficient, and demand more time and resources than non-participatory projects. ${ }^{10,14,15}$ Moreover, the contribution of young people is not always of good quality due to limited skills necessary to be a suitable partner in projects. ${ }^{12,15}$ Another challenge is maintaining their enthusiasm through all phases of a project. ${ }^{10,15}$ The levels of participation can decrease during projects primarily due to disappointment about the meaningfulness of their participation. To address these challenges, it is argued that we should search for more effective and efficient forms of participation. ${ }^{10,15}$

According to Sinclair, the practical limitations of participation can be overcome by introducing forms of participation that are "embedded within organisations, part of the mainstream, rather than an isolated or marginalised activity". ${ }^{16}$ Virtually all current studies describe participation forms that involve young people with chronic conditions during one 
project. ${ }^{11,12,14,15}$ However, following Sinclair's line of reasoning, it is necessary to move beyond these isolated forms of participation towards structural and embedded forms of participation, that provide young people with a meaningful position within an organization, allowing them to participate in multiple projects and activities over a longer period. This may increase the effectiveness of participation, since it facilitates an ongoing dialogue between young people and professionals and prevents "consultation fatigue" as a result of separate and unconnected participation activities. ${ }^{16}$ However, thus far no studies have investigated whether structural and embedded participation is suitable for young people with chronic conditions.

A possible arrangement of this type of participation is in the form of a panel of young people with chronic conditions. A participatory panel is a group of people that advise, both solicited and unsolicited, on matters that affect them with the aim to improve the relevance and quality of decisions within an organization. A panel is an integral part of the organization, and facilitates participation in multiple activities over a longer period. As it resembles existing "adult-oriented" political models, it is familiar to professionals and relatively easy to implement. ${ }^{17,18}$

The current study aims to explore how young people with chronic conditions experience their involvement in a participatory youth panel. Chronic conditions are defined as conditions "that lasted or are expected to last twelve or more months and resulted in functional limitations and/or the need for ongoing medical care". ${ }^{19}$ The study was conducted among the youth panel within the Dutch program Care and Future Prospects [in Dutch: Zorg én Perspectief] (CFP). A description of the program and the youth panel is presented in Box 1. The following research questions were examined:

1. How do young people with chronic conditions experience their participation in a youth panel, and how does this affect them?

2. What impact do young people with chronic conditions participating in a youth panel experience on research and implementation projects that aim to foster the social position of this group?

3. What factors facilitate or impede the impact of a panel of young people with chronic conditions?

The findings contribute to a growing body of knowledge about how young people with chronic conditions can play an active role in research and implementation projects that affect them. 
Box 1. The youth panel of CFP

The Dutch organization FNO-a fund that stimulates and supports initiatives that improve the opportunities of vulnerable people-developed the program Care and Future Prospects (CFP). This program hosted 45 research and implementation projects to improve the social position of young people with chronic conditions in five areas: care, school, work, sport, and personal strength. Output from these projects were, for example, a tool to improve self-management, an evidence-based method to facilitate the transition to adult-care, and a digital platform about performing physical activity with a disability.

A central element of CFP was the youth panel, that consisted of young people of 15-30 years old with chronic conditions such as rheumatism, diabetes, cerebral palsy and traumatic brain injury. Due to both new and departing members, the size of the youth panel varied from eleven to twenty-two panel members during the research period (see Table 1 for an overview of their main characteristics). Young people could apply for panel membership via the FNO website. In the selection of new panel members, attention was paid to the diversity of panel members in terms of, for example, chronic conditions, educational level and age.

One of the panel members, also a young person with a chronic condition, was the chairman of the youth panel. The chairman was formally employed by FNO, and received a salary. All other panel members received a small financial reimbursement for their efforts.

Tasks of the youth panel were to inform the program CFP, the 45 projects within the program, and the national politics about the experiences of young people with chronic conditions, and to advise on possible solutions. Within the program, for example, it played a significant role in the assessment of project applications. The projects were formally obliged to involve one panel member, whom CFP assigned to them, in design, execution and implementation. Political activities included, for example, conversations with members of the Dutch parliament and Ministers, and sending position papers to the spokesmen of political parties.

The youth panel regularly organized meetings to discuss their input and activities. 
Table 1. Characteristics of panel members in the period 2016-2018

\begin{tabular}{lr}
\hline$n$ & Panel members \\
\hline $\begin{array}{lr}\text { Gender } \\
\quad \text { Male (\%) }\end{array}$ & $35(25.7)$ \\
$\quad$ Female (\%) & $26(74.3)$ \\
\hline Age at intake & 21.8 \\
$\quad$ Mean & $17-27$ \\
$\quad$ Min-max & $0(0.0)$ \\
\hline Educational levela & $9(25.7)$ \\
$\quad$ Low (\%) & $24(68.6)$ \\
$\quad$ Medium (\%) & $2(6.7)$ \\
\hline High (\%) & \\
$\quad$ Unknown (\%) & \\
\hline Education denotes the number of panel members that attend or completed lower, \\
medium or higher education. "High" refers to University (of Applied Sciences), \\
"Medium" refers to secondary school and Intermediate Vocational Education, and \\
"Low" to primary school and no education.
\end{tabular}

\section{Methods}

\section{Study design}

Six focus groups were conducted to explore experiences and opinions with regard to participation in the youth panel of CFP. Initially, online focus groups (OFGs) were chosen, since they provide participants with the possibility to participate a-synchronously at a time and place convenient to them. ${ }^{20}$ However, during the study, it became clear that most participants found the OFGs an inconvenient way of sharing their experiences. Moreover, the chairman of the youth panel noted that some relevant topics were not discussed during the OFGs. Therefore, the last four focus groups were conducted face-to-face (FFGs). Participants preferred this way of data collection, since it improved interaction and facilitated in-depth discussions. This, in turn, led to richer data, since they were more willing to share their experiences.

During the OFGs and FFGs, a topic list was used to structure the focus groups (Appendix A). As new questions arose during data collection, the topic list was adapted during the course of the study. Themes on the different versions of the topic lists were, for example, the overall functioning of the youth panel, development of the youth panel and its activities and impact. All versions were reviewed and approved by the previous and current chairman 
of the youth panel. During all focus groups, participants were also free to suggest their own themes.

\section{Participants}

All members of the youth panel received an email inviting them to participate in the focus groups. Overall, 24 panel members participated in one or multiple focus groups in the period from July 2016 to October 2018.

Table 2. Participants in the focus groups

\begin{tabular}{|c|c|c|c|c|c|c|}
\hline & OFG 1 & OFG 2 & FFG 3 & FFG 4 & FFG 5 & FFG 6 \\
\hline$n$ & 6 & 11 & 8 & 6 & 4 & 6 \\
\hline \multicolumn{7}{|l|}{ Gender } \\
\hline \multirow[t]{2}{*}{ Male (\%) } & 3 & $2(18.1)$ & $1(12.5)$ & $3(50.0)$ & 0 & $2(33.3)$ \\
\hline & $(50.0)$ & & & & $(0.0)$ & \\
\hline \multirow[t]{2}{*}{ Female (\%) } & 3 & $9(81.8)$ & 7 (87.5) & $3(50.0)$ & 4 & $4(66.7)$ \\
\hline & $(50.0)$ & & & & (100.0) & \\
\hline \multicolumn{7}{|l|}{ Age at intake } \\
\hline Mean & 22.4 & 21.7 & 22.5 & 22.8 & 22.5 & 23.4 \\
\hline Min-max & $18-27$ & $16-28$ & $17-28$ & $21-26$ & $20-25$ & $18-27$ \\
\hline \multicolumn{7}{|c|}{ Educational levela } \\
\hline Low (\%) & $0(0.0)$ & $0(0.0)$ & $0(0.0)$ & $0(0.0)$ & $0(0.0)$ & $0(0.0)$ \\
\hline \multirow[t]{2}{*}{ Medium (\%) } & 1 & $2(18.1)$ & $2(25.0)$ & $1(16.7)$ & 1 & $2(33.3)$ \\
\hline & $(16.7)$ & & & & $(25.0)$ & \\
\hline \multirow[t]{2}{*}{ High (\%) } & 4 & $9(81.8)$ & $6(75.0)$ & $5(83.8)$ & 3 & $3(50.0)$ \\
\hline & $(66.7)$ & & & & $(75.0)$ & \\
\hline \multirow[t]{2}{*}{ Unknown (\%) } & 1 & 0 & 0 & 0 & 0 & $1(16.7)$ \\
\hline & (16.7) & $(0.0)$ & $(0.0)$ & $(0.0)$ & $(0.0)$ & \\
\hline
\end{tabular}

Education denotes the number of panel members that attend or completed lower, medium or higher education. "High" refers to University (of Applied Sciences), "Medium" refers to secondary school and Intermediate Vocational Education, and "Low" to primary school and no education.

The OFGs took place in July 2016 and January 2017. Each OFG consisted of six to eleven participants (Table 2). The FFGs were held in September 2017 and October 2018. Due to the large number of participants, the participants of the FFGs were split into two smaller groups. This resulted in FFGs with four to eight participants. 
In all focus groups, the majority of the panel members at that time participated. Reasons for non-response were conflicts of interest due to prior obligations, lack of time, temporarily living abroad, or illness.

\section{Data collection}

During OFG 2 and FFG 3, two young people with a chronic condition (not otherwise part of the program or the panel) were involved in data collection as co-researchers. They assisted the researchers in moderating the focus groups, for example, by asking follow-up questions. Based on the results of earlier studies, ${ }^{12,13,21}$ it was believed that this would increase the quality of the data collection, since the co-researchers could help focusing on relevant topics. However, due to illness and other obligations, the co-researchers were not able to assist during all focus groups. The focus groups without the co-researchers were performed by a team of researchers, of which at least one was a young researcher of the same age as the participants.

The OFGs were organized using a closed web-based discussion site. Participants received an email with the starting date of the OFG, the website link and their personal login names and passwords. Within a set period of three weeks participants could log in, read each other's anonymous comments and give their online responses at any time. One question or statement was posted every $2-3$ days.

The remaining days were used to give participants the opportunity to respond to questions of previous days and to the reactions of other participants. Two researchers (H.B. and M.I.) (OFG 1), or two researchers (H.B. and M.I.) and two co-researchers (OFG 2) moderated and monitored the discussion and asked more in-depth questions when necessary. All topics remained open for response throughout the whole study period. At the end of the OFGs the discussion site provided a complete and literal transcript of all reactions.

The FFGs were moderated by a team of one researcher (H.B.) and a co-researcher (FFG 3), or two researchers (F.S., H.B., M.I. and/or J.S.) (FFG 4-6). The FFGs lasted approximately 45$90 \mathrm{~min}$, were audio-recorded and transcribed verbatim.

\section{Data analysis}

For both the OFGs and the FFGs, a qualitative analysis method inspired by thematic analysis was used. ${ }^{22}$ All transcripts were analysed by the principal researcher (F.S.), and the first four transcripts were also independently analysed by another researcher (H.B. or M.I.). Relevant excerpts were marked and coded. Initially, codes were chosen that were close to participants' wording, such as "receiving opportunities" and "contributing to a better world". Related codes were then grouped to identify subthemes and themes related to the research questions. For example, "receiving opportunities" became a subtheme of the overall theme "personal development", and "contributing to a better world" was added to 
the overall theme "motivation". Two researchers (F.S. and H.B.) discussed the codes and themes of the first four transcripts. Following the discussions, some themes were adapted, merged or renamed. After identifying the codes and the themes, the relationships between themes were analysed. These were also discussed, until consensus was reached (F.S., H.B. and J.S.). The MAXQDA-11 software package was used as an aid in the coding process.

\section{Results}

In the analysis of the experiences of the youth panel of the Dutch program CFP, six themes were identified: (i) motivation, (ii) participation, (iii) impact, (iv) facilitating factors, (v) impeding factors, and (vi) the future. All findings were derived from the reports of participants.

\section{Motivation}

The participating panel members reported different reasons for participating in the CFP youth panel. An important reason was that participation allowed them to do something for others, despite their chronic condition. Their chronic condition became a strength, rather than a weakness, and they could use it to improve the social position of other young people with chronic conditions.

What I really like about the panel is that my experiences, my daily barriers, are useful. I can use them and help others. I can finally turn my shit [into something positive].

$$
\text { - FFG 3, female, } 24
$$

Furthermore, panel members stipulated it is important to incorporate their perspective in decisions related to the CFP program and the projects it hosts, as they are familiar with the problems young people with chronic conditions experience and are therefore able to provide new insights.

It [the youth panel] is most valuable, when we can provide insights other people did not think about. Or when we have a different opinion about a project than the program committee, or something. Then, I think, the participation and the youth panel are most valuable, because it really adds something. Yes, we know what we are talking about. We

have experienced it.

- FFG 4, male, 24

Panel members also reported they participated in the youth panel to raise awareness about having a chronic condition and to contribute to a better world. Furthermore, some of them participated, since they were enthusiastic about the program or since they enjoyed being a member of the youth panel. 


\section{Participation of the youth panel}

Initially, panel members predominantly participated in the CFP program and the projects within the program. During the program, the activities of the youth panel shifted towards national politics. Simultaneously, panel members experienced a professionalization and an increasingly structured organization of the youth panel. At the start of the panel, they were collectively responsible for all tasks within the youth panel, but, over the course of the program, tasks were divided over the five themes of the CFP program: care, school, work, sports, and personal strength.

Over time and through experience and training in, for example, promoting their interests, panel members improved their skills in conveying an overall message, instead of each panel member telling their individual story.

At first, there was nothing. Now there is structure, since a year. The first half a year was less clear: where are we going? Now we are a structured panel.

- FFG 3, female, 24

\section{Participation in the program and the projects}

Panel members were predominantly positive about their involvement in the CFP program. The program provided them with opportunities to share their opinions. However, the roles they took on within the youth panel varied. For example, some panel members were provided with additional tasks, such as writing blogs, speaking on conferences, or making movies. These differences increased during the program, because of changes within the program: the proportion of project-related activities decreased, as more projects were finished. Subsequently, panel members were more often provided with the choice to engage in alternative activities.

Yes, we want to give panel members space to choose. We don't want to oblige them to do A or B. However, that does imply more diverse roles in the panel.

- FFG 5, female, 20

There was considerably more debate among panel members about the involvement within the projects that the program hosts. Although their involvement in the hosted projects increased as the youth panel grew and developed, there was a great variation in the extent to which project leaders informed and consulted the youth panel. Some panel members were a partner in the data collection of a research project or advised on the implementation of a tool, whilst other panel members were solely informed about the progress of the project or not informed at all. Panel members suggested that their involvement depended on the type of project and on the value project leaders placed on their perspective. 
Some projects avoid contact, some want you to participate in every meeting and others have no idea what to do with us, I believe.

- OFG 2, female, 22

Participation in the national politics

According to the panel members, their participation in the CFP program and the projects was not sufficient to improve the social position of young people with chronic conditions. Therefore, they increasingly engaged in political activities such as organizing conversations with members of the Dutch parliament and Ministers, and sending position papers to the spokesmen of political parties. At first, these activities were primarily the initiative of the youth panel. However, over time, the demand for consultations outside of the program by, for example, politicians grew.

I have the feeling that we are increasingly invited to participate. Initially, we usually sent the letters. That was about politics, that we wanted to meet. Now, we are increasingly invited to join in conversations or meetings. That is really cool.

$$
\text { - FFG 6, male, } 25
$$

\section{Impact of the youth panel}

Panel members were enthusiastic about the impact of the youth panel. They felt listened to and taken seriously. According to them, their influence increased during the program, since the youth panel developed and panel members knew better how to influence decision making. However, they recognized, and found it logical and desirable, that final decisions were always made by the projects and the program themselves. Overall, the panel members reported impact of the youth panel on three levels: themselves, the program and the projects, and the national politics.

I don't feel like a showpiece [of CFP and FNO]. I most certainly feel like FNO does something with our opinions and input and they did not only add us to the program as decoration.

- OFG 2, female, 25

Impact on panel members themselves

An important personal benefit of participating in the youth panel was that it offered panel members opportunities for personal development. Panel members explained that establishing changes in the program or projects increased their confidence, which provided them with the courage to take on a greater role within the youth panel. By accomplishing their tasks in the panel they were able to improve their skills, such as public speaking and conveying their message. Besides, being a panel member offered them new opportunities, such as speaking in front of an audience, getting in contact with politicians and going to conferences. Panel members also reported that they learned from each other; experienced 
panel members shared their knowledge and experiences with new, inexperienced panel members.

Another valuable outcome of participation in the youth panel was network building, both private and business-related. Panel members emphasized that involvement in the youth panel increased social contacts with peers who also deal with a chronic illness or disability. This resulted in close friendships. Furthermore, some of them mentioned that the youth panel facilitated building a business-related network by making it easier to get in contact with professional parties.

We get to think about things I didn't even know existed, we get to open doors that otherwise would remain closed, we get to look behind the scenes and we can think, contribute and read along with the program.

- OFG 1, female, 18

Impact on the program and the projects

The youth panel had an increasing impact on the assessment of project applications in CFP. During the first call of the program, only the chairman was involved in the assessment of project applications. The other panel members were asked for feedback, after a decision was made. However, since the youth panel provided valuable feedback, it was decided to involve all panel members in the assessment of project applications in the subsequent calls. In the fourth and last call, the suggestions of the panel members were considered decisive in the assessment of project applications. Furthermore, panel members agreed that involving the youth panel contributed to an improvement of the projects. According to them, project leaders frequently made false assumptions about, or were unfamiliar with the experiences of young people with chronic conditions. The involvement of the youth panel contributed to a better alignment of the projects with the perceptions of young people with chronic conditions.

You can't work for a group, without involving them. That is the biggest mistake that is always made, that young people are talked about and not with. So without the youth panel projects [will miss their goal].

- FFG 5, female, 25

\section{Impact on the national politics}

The panel members experienced impact of their political activities. This impact primarily consisted of creating awareness about the problems experienced by young people with chronic conditions. For example, some panel members had a meeting with the Dutch Minister of Education about the barriers of studying with a chronic condition. The reaction of the Minister proved that a lot of their problems were unknown to her. Panel members experienced that their political activities contributed more directly to the social position of 
young people with chronic conditions than their activities in CFP. According to them, in projects, their contribution depended on the project leaders, but the political activities were their own initiative and responsibility. Moreover, they expected that their impact on politics had a greater reach than their impact on the projects.

I was present at a meeting with a politician. That was the first time. And we sat there together, with all those young people, and we wrote down all kinds of things. And the man with the suit told us: yes, I'm really going to use this. [...]. Then I really thought: someone's listening! [...] He was there, and he heard us.

$$
\text { - FFG 5, female, } 25
$$

\section{Facilitating factors for participation}

Participants reported some factors that could enhance their participation. For instance, an important facilitating factor was providing panel members with feedback on their work. This would improve their learning process and thereby their future advice. Although the program has formulated guidelines for providing feedback, it was not always clear to panel members whether and how project leaders included their advice in projects.

Some feedback would be nice. Sometimes it is hard to advise on the program or a project and you wonder whether you are looking at it the right way.

- OFG 2, female, 23

Another facilitating factor was transparency about decisions related to the program and the youth panel. During the first focus groups, some participants experienced receiving fewer opportunities for participation compared to other panel members. Moreover, panel members were not always informed in a timely manner about program-related decisions. This caused incomprehension and feelings of disappointment and discomfort. Therefore, they suggested that transparency would create more understanding and support for decisions in programs and projects. Consequently, the transparency of program-related decisions was increased during the program. Yet, some panel members still felt they received less opportunities than others to participate.

I have asked several times for additional tasks. They [the CFP program] answer that they will come back to it, but they never do.

- FFG 6, female, 18

A facilitating factor already present in the youth panel, included, for example, the participation policy of the program. All projects in the CFP program were obliged to involve the youth panel. This increased the influence of the youth panel. However, sometimes it also contributed to tokenism: panel members experienced that some project leaders solely involved them to comply with the rules, but did not include their contribution in projectrelated decisions. 
It depends on whether they see the added value of it or just want the funds. That makes a difference. [...] They contact us, because it is in the terms and conditions, but if they don't see the added value, they won't do anything with the information.

$$
\text { - FFG 3, female, } 17
$$

Another facilitating factor already present in the youth panel was the collective voice and the stage it provided to present ideas and opinions. Panel members believed this also aided them in influencing the program and projects.

You are provided with a stage. Since we are a part of FNO, our reach is wider and we are given a voice. It is already in us, and here we are provided with the chance to put it into practice, and that is really nice.

- FFG 3, female, 25

\section{Factors impeding participation}

Panel members reported three factors impeding the participation of the youth panel. Firstly, they stressed that attention should be paid to the capacities of the youth panel. Being a member of the panel increasingly demanded time and effort, due to the success of the panel and the subsequent growth in requests from the program and its projects. Panel members found this difficult, since most of them combined their activities in the youth panel with studying or a job. Their chronic condition could also hinder them in responding to these requests, for example, when they had to be hospitalized or when they felt ill or tired.

The second challenge concerned the recruitment of new panel members. Panel members experienced that it is hard to find young people with chronic conditions, since they are mostly anonymous. Moreover, they suggested that some young people with chronic conditions are not willing to be a panel member, since it focuses too much on them having a chronic condition.

Yes, also because, when you have found the young people, not everyone wants to participate. Look, we are all very enthusiastic and want to share our experiences. However, I can also imagine, and I also know young people that think: oh, please, leave me alone.

Let me figure out my own life.

- FFG 4, female, 26

Finally, panel members recognized that the continuation of the youth panel strongly depends on the program and the organization responsible for the program. The program and the organization offered the means to organize activities, and to financially reward panel members for their efforts. Moreover, they thought the youth panel needed the support of the program to be taken seriously by external partners. 
We can't do it without [the organisation]. They won't listen, not much anyway. That there is an organisation supporting us, gives us more power.

- FFG 5, female, 25

\section{The future}

Panel members agreed that the youth panel should continue in the future. In the past three years, the panel developed a clear structure and a solid base of knowledge. Moreover, they argued that the projects should always-also in the future-include young people with chronic conditions in their decision making, and that a youth panel is a good way to facilitate this.

The projects will continue. And they always have to, should have to, keep looking for young people. And I think the youth panel is a very good organization to facilitate this.

- FFG 4, male, 21

Furthermore, several panel members expressed a wish to increase the political engagement of the youth panel. They would like to not only influence the program and its projects, but also the national political agenda. They wished to contribute to the improvement of the social conditions of young people with chronic conditions in a broader setting than solely within the CFP program. A dream for most panel members is for the youth panel to become a recognized advisory partner in national policy issues regarding young people with chronic conditions.

For me, the ultimate dream is to become some kind of platform for young people with chronic conditions. Not just for the young people themselves, but also as a recognized partner of organisations and Ministries. That they will think: if we have to make decisions about this subject, we have to consult the youth panel.

- FFG 5, female, 25

\section{Discussion}

The current study has investigated the experiences of young people with chronic conditions participating in a youth panel, the perceived impact of their participation, and factors that can facilitate or impede the impact of their participation.

The results imply a youth panel is a suitable way to facilitate participation of young people with chronic conditions in multiple research and implementation projects and activities over a longer period of time. The finding that panel members were enthusiastic about their role in the youth panel supports previous work reporting that young people with chronic conditions are generally able and willing to participate. ${ }^{13,23}$ However, panel members in this study were also ambitious to continue and expand their influence, suggesting that they value the structural participation in a youth panel. 
The benefits of participation for panel members are similar to benefits reported in previous studies. Participation contributes to personal development $10,12,15,24,25$ and network building ${ }^{10,13,24}$ of participants. The current study adds that the structural nature of a youth panel contributes to a continuing development of panel members, since it allows panel members to apply learning experiences from one project to subsequent projects. Through this, panel members undergo some degree of "professional socialisation". ${ }^{26}$ As the panel developed, this process of professional socialization accelerated, since experienced panel members could "teach" newer panel members, based on their experiences.

According to Ives et al., ${ }^{26}$ professional socialization is needed for participants to make a substantial contribution to projects. Therefore, the finding that the youth panel reported a positive impact of their participation on projects is not surprising. Although previous work has also found that participation can improve the relevance and quality of projects, ${ }^{10,14,25}$ this study adds that panel members experienced that their impact increased over time. As a result of their personal development and the development of the panel as a whole, their perceived influence increased both within and outside of the CFP program. Although the professional socialization contributed to an increased impact of the youth panel, some researchers have warned that it may compromise the ability of participants to authentically reflect the lay perspective. ${ }^{26,27}$ In the process of professional socialization participants learn to adopt explanations and interpretations of the professionals with whom they collaborate. ${ }^{28}$ However, this theory has been disputed and it is argued that participants can combine experiential and professional knowledge. ${ }^{29}$ Moreover, the opinions of the panel members in the current study frequently differed from those of the program committee of CFP, suggesting they were able to combine their increasing professionalism with their experiential "lay" knowledge.

In addition to the professionalization of the panel, several other factors were uncovered that facilitate the impact of a youth panel. These factors share similarities with factors found in previous studies. Facilitating factors are, for example, providing panel members with feedback on their work, ${ }^{13}$ and equipping them with a collective voice and a stage to present their ideas and opinions. ${ }^{12}$ In the current study, transparency about program-related decisions, and establishing a formal participation policy within the program that obliged projects to involve panel members emerged as additional facilitating factors for the impact of a youth panel.

As opposed to the facilitating factors, some factors can impede the impact of a youth panel. An example of an impeding factor is the dependency on others. Panel members suggested the continuation of the youth panel depended on the program, and their involvement in projects depended on the value project leaders placed on their perspective. Similar findings were reported in previous studies. ${ }^{12,18}$ In the current study, the formal policy of the program 
that obliged projects to involve the youth panel offered a partial solution to the dependency on project leaders. However, it must also be noted that these rules led to forms of tokenism, when project leaders did not value the input of panel members.

Another impeding factor for the impact of a youth panel is its limited capacity, and the difficulty in recruiting new panel members. In the current study, being a panel member increasingly demanded time, due to the success of the panel. Moreover, recruiting new panel members was difficult, since not all young people with chronic conditions are willing or able to participate. These findings are in line with those of other studies. ${ }^{15,16,30,31}$ The authors of these studies have warned of creating a so-called participation elite. Involvement in formal decision making is a difficult task that requires a substantial amount of time and effort. ${ }^{31}$ As a result, participation roles are predominantly performed by the relatively welloff. In the current study, this participation elite was also present: the youth panel consisted solely of young people that either followed or completed secondary education. None of the panel members solely followed or completed lower education. Indeed, it is likely, as was also noted by Van Staa et al., ${ }^{15}$ that the risk of creating a participation elite is especially present in forms of structural participation, such as the youth panel, since these require an ongoing effort instead of a one-time isolated consultation.

The purpose of the youth panel is to broaden the range of perspectives that inform decision making. Although this appears to be achieved to a considerable extent, the perspectives of the lower educated are not represented in the youth panel. As a result, the involvement of the youth panel may have predominantly contributed to a better alignment of projects and other activities with the perceptions of young people with chronic conditions, who are medium or highly educated. Therefore, future research should address the issue of equal opportunities, and investigate ways to include more lower educated young people, to ensure a diverse youth panel that represents all young people with chronic conditions.

\section{Strengths, limitations and future research}

The current study was conducted among a relatively large youth panel. Due to the size and the structural nature of the CFP youth panel, it was possible to investigate the utilization of a youth panel among a substantial study sample over a longer period. However, the study also had some limitations.

During the study, it became clear that online focus groups were not appreciated by the panel members. In order to match the method of data collection to the preferences of the panel members, the initial methodology of the study was adapted and subsequent focus groups were conducted face-to-face. This improved data collection, since there was more willingness to share and more interaction, which facilitated in-depth discussions between panel members. 
The findings are based on one panel of young people with chronic conditions within a Dutch program and the results may thus not apply to other settings and other countries. However, as mentioned earlier, the findings are derived from a panel participating in a program that hosted a diversity of projects in various settings (e.g. school, work, sports and care) over a period of three years, which improves generalizability. Next to this, the findings share many similarities with previous studies. However, in order to provide a more complete picture of the suitability of a youth panel to facilitate participation among young people with chronic conditions more research is needed. This research should address the utilization of a panel of young people with chronic conditions in other settings than CFP. Such a study could extend the findings of the current study by including, for example, the perspective of researchers and policy makers ${ }^{21}$ and objective measurements of impact, such as project-related improvements. ${ }^{10}$

\section{Conclusions and practical implications}

The current study showed that a structural and embedded participatory youth panel is a suitable way to facilitate the participation of young people with chronic conditions in multiple research and implementation projects and activities. Panel members were enthusiastic about their participation, and ambitious to expand their influence. They reported impact of their participation on themselves, on the program and projects, and on national politics. According to panel members, the structural nature of the youth panel allowed them to increase their impact over time, since it enabled professionalization of the panel and its members. Therefore, policy makers and researchers should consider structural participation forms, such as a participatory youth panel, when involving young people with chronic conditions in their projects. However, to enable the participation of all young people with chronic conditions, they should also facilitate and closely monitor the capacities of the young people involved, since structural participation requires an ongoing effort and investment. 


\section{Disclosure statement}

No potential conflict of interest was reported by the authors.

\section{Funding}

The project is funded by Fonds NutsOhra, Amsterdam. 


\section{References}

1. Lum A, Wakefield CE, Donnan B, et al. Understanding the school experiences of children and adolescents with serious chronic illness: A systematic meta-review. Child Care Health Dev. 2017;43(5):645-662. doi:10.1111/cch.12475

2. Stam H, Hartman EE, Deurloo JA, Groothoff J, Grootenhuis MA. Young adult patients with a history of pediatric disease: Impact on course of life and transition into adulthood. $J$ Adolescent Health. 2006;39(1):4-13. doi:10.1016/j.jadohealth.2005.03.011

3. Sattoe JNT, Hilberink SR, Van Staa A, Bal R. Lagging behind or not? Four distinctive social participation patterns among young adults with chronic conditions. J Adolescent Health 2014;54(4):397-403. doi:10.1016/j.jadohealth.2013.09.017

4. Taylor RM, Gibson F, Franck LS. The experience of living with a chronic illness during adolescence: A critical review of the literature. J Clin Nurs. 2008;17(23):3083-3091. doi:10.1111/j.13652702.2008.02629.x

5. Sattoe, JNT, Bal MI, Roelofs PDDM, Bal R, Miedema HS, Van Staa A. Self-management interventions for young people with chronic conditions: A systematic overview. Patient Educ Couns. 2015;98(6):704-715. doi:10.1016/j.pec.2015.03.004

6. Willis $C$, Girdler $S$, Thompson $M$, Rosenberg $M$, Reid $S$, Elliott C. Elements contributing to meaningful participation for children and youth with disabilities: A scoping review. Disabil Rehabil. 2017;39(17):1771-1784. doi:10.1080/09638288.2016.1207716

7. Canter KS, Roberts MC. A systematic and quantitative review of interventions to facilitate school reentry for children with chronic health conditions. J Pediatr Psychol. 2012;37(10):1065-1075. doi:10.1093/jpepsy/jss071

8. INVOLVE. What is public involvement in research? Accessed April, 2018. https://www.invo.org.uk/find-out-more/what-is-public-involvement-in-research-2/

9. Hart R. Children's participation: From tokenism to citizenship. Florence: UNICEF; 1992.

10. Bailey $S$, Boddy $K$, Briscoe $S$, Morris $C$. Involving disabled children and young people as partners in research: A systematic review. Child Care Health Dev. 2015;41(4):505-514. doi:10.1111/cch.12197

11. Bruce SM, Parker AT. Young deafblind adults in action: Becoming self-determined change agents through advocacy. Am Ann Deaf. 2012;157(1):16-26. doi:10.1353/aad.2012.1607

12. Dedding C. Delen in macht en onmacht: Kindparticipatie in de (alledaagse) diabeteszorg. [PhD thesis]. Amsterdam: University of Amsterdam; 2009.

13. Lightfoot J, Sloper P. Having a say in health: Involving young people with a chronic illness or physical disability in local health services development. Child Soc. 2003;17(4):277-290 doi:10.1002/CHI.748

14. Rosen-Reynoso M, Kusminsky M, Gragoudas S, et al. Youth-based participatory research: Lessons learned from a transition research study. Pediatrics. 2010;126(S3):S177-S182. doi:10.1542/peds.2010-1466N

15. Van Staa A, Jedeloo S, Latour JM, Trappenburg MJ. Exciting but exhausting: Experiences with participatory research with chronically ill adolescents. Health Expect. 2010;13(1):95-107. doi:10.1111/j.1369-7625.2009.00574.x

16. Sinclair R. Participation in practice: Making it meaningful, effective and sustainable. Child Soc. 2004;18(2):106-118. doi:10.1002/chi.817 
17. Hill M, Davis J, Prout A, Tisdall K. Moving the participation agenda forward. Child Soc. 2004;18(2):77-96. doi:10.1002/chi.819

18. Matthews H. Citizenship, youth councils and young people's participation. J Youth Stud. 2001;4(3):299-318. doi:10.1080/13676260120075464

19. Hwang W, Weller W, Ireys $H$, Anderson G. Out-of-pocket medical spending for care of chronic conditions. Health Aff. 2001;20(6): 267-278. doi:10.1377/hlthaff.20.6.267

20. Zwaanswijk M, Van Dulmen $S$. Advantages of asynchronous online focus groups and face-to-face focus groups as perceived by child, adolescent and adult participants: A survey study. BMC Res Notes. 2014;7(1):1-7. doi:10.1186/1756-0500-7-756

21. Schalkers I, Parsons CS, Bunders JFG, Dedding C. Health professionals' perspectives on children's and young people's participation in health care: A qualitative multihospital study. I Clin Nurs. 2016;25(7-8):1035-1044. doi:10.1111/jocn.13152

22. Braun V, Clarke V. Using thematic analysis in psychology. Qual Res Psychol. 2006;3(2):77-101. doi:10.1191/1478088706qp063oa

23. Cherrill J, Hudson $\mathrm{H}$, Cocking $\mathrm{C}$, et al. Clinical trials: The viewpoint of children with a chronic illness compared with healthy children. Arch Dis Child. 2010;95(3):229-232. doi:10.1136/adc.2009.159145

24. Murray R. Yes they are listening but do they hear us? Reflections on the Journey of the Barnardo's Participation Project. Child Care Pract. 2015;21(1),78-90. doi:10.1080/13575279. 2014.973370

25. Turtle K, McElearney A, Scott J. Involving children in the design and development of research instruments and data collection procedures: A case study in primary schools in Northern Ireland. Child Care Pract. 2010;16(1):57-82. doi:10.1080/13575270903378443

26. Ives J, Damery S, Redwod S. PPI, paradoxes and Plato: Who's sailing the ship? BMJ, 2013;39(3):181185. doi:10.1136/medethics-2011-100150

27. Martin GP, Finn R. Patients as team members: Opportunities, challenges and paradoxes of including patients in multi-professional healthcare teams. Sociol Health II/n. 2011;33(7):10501065. doi:10.1111/j.1467-9566.2011.01356.x

28. Thompson J, Bissell P, Cooper C, Armitage CJ, Barber R. Credibility and the 'professionalized' lay expert: Reflections on the dilemmas and opportunities of public involvement in health research. Health. 2012;16(6):602-618. doi:10.1177/1363459312441008

29. Staley K. There is no paradox with PPI in research. J Med Ethics. 2013;39(3):186-187. doi:10.1136/medethics-2012-100512

30. Dixon J, Ward J, Blower S. "They sat and actually listened to what we think about the care system": The use of participation, consultation, peer research and co-production to raise the voices of young people in and leaving care in England. Child Care Pract. 2019;25(1):6-21. doi:10.1080/13575279.2018.1521380

31. Van de Bovenkamp HM. The limits of patient power: Examining active citizenship in Dutch health care. [PhD thesis]. Rotterdam: Erasmus Universiteit Rotterdam; 2010. 


\section{Introduction (5 minutes)}

\section{Theme 1: Development of the youth panel (20 minutes)}

- Current participation:

- How do you experience your roles within the program?

- How do you experience your roles within the projects?

- Discuss individual differences in experiences.

- Participation in the past:

- Have your roles changed since the start of the panel?

- What are your experiences with these developments?

- Dreams for future participation:

- In what project phases and in what roles do you wish to participate in the future?

- Why? Can you provide some examples?

- Do you experience sufficient possibilities to accomplish these dreams?

\section{Theme 2: Current activities (10 minutes)}

- What activities enabled you to make a difference?

- Why?

- What activities failed?

- Why?

- $\quad$ From what activities did you learn most?

- Why?

\section{Theme 3: Impact (10 minutes)}

- What would the program CFP have been without the youth panel?

- Looking back, do you feel like you have been listened to sufficiently?

- What can other programs/projects learn from CFP and youth participation?

- Is a youth panel a suitable form of youth participation compared to other forms of youth participation?

\section{Conclusion}

- Did we discuss all relevant topics? Or do you know new topics we should discuss? 




\section{Chapter 4}

Lessons learned and practical tips from over thirty projects involving young people with a chronic condition: a mixed methods study

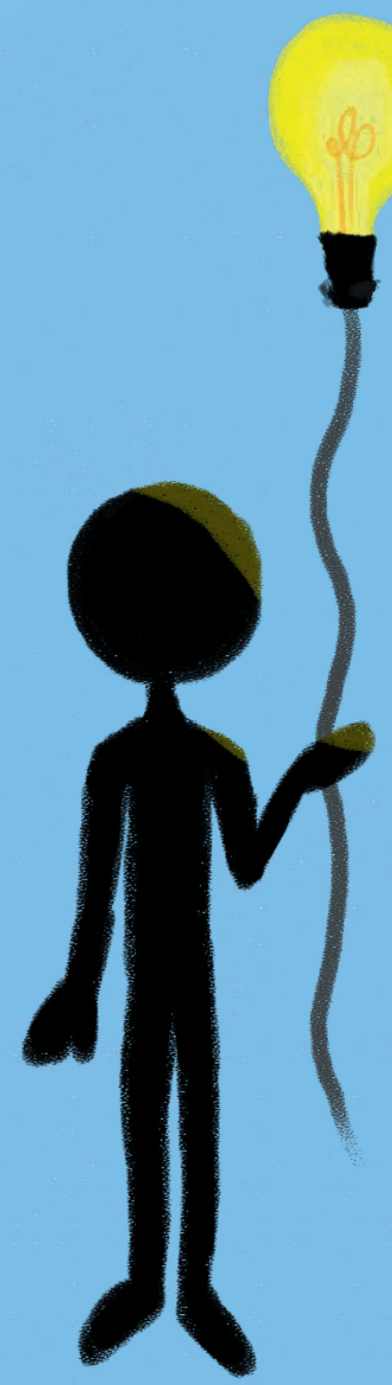

Published as: Schelven F van, Meulen E van der, Kroeze N, Ketelaar M, Boeije H. Patient and public involvement of young people with a chronic condition: Lessons learned and practical tips from a large participatory program. Research Involvement and Engagement. 2020;6(59):1-13. doi:10.1186/s40900-020-00234-1 


\begin{abstract}
Background. The Patient and Public Involvement (PPI) of young people with a chronic condition receives increasing attention in policy and practice. This is, however, not without its challenges. Consequently, calls have been made to share lessons learned during PPI practice.
\end{abstract}

Methods. We share our lessons learned from a large participatory program, called Care and Future Prospects. This program aims to improve the social position of young people aged $0-25$ with a physical or mental chronic condition by funding participatory projects. We have drawn our lessons from 33 of these projects, using four data sources. One data source provided information from the perspective of young people with a chronic condition, i.e. questionnaires. Three data sources contained information from the perspectives of project teams, i.e. project reports, case studies of projects and Involvement Matrices. For most of the projects, we have information from multiple data sources.

Results. We have combined the findings derived from all four data sources. This resulted in multiple lessons learned about PPI with young people with a chronic condition. Those lessons are divided into six themes, including practicalities to take into account at the start, involvement from the start, roles and responsibilities, support, flexibility and an open mind, and evaluation of process and outcomes.

Conclusions. The lessons learned have taught us that meaningful PPI requires effort, time and resources from both young people and project teams, from the beginning to the end. It is important to continuously discuss roles and responsibilities, and whether these still meet everyone's needs and wishes. Our study adds to previous research by providing practical examples of encountered challenges and how to deal with them. Moreover, the practical tips can be a valuable aid by showing young people and project teams what concrete actions can support a successful PPI process. 


\section{Background}

The Patient and Public Involvement (PPI) of young people with a chronic condition, such as rheumatism, diabetes, cerebral palsy and traumatic brain injury, receives increasing attention in policy and practice. ${ }^{1,2}$ Young people with a chronic condition are increasingly invited to contribute to research projects, i.e. scientific projects aimed at increasing knowledge, and innovation projects, i.e. practice-oriented projects aimed at developing, for example, tools and interventions. This development is driven by the realisation that involving those young people as co-actors in decision-making processes contributes to the relevance of projects ${ }^{3-5}$ and improves the uptake of results. ${ }^{4,6,7}$ According to the United Nations Convention on the Rights of the Child, it is a fundamental right of young people to have a say in matters that affect them, without discrimination and irrespective of disabilities. $^{8}$

An early definition of young people's PPI has been provided by Hart. ${ }^{9}$ He described it as "the process of sharing decisions which affect one's life and the life of the community in which one lives". Based on work of Arnstein on citizen participation, ${ }^{10}$ he developed a Ladder of Involvement which distinguishes eight roles that provide young people with different degrees of agency when working together with adults. Although a lot of thinking about PPI is still based on and inspired by these principles of Hart's model, it has also been criticised. ${ }^{11-13}$ Especially the hierarchy implied by the ladder and the elements of tokenism included in the model are topics of discussion. Consequently, several researchers have adapted the model and/or formulated new definitions. ${ }^{12,14}$ Nowadays, the INVOLVE's definition is one that is often referred to: PPI is "research [or innovation projects] being carried out with or by members of the public rather than to, about or for them". ${ }^{1}$

Despite the realisation that the perspectives of young people with a chronic condition should not be neglected in research and innovation projects addressing issues that concern them, many young people and project teams are struggling how to shape their collaboration. Substantive issues include, for example, how to achieve meaningful impact on the relevance and quality of research and innovation projects ${ }^{6,15}$ and how to handle differences in ideas and opinions. ${ }^{16,17}$ More practical challenges were observed as well. PPI of young people with a chronic condition requires an additional effort, in terms of time and resources, from both project teams and young people with a chronic condition. 3,4,6,7,18,19 Also, questions remain about what roles young people with a chronic condition can play and in what project phases. $6,11,19,20$ The health issues, fatigue and sudden hospital stays young people with a chronic condition have to cope with can make a PPI process even more complicated.

Limited progress has been made in addressing the challenges of PPI of young people with a chronic condition in recent years. Project teams have encountered similar challenges and 
reported on them time and again. ${ }^{2}$ Failure to overcome these challenges can cause insecurity and a fear of doing it wrong among both young people with a chronic condition and project teams, discouraging future attempts of PPI. ${ }^{21}$ In this light, several calls have been made to share experiences and lessons learned on PPI and on how to deal with its challenges. $^{22,23}$

In this article, we wish to respond to these calls and share our lessons learned about PPI with young people with a chronic condition from a four-year participatory program, called Care and Future Prospects [in Dutch: Zorg én Perspectief] (CFP). CFP aimed to improve the social position of young people aged 0-25 with a chronic condition, i.e. conditions that 'that lasted or are expected to last twelve or more months and resulted in functional limitations and/or the need for ongoing medical care'. ${ }^{24}$ In order to achieve, CFP funded numerous participatory research and innovation projects (Box 1). In an evaluation study conducted between 2016 and 2019, we investigated whether they had achieved this goal. The data collected included valuable lessons about PPI of young people with a chronic condition in research and innovation projects. In this article, we aim to share these lessons and provide practical tips for young people and project teams, by answering the following research questions:

1. How have young people with a chronic condition been involved in research and innovation projects in the large participatory program of CFP?

2. What difficulties do young people with a chronic condition and project teams encounter during their collaboration?

3. What are conditions for meaningful PPI, both for young people with a chronic condition and project teams?

4. What impact of PPI do young people with a chronic condition and project teams experience?

\section{Box 1. The Care and Future Prospects Program}

The Dutch organisation FNO - a fund that stimulates and supports initiatives improving the opportunities of vulnerable people - developed the program Care and Future Prospects (CFP). The goal of this program was to improve the social position of young people aged 0-25 with a physical or mental chronic condition in five areas: care, school, work, sport, and personal strength. To achieve this aim, forty-five research projects and innovation projects were funded. Thirty-three of these projects were funded during four open calls; twelve received specified funding (not in an open call). Output from the projects included, for example, a tool to improve self-management and a digital platform about performing physical activity with a disability. 
An important element of the program was PPI of young people with a chronic condition. A participatory youth panel was set up with young people with different chronic conditions, such as diabetes, cerebral palsy and traumatic brain injury. All research and innovation projects that received funding were also asked to involve individual young people with a chronic condition that was relevant to the project. For example, projects about young people with rheumatism were asked to work together with young people with rheumatism. Later on in the program, PPI became mandatory for the projects that received funding.

Project teams were allowed to decide for themselves, preferably in consultation with the young people, how they would shape the PPI in their project. Within the program, meetings were organised for project teams to share experiences and facilitate PPI.

Research on the youth panel has been reported elsewhere. ${ }^{25}$ The current article focuses on the lessons learned from the PPI of individual young people in the research and innovation projects.

\section{Methods}

\section{PPI in the current study}

Young people with a chronic condition were actively involved in conducting the overall evaluation study of CFP and in writing this article. During the evaluation study, we regularly spoke to the chair of CFP's participatory youth panel to discuss draft versions of data collection methods and to reflect on our findings. Other young people with a chronic condition pilot tested the questionnaire to make sure the questions were relevant and comprehensible. A data analysis meeting with young people with a chronic condition and their parents was organised to analyse and interpret the findings of the Involvement Matrix.

This article is a co-production of researchers and experience experts as well. Two young people with a chronic condition are co-authors on this article. They provided critical feedback on draft versions of the article and advised on the practical tips.

\section{Data collection}

The lessons learned in this article are based on four data sources from the overall evaluation study of CFP. One data source provided information from the perspective of young people with a chronic condition, i.e. questionnaires. Three data sources contained information on PPI from the perspectives of project teams, i.e. project reports, case studies of projects and Involvement Matrices. The data we have used concerned 33 research and innovation 
projects. For most of the projects, we have information from multiple data sources (Table $1)$.

Table 1. Data sources available for projects included in this study

\begin{tabular}{lr} 
& $\begin{array}{r}\text { Number of } \\
\text { projects }\end{array}$ \\
\hline All four data sources & 1 \\
Project report, case study and questionnaires & 1 \\
Project report, Involvement Matrix and questionnaires & 6 \\
Project report and case study & 2 \\
Project report and Involvement Matrix & 7 \\
Project report and questionnaires & 8 \\
Involvement Matrix and questionnaires & 1 \\
Project report & 6 \\
Questionnaires & 1 \\
Total & $\mathbf{3 3}$ \\
\hline
\end{tabular}

\section{Questionnaires}

To evaluate the projects from the perspective of the young people, a questionnaire has been developed. The questionnaire contained open- and closed-ended questions about the following topics: background, opinion about the content of the project, PPI and outcomes of the project, For the current study, we only used data from the questionnaires addressing PPI of young people with a chronic condition, e.g. what did they do in the project and how much they did do. An example of a question is: 'How important were you for the project?'. The part of the questionnaires that contained relevant questions for the current study can be found in the supplementary materials.

All project teams were asked to invite the young people who were in any way involved in their project to fill out an online or written version of the questionnaire. Nineteen of the 45 projects co-operated. Young people were invited to fill out the questionnaires within 1 month after the project ended. Per project, the maximum amount of filled out questionnaires was 50. Within the 19 projects, 222 young people filled out the questionnaire (Table 2). The number of questionnaires varied between 1 and 46 per project. 
Table 2. Characteristics of the young people with a chronic condition who participated in the questionnaire $(\mathrm{N}=222)$

\begin{tabular}{lrr}
\hline Sex & n & \% \\
Boy & 100 & 45 \\
Girl & 122 & 55 \\
\hline Age & & \\
18 and younger & 88 & 40 \\
$19-24$ & 58 & 27 \\
$25-30$ & 59 & 27 \\
31 and older & 15 & 6 \\
\hline Living situation & & 63 \\
With parents & 139 & 12 \\
On their own & 26 & 11 \\
With partner & 25 & 10 \\
In a group & 22 & 4 \\
Different & 10 & 1 \\
\hline Education or work status & & 6 \\
Elementary school & 3 & 11 \\
Secondary education & 69 & 22 \\
Post-secondary education & 47 & 22 \\
Unemployed / seeking a job & 16 & \\
Paid employment & 49 & 12 \\
Volunteer work & 25 & \\
Different & & \\
\hline
\end{tabular}

\section{Project reports}

As a subsidy condition, project teams were requested to fill out a project report at the end of the project. The format of the report contained open- and closed-ended questions, addressing the following topics: general project information, PPI, future of the project, and project outcomes. For the current study, we only used data from the reports addressing PPI of young people with a chronic condition, e.g. how where they involved and in what project phases. A closed-ended question on this topic included, for example, 'On a scale from 0 to 10 , to what extent did the participation of young people yield the desired results?' The part of the format of the project reports that contained questions about PPI can be found in the supplementary materials. A total of 31 project teams wrote a project report.

Case study

Some of the projects were studied in an in-depth case study. Cases were selected in consultation with the CFP bureau. Attention was paid to selecting cases that could provide 
valuable lessons and that varied in terms of the young people targeted (e.g. different ages and addressing different chronic conditions) and type of project (research or innovation). Five case studies contained information on the PPI of young people with a chronic condition. The characteristics of projects used as case studies are displayed in Table 3.

Table 3. Characteristics of case studies and number of project team members interviewed

\begin{tabular}{|c|c|c|c|c|}
\hline Case & Goal & $\begin{array}{l}\text { Young people } \\
\text { addressed }\end{array}$ & Type & $\begin{array}{l}\text { Number of } \\
\text { project team } \\
\text { members } \\
\text { interviewed }\end{array}$ \\
\hline 1 & $\begin{array}{l}\text { Help students to study } \\
\text { and provide them with } \\
\text { the opportunity to } \\
\text { have a normal student } \\
\text { life }\end{array}$ & $\begin{array}{l}\text { Young people } \\
\text { with a severe } \\
\text { physical } \\
\text { impairment } \\
\text { (age 18-25) }\end{array}$ & Innovation & 2 \\
\hline 2 & $\begin{array}{l}\text { Develop a tool that } \\
\text { enables the active } \\
\text { involvement of young } \\
\text { people in their care }\end{array}$ & $\begin{array}{l}\text { Young people } \\
\text { with a chronic } \\
\text { condition in } \\
\text { general } \\
\text { (age 4-18) }\end{array}$ & Research & 2 \\
\hline 3 & $\begin{array}{l}\text { Provide practical tips } \\
\text { on how to participate } \\
\text { in society, despite the } \\
\text { sometimes } \\
\text { unanticipated } \\
\text { consequences of a } \\
\text { chronic condition }\end{array}$ & $\begin{array}{l}\text { Young people } \\
\text { with a chronic } \\
\text { condition in } \\
\text { general } \\
\text { (age 12-25) }\end{array}$ & Research & 4 \\
\hline 4 & $\begin{array}{l}\text { Improve the transition } \\
\text { of young people with } \\
\text { a disability from } \\
\text { school to work }\end{array}$ & $\begin{array}{l}\text { Young people } \\
\text { following } \\
\text { Intermediate } \\
\text { Vocational } \\
\text { Education } \\
\text { (age 16-20) }\end{array}$ & Research & 2 \\
\hline 5 & $\begin{array}{l}\text { Inform students with a } \\
\text { functional disability } \\
\text { about studying with a } \\
\text { disability }\end{array}$ & $\begin{array}{l}\text { (Future) } \\
\text { students with a } \\
\text { physical } \\
\text { impairment } \\
\text { (age 15-25) }\end{array}$ & Innovation & 5 \\
\hline
\end{tabular}


The CFP bureau invited project teams to participate in an interview. In total, 15 members of project teams participated. The interviews were semi-structured using a topic list. Topics included project development, collaboration with other parties, PPI, and lessons learned. For the current study, we used the data on young people's PPI. For example, questions about this topic included 'How did you plan to involve young people with a chronic condition, and did the involvement in your project turn out as you planned?' and 'How did young people's PPI influence your project?'

All interviews have been recorded. Based on the recordings, we have written five case descriptions. All case descriptions contained the following sections: the project and its aim, collaboration between project team members, with the funder, with external partners and with young people with a chronic condition and PPI, For the current study, we have used the information in the sections on collaboration with young people with a chronic condition and PPI for further analyses.

\section{Involvement matrices}

We have used the Involvement Matrix to gain insight into how young people were involved in projects. ${ }^{26}$ Originally, the intention of this tool is to facilitate PPI and the dialogue between patients and project teams about their roles in a project. ${ }^{27}$ In the current study, we asked project teams to fill out the Involvement Matrix after the project ended.

The Involvement Matrix helps to map PPI activities during different project phases. Project phases are on the vertical axes of the Involvement Matrix, consisting of 'preparation', 'execution' and 'implementation'. The roles young people with a chronic condition can play are on the right axe, including 'listener', 'co-thinker', 'advisor', 'partner', and 'decisionmaker' (Box 2). By combining the phases and roles, a matrix with cells is generated. In the current research, we have asked project teams to describe PPI activities that took place, and report these in the corresponding cells.

Box 2. Distinction between different roles in the Involvement Matrix

The distinction between different roles in the Involvement Matrix is as follows (26):

- $\quad$ Listeners are given information about the project by the project team;

- Co-thinkers are asked to give their opinion. Project teams can decide whether they will use it and how;

- $\quad$ Advisors provide solicited and unsolicited advice. Solicited advice is binding. Unsolicited advice must be given formal attention and may only be rejected with substantiated arguments;

- Partners collaborate with other project team members as equals.

- Decision-makers take initiative themselves and/or make necessary decisions. 
Projects teams were invited to fill out an Involvement Matrix. In addition, they were asked to answer some open-ended questions regarding motivations for choosing specific involvement activities and what they perceive as required for meaningful involvement. For some project teams filling out the Involvement Matrix was optional and for others it was compulsory, depending on the subsidy conditions.

Fifteen project teams filled out the Involvement Matrix. All data collected with the Involvement Matrices concerned PPI and were used for further analyses.

\section{Analysis}

All data from the project reports, case studies, Involvement Matrices and questionnaires that concerned PPI were included in the analyses. First, the data from each data source were analysed separately. We quantitatively analysed the data from the project reports and questionnaires in Stata/SE 15, using descriptive statistics. The data from the Involvement Matrices were analysed both quantitatively and qualitatively. We counted the number of projects that reported activities in each cell of the matrix. The open-ended questions were analysed qualitatively in MaxQDA, using thematic analyses. Themes included facilitating factors, impeding factors, designing PPI, positive impact, support and collaboration with young people. For the case studies, we used the case descriptions that were written based on the interview data. In these case descriptions, we highlighted all passages that addressed PPI.

The second step was to conduct an overall analysis to combine the four data sources and extract the lessons learned. We uploaded all findings from the four data sources in MaxQDA. Then, we conducted a thematic analysis to identify themes across the data sources. In other words, we grouped the findings of the different data sources (both qualitative and quantitative) that addressed the same issue. This resulted in six themes: practicalities, involvement from the start, roles and responsibilities, support, flexibility and an open mind and evaluation of process and outcomes. Those themes and the lessons we have learned within the themes are described in the Results section.

\section{Reporting}

We have used the GRIPP2-checklist (Guidance for Reporting Involvement of Patients and the Public) as a guideline in reporting our study. ${ }^{28}$

\section{Results}

In this section, we describe the themes from the overall analysis and the lessons learned within these themes about PPI of young people with a chronic condition in research and innovation projects. The lessons are presented following the chronological course of projects; from 'Practicalities to take into account at the start' to 'Evaluation of process and outcomes'. 


\section{Practicalities to take into account at the start}

In the development and planning of a participatory project, it is vital to take some practicalities into account.

First, we found that participatory projects demand more time compared to nonparticipatory projects. In the project reports, case study and Involvement Matrices, project teams and coordinators noted that young people's PPI frequently - if not consistently had consequences for the continuity of projects. For example, one project coordinator added the following statement to her Involvement Matrix: 'Before you start, you have to clearly plan the moments you will talk to young people, so you actually have to make time to think about this'. One of the cases in the case study provided a good example of how PPI can be time consuming. This case concerned an innovation project aimed at improving information provision for future students with disabilities. The planning in this project regularly had to be adapted to the needs of the young people involved. The project coordinator noted, for example, that the young people involved preferred individual meetings with the project coordinator, instead of the planned group meetings. Changing this took time, and caused the project team to postpone deadlines in the planning. According to the project coordinator, events like this highlight the need for a flexible planning in project plans and proposals.

From the case study and Involvement Matrices, we have learned that the reimbursement of young people is another practicality to consider, and should also be included in project plans and proposals. Reimbursements are a valuable and tangible appreciation for young people's input. Moreover, reimbursing young people increases their commitment to their tasks and the project, and thereby clarifies mutual expectations about roles and responsibilities. A project coordinator explained in the Involvement Matrix: 'It is essential to give them a compensation for their efforts. [...] That is most certainly an encouragement, but even then it is difficult to involve young people and keep them engaged'. In most projects, young people received gift vouchers for involvement efforts. This is a relatively easy way to reimburse young people. However, a minority of the project coordinators chose to offer them a paid appointment in their organisation, since they believed this could facilitate involvement as equal partners.

In one of the cases in the case study, the project team extensively described the process of providing young people with rheumatism with a paid appointment in a hospital. They came up with two recommendations. The first one was to let young people themselves decide how they wish to be appointed, for example with a permanent contract, a zero-hours contract, or as a freelancer with a specific assignment. This is important, because some forms of reimbursements can interfere with the disability benefits young people with a chronic condition may receive. The project team can provide information on pros and cons of each possibility, so young people can decide what fits them and their situation best. Their 
second recommendation was to make sure that working conditions are adapted to the needs of the young people involved. For example, in their project, they needed to make sure workplaces were accessible by elevator. They also adapted the working hours, as the unexpected course of rheumatism required flexibility.

A third practicality in developing and planning a participatory project is the recruitment of young people with a chronic condition and gaining their commitment. This appears to be a difficult task, since not all young people wish to be engaged in matters that relate to their condition, and project teams do not know where to find them. Of all project coordinators who filled out a project report, one in five mentioned the vulnerability and therefore the limited input of young people with a chronic condition as a factor that impeded the progress of their project. From the case study, we learned that collaborating with patient or youth organisations and developing participatory activities that appeal to young people are facilitating factors in recruitment. For example, in a research project, meetings of its young people's advisory board were organised in a Dutch theme park. After the meetings, young people were given free entry to the theme park.

\section{Practical Tips}

\section{For young people}

- If you wish to be involved in a project, make yourself known. A patient or youth organisation may be able to help you.

If possible, consult with other young people who are involved in the project about how they handle their involvement

Agree on how you will be rewarded for your involvement and how you deal with expenses you have to make, such as travelling costs.

Make sure you have sufficient time to play a meaningful role in the project.

\section{For project teams}

- PPI takes time. Take this into account and set up a flexible planning.

Reward young people for their involvement. Think about how you wish to reimburse them and how you deal with expenses they have to make, such as travelling costs. Discuss the possibilities with them and make the necessary arrangements.

Rewards for PPI may interfere with disability benefits young people receive. Take this into account, when discussing the possibilities.

Make sure you timely start recruiting young people. Collaborating with a patient or youth organisation may be helpful. 


\section{Involvement from the start}

For an effective PPI process, it is advantageous to collaborate with young people with a chronic condition from the start of a project. Involving them in generating new project ideas and in writing project proposals can contribute to the meaningfulness of their involvement. In the case study and Involvement Matrices, project teams and coordinators have noted that this allows young people with a chronic condition to influence the content and course of the project, before it is set in stone. Also, it facilitates the collaboration between the young experience experts and other members of the project team as equal partners. A project coordinator who filled out the Involvement Matrix: 'One adolescent with a developmental language disorder thought with us about the content of the project, before it even started. From the start of the project, he was involved as a paid employee. This contributed to the equal collaboration between him and the rest of the project team'.

In CFP, some projects were initiated by young people with a chronic condition and, as a result, they were inherently involved from an early stage. In these projects, the relevance for and interest of young people was guaranteed. However, most project ideas did not come from young people with a chronic condition. In these cases, both the case study and the Involvement Matrices show that project teams should actively seek for the input of experience experts in generating ideas and writing a proposal. In one of the cases in the case study, concerning a research project that addressed the (psycho)social consequences of having a chronic condition, the research question was formulated based on the experiences of young people. In collaboration with other members of the project team, experience experts conducted interviews to explore issues that matter to young people with a chronic condition and translated these into a relevant research question. Other ways to involve young people with a chronic condition from the start are by asking them to cowrite a project proposal or to provide feedback on draft versions.

\section{Practical Tips}

\section{For young people}

If possible, co-write the project proposal. Introduce your experiences and ideas.

\section{For project teams}

Invite young people to contribute to or co-write the project proposal.

Think about how you will obtain the resources you need to involve young people in writing a project proposal, such as time and reimbursements, as funding may not yet be available during this phase. 


\section{Roles and responsibilities}

To facilitate commitment and meaningful PPI of young people, it is necessary to create a good and equal partnership between them and the other members of the project team. Becoming a successful team is dependent on taking young people seriously, listening to them, and providing them with a certain amount of autonomy. A project coordinator who filled out the Involvement Matrix reported: 'Don't just pretend you are listening, but actually follow-up on their advices'.

From the case study and Involvement Matrices, we have learned that an essential step in creating a partnership is defining roles and responsibilities. Clarity about roles and responsibilities helps young people to understand what is expected from them and what their contribution is to the project. As such, project teams argued that PPI activities should be concrete and well-defined. For example, a project coordinator noted in the Involvement Matrix: 'Young people need clarity about what is expected from them. Therefore, as a project coordinator, it was important to make clear arrangements.'

From the questionnaires and Involvement Matrices, we learned that young people with a chronic condition and project teams can have different perspectives on roles and responsibilities. Table 4 shows the results of the questionnaire among young people with a chronic condition. There is variation in how they perceive their roles in the projects. They see themselves mainly as participants in projects that were set up for them. They also found they were mostly passively involved, by receiving information. Smaller percentages of young people reported giving their opinion, cooperating in the execution of a project, thinking about (further) improvements, generating publicity, or cooperating on the design of the project. They were the least involved in helping with recruitment.

When we asked young people in the questionnaire $(\mathrm{N}=226)$ to quantify how much they did in the project they were involved in, $5 \%$ reported they did 'really a lot' and $18 \%$ did 'a lot'. Approximately a third reported they did 'pretty much' (38\%). The remaining young people answered they did 'a little' (35\%) or 'nothing at all' (4\%).

Table 4. Roles young people with a chronic condition played in projects, based on the perceptions of young people involved in nineteen different projects (multiple answers possible; $\mathrm{N}=217$ )

\begin{tabular}{lrr} 
I... & $\mathbf{n}$ & \% \\
\hline ... was one of the (passive) participants & 170 & 78 \\
... received information about the project & 70 & 32 \\
$\ldots$ gave my opinion about the project & 47 & 22 \\
... cooperated on the execution of the project & 47 & 22 \\
... thought about (further) improvements of the project & 40 & 18 \\
\hline
\end{tabular}


I...

... cooperated on the design of the project

... generated publicity for the project

... helped recruiting participants for the project

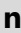

34

26

19
9

Comparing this to the perspectives of the other members of the project teams, we see that project teams reported a more active role of young people. According to the results of the Involvement Matrices, young people were generally involved in all project phases, e.g. preparation, execution and implementation. They were mostly co-thinkers. In this role, they provided feedback on a training developed by other members of the project team or on the items in a concept questionnaire. It must be noted that some project teams classified young people with a chronic condition co-thinkers, when they were actually study respondents sharing their experiences through interviews or questionnaires. These cases were removed from Table 5. In CFP projects, young people were also regularly advisors and partners. They advised project teams on the development of, for example, a book, game or training. Partners participated by (co-)writing blogs, (co-)presenting at conferences and (co-)organising trainings. The roles at the extremes of the spectrum, e.g. 'listener' and 'director', were the least often reported. Listeners were mostly informed by the project teams about the progress of the project or future participatory activities. In the role of director, young people autonomously carried out trainings or filmed and interviewed professionals in the field.

Table 5. Roles young people with a chronic condition played in different phases of projects according to the project teams $(\mathrm{N}=15)$

\begin{tabular}{lrrrrrr} 
N & Listener & $\begin{array}{r}\text { Co- } \\
\text { thinker }\end{array}$ & Advisor & Partner & $\begin{array}{r}\text { Decision- } \\
\text { maker }\end{array}$ & Totala $^{\mathbf{a}}$ \\
\hline Total & 8 & 13 & 10 & 10 & 6 & $\mathrm{X}$ \\
Preparation & 3 & 8 & 6 & 5 & 0 & 13 \\
Execution & 5 & 9 & 6 & 7 & 6 & 14 \\
Implementation & 2 & 9 & 7 & 4 & 3 & 15 \\
\hline
\end{tabular}

a The number of unique projects that involved young people with a chronic condition in a specific role or during a specific phase. The totals are lower than the sum of the rows and columns, since young people with a chronic condition can play multiple roles during one phase.

In general, project teams did not (explicitly) describe why young people were involved in a specific role or phase. However, the open-ended questions of the Involvement Matrix showed that project teams not necessarily strive to provide young people with as much influence as possible. According to them, key in achieving a good and equal partnership is 
that PPI activities match the experiences and abilities of young people with a chronic condition, and cannot be too strenuous. Several project coordinators recommended involving young people in determining what their responsibilities will be, and not deciding this for them. A project coordinator who reported limited PPI in a project noted: 'If we want to involve young people with a chronic condition to a greater extent, we have to involve them from the start, so they can indicate themselves how they can and wish to be involved'. Together, they can discuss what young people wish to do, how much time and energy they have, and choose fitting activities.

In one of the cases in the case study, the project team explicitly highlighted the importance of involving young people in determining their roles and responsibilities. In their project, they noticed that the young people involved were not always able to follow up on agreements. The enthusiasm of these young people seemed to be overshadowed by their limited energy. Formulating clear activities helped them to focus on specific tasks, and accomplish these.

\section{Practical Tips}

\section{For young people}

Discuss with the project team what you can and want to do and what you need for this. Ask, for example: 'Where and when do we meet and what do I have to do, exactly?'.

- Regularly discuss whether your input and role are still clear to you and the other members of the project team.

- If - for whatever reason - you cannot complete the tasks you agreed to do, be honest about it. Together with the project team you can find a solution for this.

- You can use the Involvement Matrix as a tool in discussing your roles and responsibilities before and during the project

\section{For project teams}

- Listen to what young people have to say. Only ask for their involvement, when you can follow-up on their opinions and feedback.

Involve young people in determining their roles and responsibilities.

Keep tasks of young people clear. Discuss tasks and responsibilities of other members of the project team with them as well.

Regularly discuss with young people how they are doing. If necessary, adapt their roles and responsibilities.

- You can use the Involvement Matrix as a tool in discussing young people's roles and responsibilities before and during the project. 


\section{Support}

In the project reports, one in five project coordinators reported the vulnerability of young people with a chronic condition as a factor that impeded the progress of their project. According to the findings of the case study and the Involvement Matrices, this vulnerability sometimes limited possibilities for involvement. Due their chronic- condition, the young people frequently had to deal with, for example, lower energy levels, health issues or sudden hospital stays. According to a project coordinator who filled out the Involvement Matrix, it is important that 'young people can shape and carry out the project process in their own way and within the restrictions of their time and energy'. When young people drop out, additional time has to be invested in finding other young people who are willing to be involved. Attention should be paid to the fact that young people with a chronic condition have to perform PPI activities within the restrictions of their (limited) energy.

The vulnerability of young people with a chronic condition highlights the importance of providing sufficient support. One project coordinator who filled out the Involvement Matrix reported that 'it is necessary that the right professionals support and coach young people from the start'. Project leaders state that training and coaching can make PPI less strenuous, as it improves the match between PPI activities and the knowledge and skills of young people. Project teams can also benefit from training and coaching. The project coordinators did not specify what topics should be addressed in training and coaching for young people with a chronic condition and project teams.

\section{Practical Tips}

\section{For young people}

- Be open about your knowledge and skills and your physical and mental capacities. The project team will keep this in mind.

Determine for yourself what you need to perform your tasks. Ask for help if you need it and be clear about what working conditions suit your needs.

\section{For project teams}

- Be sensitive to the capacities and possibilities of all members of the project team and take this into account. If necessary, organise training and coaching.

Discuss with the young people how they would like to meet. Be aware that travelling may be an obstacle to some. Also consider conducting meetings online or by phone.

\section{Flexibility and an open mind}

Experiences reported in the case study and Involvement Matrices taught us that flexibility and an open mind are essential for meaningful PPI. In all project phases, young people need to be provided with 'space' to make a difference. That is to say, project teams have to make time to listen attentively to the ideas of young people, and take them seriously. 
Furthermore, a willingness to change initial project plans is fundamental for the input of young people to lead to real and meaningful changes in the project. A project coordinator who filled out the Involvement Matrix: '[For meaningful PPI] you need the ability to process feedback and to do some things completely different than you planned'.

The importance of flexibility and an open mind was especially noted in one of the cases in the case study about an innovation project aimed at improving information provision for future students with disabilities. The project team experienced that participatory processes never develop as expected, and found it difficult - if not impossible - to determine in advance how project goals would be achieved. In the project, students were invited to make vlogs about their student life, and, initially, they were enthusiastic and eager to participate. However, during the project, it became clear that some young people found it too confronting to film themselves, causing them to dropout. To prevent the project from failing, the project team decided to make several adaptations to the initial project plans. For example, instead of filming themselves, they invited young people to an interview on camera or to write their experiences down on paper. Also, when young people did not want to share their experiences, they were asked to be involved in technical activities, such as filming or editing.

The revisions of the initial project plans facilitated the PPI of young people. According to the project team, it contributed to the involvement of more young people in making the videos than would have been the case if the initial plans were followed. Consequently, they concluded that only project results should be determined in advance; the processes leading to these results should be flexible. During the project, the project team should 'be bold and move along' with the young people, and jointly discover the best way to achieve project results.

\section{Practical Tips}

\section{For young people}

Every member of the project team is important. Be open to input of other's.

\section{For project teams}

- Take time to listen attentively to the ideas of young people and take them seriously.

- Be flexible and willing to change initial project plans. You don't know in advance what the input of members of the project team, and especially the young people, will be. 


\section{Evaluation of process and outcomes}

During and after a participatory project, it is important to critically evaluate processes and outcomes. This can provide valuable feedback to both young people with a chronic condition and the other members of the project team. It also contributes to the motivation of the people involved. In the open-ended questions of the Involvement Matrix, one of the project teams reported that young people find it valuable to know how their advices are used in practice. In addition, in another project where parents were involved on behalf of their children, the project coordinator noticed: 'it is more meaningful for parents to participate, when the project has a tangible, positive impact on their child'.

In our evaluation, we also looked at the impact of young people's PPI. We learned that both young people with a chronic condition and other members of project teams experience a positive impact of the PPI of young people with a chronic condition on the projects. In the questionnaire, more than two out of five young people experienced they were '(really) important' to the project (Table 6). They valued their own contributions, since they shared their experiential knowledge, participated in meetings that helped others, and helped to set up projects and disseminate project results. Project coordinators rated the extent to which the PPI of young people with a chronic condition yielded the desired results in the project reports on average an 8 on a scale from 0 to 10. They described young people's contribution as 'unique' and 'irreplaceable'. According to the project teams, young people improved the relevance and quality of their projects.

Table 6. Extent to which young people with a chronic condition were important to projects, based on the perceptions of young people involved in nineteen projects $(\mathrm{N}=$ 226)

\begin{tabular}{lr} 
Extent to which they considered themselves important to \\
the project & $\%$ \\
\hline Really important & 9 \\
Important & 34 \\
A little important & 23 \\
Not important at all & 3 \\
Doesn't know & 31 \\
\hline
\end{tabular}

Despite the enthusiasm about the value of young people's PPI, it seemed to be difficult to describe the specific impact of their input in the project reports, case study and Involvement Matrices. Project coordinators mostly provided general descriptions of impact, such as 'without their [young people's] input, the project would not have been of the same quality'. Concrete contributions mentioned by project coordinators include that young people can facilitate the recruitment of other young people, that they can assess the relevance of projects, and that they can help disseminate project findings. However, we have gained 
little insight in the extent to which young people's PPI contributed to the actual outcomes of a project; project teams were unable to specify this.

\section{Practical Tips}

\section{For young people}

Try to learn from feedback. Ask for feedback yourself.

Your experiences are important for the project, so don't be afraid to say what you want to say! The project team can learn from your feedback.

\section{For project teams}

- Provide young people with feedback on what they do and how they do it, so they can learn from it.

- Critically and systematically evaluate the involvement process and its outcomes. Come up with an evaluation plan in advance, and evaluate both the process and outcomes of PPI.

\section{Discussion}

In the current study, we aimed to discuss the lessons we learned about PPI of young people with a chronic condition, drawn from a case study of a program that hosted numerous participatory projects over a period of 4 years. These lessons contribute to the existing evidence base of young people's PPI by providing practical examples and tips on how young people with a chronic condition and adult members of project teams can work together, what difficulties they can encounter, and what is needed for meaningful PPI.

In part, our findings echo the results of previous studies. It is, for example, well-known that projects in which young people with a chronic condition are involved take more time than non-participatory projects ${ }^{4-6,15}$ and previous studies have also emphasised the importance of involving them in the early phases of a project. ${ }^{5,29,30}$ The importance of reimbursements ${ }^{4,29,30}$ and support ${ }^{15,17,31,32}$ has been reported in previous studies as well. Our study adds to this knowledge by providing practical examples of these challenges and - more importantly - of how these challenges can be addressed. Moreover, we have taken it one step further by formulating practical tips that are helpful in organising a participatory project.

The lessons we have presented concern both the process and outcomes or impact of involving young people with a chronic condition in projects. The lessons learned about the process have shown that meaningful PPI starts with - or even before - the writing of the project proposal and continues all the way through the dissemination of the results. During the entire project, time and resources need to be invested in the collaboration. This involved 
continuous discussions on the roles of young people with a chronic condition and other members of project teams and the development of the project, and whether these are (still) aligned with everyone's needs and preferences.

Regarding the outcomes or impact of PPI of young people with a chronic condition, we have noted a general enthusiasm about the value of working together. From the literature, we know that young people's PPI can have positive impacts on, for example, the design of projects, ${ }^{4,19}$ the people involved, ${ }^{4,15,19,32}$ and the dissemination of project results. ${ }^{4-7,19}$ However, the evidence of this impact is of relatively low quality. ${ }^{2}$ In the current article, we also found that project teams had a hard time specifying the impact of PPI, as became clear from the relatively few and vague examples they provided. Approximately a third of the young people were unable to specify how important they were to a project. PPI is a complex process and therefore it is difficult to exactly determine its impact. ${ }^{2,33,34}$ This highlights the need for research on how to evaluate the impact of PPI with young people with a chronic condition. As has become clear from our results, knowing that working together has a (positive) impact can motivate young people with a chronic condition and other members of the project team and teach them about how they should work together.

\section{PPI in the current study}

In conducting this study and writing the manuscript, researchers have worked together with experience experts. In general, this enabled us to match data collection methods to the young people who had to fill them out and to reflect on our findings and place them in the right context. For example, the pilot tests of the questionnaire helped us to simplify questions and answering possibilities. The analysis of the Involvement Matrices with young people taught us that analysing open-ended questions is difficult for young people who are not researchers and who have no experience with studying other people's opinion and experiences. They emphasised their own experiences over the data. Some chose to not include some statements of project coordinators, because they did not agree with him or her. Although we were not able to use the analyses made by those young people, they did provide insight in differences in perspectives between project coordinators and young people.

Co-producing this manuscript with experience experts has been a valuable experience. Reflecting on their PPI, the experience experts explained that they considered this to be a valuable experience as they were involved from the start of the writing process. This allowed them to not only reflect and agree on what the researchers wrote, but they were also able to co-write from the start. As a result, they felt their contribution to be valuable and appreciated. They stated: 'In our opinion, it is very important to involve young people as much as possible in research and policy that concerns them. However, as the time and energy of researchers is precious, so is ours. We would like to contribute, but only if and 
when we can be of value.' The researchers and experience experts who wrote this manuscript agree that their collaboration enabled them to describe lessons learned and practical tips that are understandable and relevant to both young people with a chronic condition and project teams.

\section{Strengths and limitations}

The current study had some limitations. First, the majority of the data sources we used were based on the experiences of project teams. Solely the questionnaire focused on perspectives of young people and not all projects participated in the questionnaire. Consequently, most results are based on project teams' perspectives. We recommend that future research includes young people's perspectives to a greater extent. Second, we invited all young people who were involved in projects in any way to fill out the questionnaire; also those who played a passive roles, e.g. receivers of an intervention or users of a tool created in the project. This explains the relatively large part of young people reporting they were (passive) participants in their project. Ideally, we would only have reported findings for the young people who (should have) played a PPI role, but we were unable to make this distinction. Finally, there is a risk of response bias in the data sources. The project reports of the project coordinators, for example, were not solely used for our research, but also for reporting progress to the funder (FNO). Furthermore, in the case of the Involvement Matrix, not all project coordinators were obliged to fill out the Involvement Matrix. This may have resulted in selection effects; project coordinators who wanted to fill out the Involvement Matrix may have been more positive towards young people's involvement compared to project coordinators who did not. The young people with a chronic condition who returned the questionnaire may also have been more positive attitude towards their PPI in a project than the non-responders, as they are likely to be more eager to share their contributions to the project. However, in the project reports, the Involvement Matrix and the questionnaires, project coordinators and young people were critical of the PPI in their project. Project coordinators provided critical descriptions of involvement in their project, suggesting they were eager to learn from both the facilitators and barriers they experienced. Also, a considerable part of the young people who participated in the questionnaires consider themselves only a little or not important to a project, suggesting they were critical as well.

An important strength of this study is its size. The lessons learned are drawn from a large participatory program that has funded 33 different participatory projects. Also, data were derived using multiple research methods, both qualitative and quantitative.

\section{Conclusion}

In the literature, calls have been made to share experiences and lessons learned on PPI and how to deal with its challenges. The lessons learned in the current study have led us to draw 
two conclusions. First, meaningful PPI requires effort, time and resources from both young people with a chronic condition and project teams, from the beginning to the end. It is important to continuously discuss roles and responsibilities. Second, we found that the young people and project teams were enthusiastic about their collaboration, but found it difficult to specify its impact. This highlights the need for more research on evaluating the impact of PPI.

The translation of the lessons learned into practical tips is a valuable contribution of this study to the PPI field. The lessons learned provide examples on how others have dealt with challenges in PPI; translating them into practical tips shows young people and project teams what concrete actions they can undertake to achieve successful PPI. As a guide for future PPI projects, a document in which all practical tips are combined has been added to the supplementary materials.

\section{Funding}

The research was funded by FNO, Amsterdam.

\section{Ethics approval and consent to participate}

The study was conducted in accordance with the General Data Protection Regulation.

Further ethical approval of this study was not required under the applicable Dutch legislation.

\section{Competing interests}

The authors declare that they have no competing interests. 


\section{References}

1. INVOLVE. Approaches to public involvement in research. Accessed April, 2019. http://www.invo.org.uk/posttyperesource/approaches-to-public-involvement

2. Schelven F van, Boeije $H$, Mariën V, Rademakers J. Patient and public involvement of young people with a chronic condition in projects in health and social care: A scoping review. Health Expect. 2020;23(4):789-801. doi:10.1111/hex.13069

3. Bailey S, Boddy K, Briscoe S, Morris C. Involving disabled children and young people as partners in research: A systematic review. Child Care Health Dev. 2015;41(4):505-514. doi:10.1111/cch.12197

4. Flicker $\mathrm{S}$. Who benefits from community-based participatory research? A case study of the positive youth project. Health Educ Behav. 2006;35(1):70-86. doi:10.1177/1090198105285927

5. Marshall Z, Nixon S, Nepveux D, et al. Navigating risks and professional roles: Research with lesbian, gay, bisexual, trans, and queer young people with intellectual disabilities. J Empir Res Hum Res Ethics. 2012;7(4):20-33. doi:10.1525/jer.2012.7.4.20

6. Van Staa A, Jedeloo S, Latour JM, Trappenburg MJ. Exciting but exhausting: Experiences with participatory research with chronically ill adolescents. Health Expect. 2010;13(1):95-107. doi:10.1111/j.1369-7625.2009.00574.x

7. Sloper P, Lightfoot J. Involving disabled and chronically ill children and young people in health service development. Child Care Health Dev. 2003;29(1):15-20. doi:10.1046/j.13652214.2003.00315.x

8. United Nations General Assembly. Convention on the Rights of Child, 1989.

9. Hart R. Children's participation: From tokenism to citizenship. Florence: UNICEF; 1992.

10. Arnstein S. A ladder of citizen participation. J Am I Planners. 1969;35(4):216-224. doi:10.1080/01944366908977225

11. Dedding C. Delen in macht en onmacht: Kindparticipatie in de (alledaagse) diabeteszorg. [PhD thesis]. Amsterdam: University of Amsterdam; 2009.

12. Hart R. Stepping back from "the ladder": Reflections on a model of participatory work with children. In: Reid A, Bruun B, Nikel J, Simovska V, eds. Participation and Learning: Perspectives on Education and the Environment, Health and Sustainability. Springer; 2008:19-31.

13. Tritter JQ, McCallum A. The snakes and ladders of user involvement: Moving beyond Arnstein. Health Policy. 2006;76(2):156-168. doi:10.1016/j.healthpol.2005.05.008

14. Shier H. Pathways to participation: Openings, opportunities and obligations. Child Soc. 2001;15(2):107-117. doi:10.1002/chi.617

15. Franklin A, Sloper P. Supporting the participation of disabled children and young people in decision-making. Child Soc. 2009;23:3-15. doi:10.1111/j.1099-0860.2007.00131.x

16. Graham N, Mandy A, Clarke C, Morriss-Roberts C. Using children and young people as advocates to inform research design. Brit J Occup Ther. 2017;80(11):684-688. doi:10.1177/0308022617725491

17. Murray R. Sixth Sense: The disabled children and young people's participation project. Child Soc. 2012;26(3):262-267. doi:10.1111/j.1099-0860.2012.00439.x

18. Coad JE, Shaw KL. Is children 's choice in health care rhetoric or reality? A scoping review. $J \mathrm{AdV}$ Nurs. 2008;64:318 -27. doi:10.1111/j.1365-2648.2008.04801.x 
19. Rosen-Reynoso M, Kusminsky M, Gragoudas S, et al. Youth-based participatory research: Lessons learned from a transition research study. Pediatrics. 2010;126(S3):S177-S182. doi:10.1542/peds.2010-1466N

20. Kramer J, Barth $Y$, Curtis $K$, et al. Involving youth with disabilities in the development and evaluation of a new advocacy training: Project TEAM. Disabil Rehabil. 2013;35(7):614-622. doi:10.3109/09638288.2012.705218

21. Lundy L. In defence of tokenism? Implementing children's right to participate in collective decision-making. Childhood. 2018;25(3):340-354. doi:10.1177/0907568218777292

22. Ferguson D, Monfaredi $Z$, Pussegoda $K$, et al. The prevalence of patient engagement in published trials: A systematic review. Res Involv Engagem. 2018;4(1):1-9. doi:10.1186/s40900-018-0099-x

23. Ketelaar M, Smits DW, van Meeteren $K$, Klem M, Alsem M. Involvement of young people and families in all stages of research: what, why and how? In: Imms C, Green D, editors. Participation: optimising outcomes in childhoodonset neurodisability. London: Mac Keith Press; 2020:105-17.

24 Hwang W, Weller W, Ireys $\mathrm{H}$, Anderson G. Out-of-pocket medical spending for care of chronic conditions. Health Aff. 2001;20(6): 267-278. doi:10.1377/hlthaff.20.6.267

25. Schelven F van, Boeije $H$, Inhulsen MB, Sattoe JNT, Rademakers J. "We know what we are talking about ": Experiences of young people with a chronic condition involved in a participatory youth panel and their perceived impact. Child Care Pract. 2019;27(2):191-207. doi:10.1080/13575279.2019.1680529

26. Smits DW, van Meeteren $K$, Klem M, Alsem M, Ketelaar M. Designing a tool to support patient and public involvement in research projects: The Involvement Matrix. Res Involv Engagem. 2020;6(1):1-7. doi:10.1186/ s40900-020-00188-4

27. Smits DW, Klem M, Ketelaar M. The involvement matrix: Involvement of patients in projects and research. Utrecht: Centre of Excellence for Rehabilitation Medicine Utrecht; 2019.

28. Staniszewska S, Brett J, Mockford C, Barber R. The GRIPP-checklist: Strengthening the quality of patient and public involvement reporting in research. Int I Technol Assess Health Care. 2011;27(4):391-399. doi:10.1017/S0266462311000481

29. Lightfoot J, Sloper P. Having a say in health: Involving young people with a chronic illness or physical disability in local health services development. Child Soc. 2003;17(4):277-290. doi:10.1002/CHI.748

30. Castensoe-Seidenfaden P, Reventlov Husted G, Teilmann G, Hommel E, Olsen BS, Kensing F. Designing a self-management app for young people with type 1 diabetes: Methodological challenges, experiences, and recommendations. JMIR Mhealth Uhealth. 2017;5(10):e124. doi:10.2196/mhealth. 8137

31. Moreau KA, Eady K. The involvement of adolescents with chronic health conditions in medical education: An exploratory qualitative study. Hosp Pediatr.2017;7(11):668-674. doi:10.1542/hpeds.2017-0010

32. Stevenson M. Participatory data analysis alongside co-researchers who have Down syndrome. $J$ Appl Res Intellect Disabil. 2014;27(1):23-33. doi:10.1111/jar.12080

33. Greenhalgh $T$, Hinton $L$, Finlay $T$ et al. Frameworks for supporting patient and public involvement in research: Systematic review and co-design pilot. Health Expect. 2019;22(4):785-801. doi:10.1111/hex.12888

34. Collins M, Long R, Page A, Popay J, Lobban F. Using the Public Involvement Impact Assessment Framework to assess the impact of public involvement in a mental health research context: $A$ reflective case study. Health Expect. 2018;21(6):950-963. doi:10.1111/hex.12688 


\section{Appendix A}

\section{Background}

1. How old are you?

years old

2. Are you a boy or a girl?

$\square$ Boy

$\square$ Girl

3. What situation is most applicable to you?

$\square$ I am in elementary school

$\square$ I am in secondary education

$\square$ I am in post-secondary education

$\square$ I am unemployed / looking for a job

$\square$ I have a paid job

$\square$ I volunteer

$\square$ Other

3. How do you live?

$\square$ I live at my parents' house

$\square$ I live by myself, without other people

$\square$ I live by myself, with other people in one house

$\square$ I live with a friend

$\square$ I live in a care facility

$\square$ I volunteer

$\square$ Other

\section{Questions about the project}

4. What did you do in the project?

$\square$ I received information about the project

$\square$ I gave my opinion about the project

$\square$ I was ambassador

$\square$ I was involved in the design of the project

$\square$ I was involved in the execution of the project

$\square$ I helped finding participants for the project

$\square$ I was one of the participants myself

$\square$ I was involved in thinking about how the project can be improved 
$\square$ I was involved in making sure that others know and use the project

$\square$ Other

5. How much did you do in the project?

$\square$ Nothing at all

$\square$ A little

$\square$ Pretty much

$\square$ A lot

$\square$ Really a lot

6. How important were you to the project?

$\square$ Not important at all

$\square$ A little important

口 I don't know

$\square$ Important

$\square$ Very important

7. If you want to, you can explain your answer here: 


\section{Appendix B}

\section{Project report format for project coordinators}

1. To what extent did you involve young people with a chronic condition in the project?

Not at all

$\begin{array}{ccccccc}4 & 5 & 6 & 7 & 8 & 9 & 10 \\ \square & \square & \square & \square & \square & \square & \square \\ & & & & & & \text { In full }\end{array}$

2. How where young people with a chronic condition involved in your project?

Multiple answers possible

$\square$ We informed them

$\square$ We consulted them

$\square$ They advised us

$\square$ They designed and executed the projects together with us

$\square$ They co-decided during the project

$\square$ Other

$\square$ Not applicable, young people were not involved in our project

3. During what phase of the project did you involve young people with a chronic condition?

$\square$ During the development of first ideas for the project

$\square$ During writing and submitting the project proposal

$\square$ During the design of the project

$\square$ During the execution of the project

$\square$ During the dissemination and implementation of project results

$\square$ During the evaluation of the project

$\square$ Other

$\square$ Not applicable, young people were not involved in our project

4. To what extent did the involvement of young people with a chronic condition yield the desired results?

$\begin{array}{ccccccccccc}0 & 1 & 2 & 3 & 4 & 5 & 6 & 7 & 8 & 9 & 10 \\ \square & \square & \square & \square & \square & \square & \square & \square & \square & \square & \square \\ \text { Not at all } & & & & & & & & & \text { In full }\end{array}$

Can you explain your answer? 


\section{Appendix C Practical tips on Patient and Public Involvement with young people with a chronic condition}

Young people with a chronic condition are increasingly involved in doing research and developing tools and interventions that concern them. Working together with patients is called Patient and Public Involvement (PPI). We know from the literature that PPI with young people with a chronic condition can be challenging. In the article 'Patient and Public Involvement of young people with a chronic condition: Lessons learned and practical tips from a large participatory program', we have formulated tips that can help in achieving successful PPI. In this document, we provide an oversight of all practical tips for young people and for project teams.

\section{Practicalities to take into account at the start}

\section{For young people}

If you wish to be involved in a project, make yourself known. A patient or youth organisation may be able to help you.

If possible, consult with other young people who are involved in the project about how they handle their involvement

Agree on how you will be rewarded for your involvement and how you deal with expenses you have to make, such as travelling costs.

Make sure you have sufficient time to play a meaningful role in the project.

\section{For project teams}

PPI takes time. Take this into account and set up a flexible planning.

Reward young people for their involvement. Think about how you wish to reimburse them and how you deal with expenses they have to make, such as travelling costs. Discuss the possibilities with them and make the necessary arrangements.

Rewards for PPI may interfere with disability benefits young people receive. Take this into account, when discussing the possibilities.

Make sure you timely start recruiting young people. Collaborating with a patient or youth organisation may be helpful. 


\section{Involvement from the start}

\section{For young people}

If possible, co-write the project proposal. Introduce your experiences and ideas.

\section{For project teams}

Invite young people to contribute to or co-write the project proposal.

- Think about how you will obtain the resources you need to involve young people in writing a project proposal, such as time and reimbursements, as funding may not yet be available during this phase.

\section{Roles and responsibilities}

\section{For young people}

Discuss with the project team what you can and want to do and what you need for this. Ask, for example: 'Where and when do we meet and what do I have to do, exactly?'.

Regularly discuss whether your input and role are still clear to you and the other members of the project team.

If - for whatever reason - you cannot complete the tasks you agreed to do, be honest about it. Together with the project team you can find a solution for this.

You can use the Involvement Matrix as a tool in discussing your roles and responsibilities before and during the project.

\section{For project teams}

Listen to what young people have to say. Only ask for their involvement, when you can follow-up on their opinions and feedback.

Involve young people in determining their roles and responsibilities.

Keep tasks of young people clear. Discuss tasks and responsibilities of other members of the project team with them as well.

Regularly discuss with young people how they are doing. If necessary, adapt their roles and responsibilities.

You can use the Involvement Matrix as a tool in discussing young people's roles and responsibilities before and during the project. 


\section{Support}

\section{For young people}

- Be open about your knowledge and skills and your physical and mental capacities. The project team will keep this in mind.

Determine for yourself what you need to perform your tasks. Ask for help if you need it and be clear about what working conditions suit your needs.

\section{For project teams}

Be sensitive to the capacities and possibilities of all members of the project team and take this into account. If necessary, organise training and coaching.

Discuss with the young people how they would like to meet. Be aware that travelling may be an obstacle to some. Also consider conducting meetings online or by phone.

\section{Flexibility and an open mind}

\section{For young people}

- Every member of the project team is important. Be open to input of other's.

\section{For project teams}

Take time to listen attentively to the ideas of young people and take them seriously.

Be flexible and willing to change initial project plans. You don't know in advance what the input of members of the project team, and especially the young people, will be.

\section{Evaluation of process and outcomes}

\section{For young people}

Try to learn from feedback. Ask for feedback yourself.

- Your experiences are important for the project, so don't be afraid to say what you want to say! The project team can learn from your feedback.

\section{For project teams}

Provide young people with feedback on what they do and how they do it, so they can learn from it.

Critically and systematically evaluate the involvement process and its outcomes. Come up with an evaluation plan in advance, and evaluate both the process and outcomes of PPI. 



\section{Chapter 5}

An exploration of the relation between the way PPI with young people with a chronic condition is organized and its impact: a multilevel study

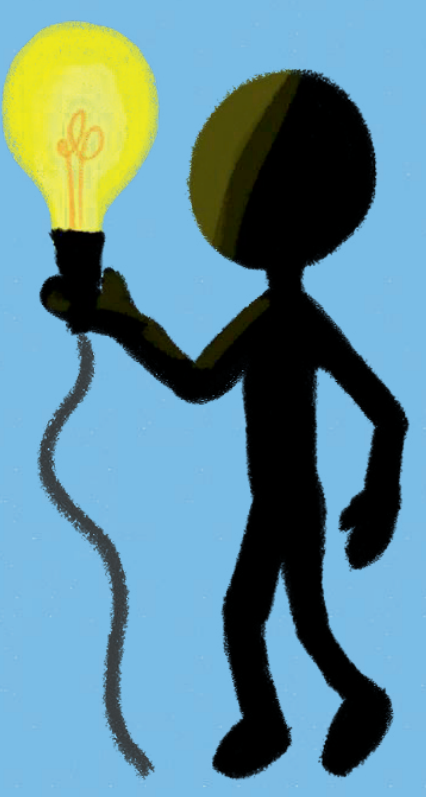

Published as: Schelven F van, Groenewegen P, Spreeuwenberg P, Rademakers J, Boeije H. Exploring the impact of patient and public involvement of young people with a chronic condition: A multilevel analysis. Child: Care, Health and Development. 2021:47(3): 349356. doi:10.1111/cch.12847 


\begin{abstract}
Background. Patient and Public Involvement (PPI) of young people with a chronic condition (YPCC) receives increasing attention. However, evidence of its impact is lacking. This study explores the impact of PPI on outcomes of projects in health and social care, using quantitative measures.
\end{abstract}

Methods. Data were collected from projects funded by a 4-year participatory program addressing the social position of YPCC. These projects addressed challenges associated with, for example, going to college with a physical disability, transitions in care and finding a job. Project coordinators filled out project reports with questions about PPI, that is, to what extent were YPCC involved, were they involved as co-deciders and were they involved in developing the project idea. YPCC filled out questionnaires with questions about PPI, that is, the number of PPI activities and self-perceived importance for the project. They also answered questions about the influence of the project on their social position. Based on these questions, a project outcome scale was developed.

Results. The data concerned 17 projects and 146 YPCC. Variation existed in project outcomes, of which $27 \%$ was associated with differences between projects. Using multilevel analyses, a significant relation was found between the self-perceived importance of YPCC for the project and the project outcomes they experience $(0.232, p<0.01)$. There was no significant association with the other PPI variables.

Conclusions. This study provided some first quantitative evidence that PPI has a positive impact on the YPCC involved. It is suggested that the meaningfulness of PPI matters more to them than the number of activities and amount of influence provided to YPCC. We strongly recommend conducting more research that critically examines impact of PPI. 


\section{Background}

The challenges associated with having a chronic condition can adversely affect the lives of young people with a chronic condition (YPCC). Several studies have shown that YPCC experience social disadvantages compared to their peers in the areas of, for example, school ${ }^{1}$ and social participation. ${ }^{2}$ To address these social disadvantages, scientific research projects have been developed to increase our knowledge about the barriers YPCC face ${ }^{3,4}$ and practice-oriented implementation projects to create tools and interventions to resolve these barriers. ${ }^{5-7}$

In the past, YPCC have had a passive role in projects in health and social care (for brevity, the term 'projects' will be used to cover both research and implementation projects). They were research subjects, receivers of an intervention and users of a tool. Nowadays, there is a growing consensus that YPCC should be actively involved in matters that concern them. This has been termed 'Patient and Public Involvement' (PPI). In 1992, Hart defined PPI with young people in general as 'the process of sharing decisions which affect one's life and the life of the community in which one lives. ${ }^{8}$ More recently, INVOLVE (2013) has formulated a more practical definition, emphasizing that PPI is about projects being carried out 'with' or 'by' members of the public instead of 'to,' 'about' or 'for' them. ${ }^{9}$ This definition may apply to YPCC and other (potential) patients, carers, people who use health and social care services and people from organizations that represent people who use services.

An important rationale for involving YPCC is its expected impact. First, it is believed that PPI contributes to the personal development of the YPCC involved. ${ }^{10-12}$ Second, it is expected to indirectly contribute to the social position of other YPCC by improving the quality and relevance of projects. ${ }^{10,11,13-15}$ YPCC are able to provide new insights from their lived experience, which can improve, for example, data collection and analysis in research ${ }^{10,11}$ and dissemination of results. ${ }^{11,15}$

Despite the widespread assumption that PPI improves project outcomes, robust evidence for its impact is lacking. ${ }^{16,17}$ Most studies describe PPI processes rather than impact and reporting often includes the informal sharing of knowledge and experiences rather than a consistent collection of comparable data. Furthermore, virtually all research on PPI with YPCC is qualitative. ${ }^{17}$ Although qualitative studies have provided rich insights into experiences, lessons learned and meaningfulness of impact, quantitative evaluations would be a valuable addition to this area of research. Looking at PPI and its impact from this different, quantitative perspective can improve our understanding of the relations between different PPI variables.

Young people can be involved in different phases of a project. They can contribute to the preparation of a project, for example, during a grant application, ${ }^{18}$ in the execution, for 
example, by codesigning a questionnaire ${ }^{13}$ or training ${ }^{18}$, and in the implementation of project results, for example, by co-creating a youth-friendly report. ${ }^{11}$ Within these project phases, they can play different roles with different degrees of agency, as depicted by Hart's ladder of young people's involvement. ${ }^{8}$ Hart distinguishes between non-participation roles, for example, tokenism, roles in which young people are informed and consulted, and roles in which they are provided with decision-making power. Over the years, Hart's ladder has been criticized. Especially the hierarchy implied by the ladder has received criticism. However, the notion that young people can play different roles in a project remains highly relevant and a lot of thinking about PPI roles of young people is still based on the principles of Hart's work.

How and when YPCC are involved in a project may affect their impact. Several assumptions can be made about how PPI should be organized. One assumption may be that YPCC should be provided with the opportunity (when feeling comfortable and confident) to have the highest degree of agency, that is, as co-deciders. In PPI with young people and with users of health services in general, researchers have argued that we should avoid hierarchal thinking about involvement roles; higher degrees of agency are not necessarily superior to lower degrees of agency. ${ }^{19,20}$ However, it is likely that co-deciding allows YPCC to have a more direct impact on project decisions than, for example, providing feedback. A second assumption is that their impact increases when YPCC are involved in as many activities as possible within projects. ${ }^{5,13} \mathrm{~A}$ third widespread assumption is that involvement from the beginning of a project facilitates their impact, as it allows them to be involved before project proposals are set in stone. 5,12,21 Although these assumptions are fundamental to the design of many participatory trajectories, they are predominantly based on personal experiences and observations of YPCC and researchers.

Between 2015 and 2019, a large participatory program, called Care and Future Prospects, ran in the Netherlands. The aim of this program was to resolve the social disadvantages experienced by YPCC, and several projects were funded that contributed to this aim (Box 1). Central to both the program and the projects it funded was the involvement of YPCC in decision-making. A participatory youth panel was set up by the program organization to advise the program and projects that received funding. ${ }^{22}$ All projects were assigned one panel member, who informed and advised the project team and co-monitored the project's progress. The program also encouraged project teams to involve YPCC who were not part of the youth panel in their decision making; this was a condition for receiving funding.

In the period from 2016 to 2019, we conducted an evaluation study of Care and Future Prospects. The data we collected included information about how and when individual YPCC (not part of the panel) were involved in the projects and project outcomes. This provided us with the unique opportunity to quantitatively study the relation between PPI 
and project outcomes, that is, the impact. It should be noted that the available sample of projects and YPCC was limited. The aim of the current study was, therefore, to do a first quantitative exploration. Such an exploration is a valuable addition to this area of research, in which virtually all findings are derived from qualitative methods. We have studied the following research question: how is PPI of YPCC and how PPI of YPCC is organized related to outcomes of research and implementation projects in health and social care?

It should be noted that this is an exploratory study because the available data concerned only a small sample of YPCC and projects. However, we expected a quantitative exploration to be a valuable addition to this area of research, in which virtually all findings are derived from qualitative methods.

Box 1. The Care and Future Prospects Program

The Dutch organization FNO- $\mathrm{a}$ fund that stimulates and supports initiatives that improve the opportunities of vulnerable people-developed the program Care and Future Prospects. Within this program, FNO hosted and funded numerous research and implementation projects to improve the social position of young people with chronic conditions in five areas: care, school, work, sport and personal strength.

A wide variety of projects were funded. In research projects several topics were studied, for example, the unpredictability of chronic conditions and its consequences for participating in daily life, the effectiveness of an intervention aimed at improving functioning at school and challenges in primary care. Implementation projects addressed, for example, the development of an intervention to help young people to find a job and the creation and dissemination of vlogs about going to college with physical disabilities. Projects targeted young people with diverse chronic conditions, both physical (e.g., rheumatism, diabetes and acquired brain injury) and mental (e.g., depression and learning disabilities). All projects were carried out by a project team and were led by a project coordinator who maintained contact with FNO and was responsible for the progress of the project.

\section{Methods}

\section{Participants and procedure}

Data were collected from project reports filled out by coordinators of CFP projects and from questionnaires among YPCC involved in these projects. 
We started with 32 project reports hand in by project coordinators. The reports were based on a fixed format and contained open-and closed-ended questions about PPI projects. A questionnaire was developed to evaluate project processes and outcomes from the perspective of YPCC. Several YPCC have tested a pilot version of a questionnaire to make sure the questions were relevant and comprehensible. At the end of a project, coordinators were asked to invite YPCC who were in any way involved in their project to fill out an online or written questionnaire. In total, 226 YPCC participating in 19 projects were surveyed. The number of YPCC that filled out the questionnaire varied from 1 to 46 per project.

Only projects for which data from both questionnaires and project reports were available were included in the current study. We excluded data from participants who were older than 30 years $(n=15)$. In total, data from 17 projects and 146 YPCC were included in the analyses. The included projects were a good representation of the projects funded within CFP in terms of focus (i.e., care, school, work, sport and personal strength) and YPCC and the number of YPCC involved.

\section{Measures}

\section{Outcome variable}

A project outcome scale was developed to assess the self-perceived contribution of projects to the social position of YPCC. The scale was based on all nine items in the questionnaire that addressed project outcomes, including 'Because I participated in the project ... (1) " ... I am more self-confident," (2) "... I am more independent," (3) " ... I am able to do the things I want to do," (4) "... I am more positive about life with my condition or disability," (5) " ... I have the same opportunities in life as young people without a condition or disability," (6) " ... I see more opportunities to be physically active," (7) "... I see more opportunities to find a job (in the future)," (8) "... I see more opportunities to finish the education I prefer" and (9) "... I have more faith in the care I receive for my condition or disability".' Items are followed by a 5 -point scale ( 1 = 'Strongly disagree,' 2 = 'Disagree,' $3=$ 'No opinion,' $4=$ 'Agree,' and 5 = 'Strongly agree'). Reliability of the scale in the present sample was 0.87 on the individual level, and 0.59 on the project level, based on the total sample of YPCC.

\section{Individual characteristics}

We included three variables to control for characteristics of YPCC, that is, age, sex and chronic condition. Age was measured with the item 'How old are you?,' and sex with the item 'Are you a boy or a girl?' The burden of their chronic condition was assessed with the item 'How much does your chronic condition burden you in your daily life?,' followed by a 5-point scale ( 1 = 'Not at all,' 2 = 'A little,' 3 = 'Pretty much,' 4 = 'A lot,' and 5 = 'Really a $\left.\operatorname{lot}^{\prime}\right)$. 


\section{Predictors}

The independent variable of interest in our study was PPI. We measured this with three project-level variables and two individual-level variables.

The first item on the project level included 'To what extent did you involve young people with a chronic condition in your project?' (scale 0-10, $0=$ 'Not at all,' $10=$ 'Fully'). Another item was 'How did you involve young people with a chronic condition in your project?', followed by seven answering possibilities. We translated this item into a dummy variable of whether (1) or not (0) YPCC did co-decide. The third project-level predictor was 'In what phases of the project did you involve young people with a chronic condition?,' followed by eight answering possibilities. We translated this item into a dummy variable of whether (1) or not $(0)$ young people were involved during the development of the project ideas.

On the individual level, items included 'How much did you do in the project' ( $1=$ 'Nothing at all,' 2 = 'A little,' 3 = 'Pretty much,' 4 = 'A lot,' and $5=$ 'Really a lot'), and 'How important were you for the project?' ( 1 = 'Not important at all,' 2 = 'A little important,' 3 = 'Important,' and $4=$ 'Really important').

\section{Data analysis}

Because of the hierarchical structure of the data (with YPCC nested within projects), we conducted multilevel regression analysis with the outcome scale as a continuous variable. ${ }^{23}$ Several models were fitted to explain the variation in project outcomes. Model 1 was empty and included only the project outcome scale. In this model, we analysed variation in project outcomes, without considering involvement variables. Next, we added characteristics of the YPCC, that is, age, sex and burden of chronic condition, as control variables and the individual-level variables on involvement, for example, how much did they do in the project and what was their importance for the project (Model 2). In Model 3, we included the variables on the project level, for example, level of involvement, involvement as co-deciders and involvement in idea development. Due to the small number of projects in our sample, these variables were added one by one. Analyses were conducted using MLwiN 2.30. P values were significant if $\leq 0.05$.

\section{Ethical considerations}

The study was conducted in accordance with the General Data Protection Regulation. Further ethical approval of this study was not required under the applicable Dutch legislation. 


\section{Results}

\section{Descriptive statistics}

Table 1 shows the characteristics of YPCC $(n=146)$ and projects $(n=17)$ in the study sample. The mean age of the YPCC was 22.0 years. The sample was $55.2 \%$ female and $44.8 \%$ male. The mean score on the burden of their chronic condition was 3.0 (SD $=0.9$; range = $1-5)$. YPCC rated how much they did in the project on average a 2.7 (SD $=1.0$; range $=1$ $5)$ and their importance for the project a $2.7(S D=0.8$; range $=1-4)$.

Project coordinators rated the degree of involvement of YPCC in their project on average an 8.6 (SD $=1.6$; range $=4-10$ ). Almost half of the project coordinators involved them as co-deciders (47.1\%) and a similar part involved YPCC in the project phase of idea development (47.1\%).

Table 1. Sample characteristics

\begin{tabular}{|c|c|c|}
\hline Variables & $\mathbf{n}$ & $\begin{array}{r}\text { Mean (SD) or } \\
\text { percentage }\end{array}$ \\
\hline Overall number of YPCC & 146 & - \\
\hline \multicolumn{3}{|l|}{ Characteristics of YPCC } \\
\hline Age (years) & 143 & $22.0(5.1)$ \\
\hline \multicolumn{3}{|l|}{ Sex (\%) } \\
\hline Male & 64 & 44.8 \\
\hline Female & 79 & 55.2 \\
\hline Burden of chronic condition & 139 & $3.0(0.9)$ \\
\hline \multicolumn{3}{|l|}{ Involvement (perspective YPCC) } \\
\hline How much did YPCC do & 132 & $2.7(1.0)$ \\
\hline Importance of YPCC for project & 101 & $2.7(0.8)$ \\
\hline Overall number of projects & 17 & - \\
\hline \multicolumn{3}{|c|}{ Involvement (perspective project coordinators) } \\
\hline Degree of involvement & 17 & $8.6(1.6)$ \\
\hline \multicolumn{3}{|l|}{ Involvement as co-deciders (\%) } \\
\hline Yes & 8 & 47.1 \\
\hline No & 9 & 52.9 \\
\hline \multicolumn{3}{|c|}{ Involvement in idea development (\%) } \\
\hline Yes & 8 & 47.1 \\
\hline No & 9 & 52.9 \\
\hline
\end{tabular}




\section{Variance between projects}

Variance in the outcome scale attributable to project-level differences is estimated by the intraclass correlation coefficient (ICC). The ICC can be derived from the individual-level and project-level variance in the null model (Model 1 ; Table 2): $0.119 /(0.119+0.323$ ) $=0.27$. This means that $27 \%$ of the variation in project outcomes, as assessed by the YPCC through the outcome scale, is associated with project differences.

Table 2. Multilevel analysis on the association between involvement variables and project outcomes, estimates (SEM)

\begin{tabular}{|c|c|c|c|c|c|}
\hline Variables & Model 1 & Model 2 & Model 3a & Model 3b & Model 3c \\
\hline \multirow[t]{2}{*}{ Intercept } & 3.013 & 3.041 & 3.355 & 3.085 & 3.030 \\
\hline & $(0.110)$ & $(0.101)$ & $(0.514)$ & $(0.144)$ & $(0.133)$ \\
\hline \multicolumn{6}{|c|}{ Characteristics of YPCC } \\
\hline \multirow[t]{2}{*}{ Age } & - & 0.012 & 0.018 & 0.018 & 0.018 \\
\hline & & $(0.013)$ & $(0.013)$ & $(0.013)$ & $(0.013)$ \\
\hline \multirow[t]{2}{*}{ Sex } & - & -0.147 & -0.147 & -0.145 & -0.147 \\
\hline & & $(0.105)$ & $(0.104)$ & $(0.104)$ & $(0.105)$ \\
\hline Burden of chronic & - & 0.031 & 0.031 & 0.030 & 0.031 \\
\hline condition & & $(0.056)$ & $(0.056)$ & $(0.056)$ & $(0.056)$ \\
\hline \multicolumn{6}{|c|}{ Involvement (perspective YPCC) } \\
\hline How much did YPCC & - & 0.077 & 0.079 & 0.074 & 0.078 \\
\hline do & & $(0.056)$ & $(0.056)$ & $(0.056)$ & $(0.056)$ \\
\hline Importance of YPCC & - & 0.232 & 0.232 & 0.231 & 0.232 \\
\hline for project & & $(0.076)^{*}$ & $(0.076)^{*}$ & $(0.076)^{*}$ & $(0.076)^{*}$ \\
\hline \multicolumn{6}{|c|}{ Involvement (perspective project coordinators) } \\
\hline Degree of & - & - & -0.036 & - & - \\
\hline involvement & & & $(0.058)$ & & \\
\hline Involvement as co- & - & - & - & -0.082 & - \\
\hline deciders & & & & $(0.188)$ & \\
\hline Involvement in idea & - & - & - & - & 0.025 \\
\hline development & & & & & $(0.191)$ \\
\hline \multicolumn{6}{|l|}{ Random part } \\
\hline Individual level & 0.323 & 0.276 & 0.276 & 0.276 & 0.276 \\
\hline variance & $(0.043)$ & $(0.034)$ & $(0.037)$ & $(0.037)$ & $(0.037)$ \\
\hline \multirow[t]{2}{*}{ Higher level variance } & 0.119 & 0.076 & 0.074 & 0.076 & 0.075 \\
\hline & $(0.066)$ & $(0.046)$ & $(0.045)$ & $(0.046)$ & $(0.046)$ \\
\hline
\end{tabular}

Abbreviation: YPCC = young people with a chronic condition.

${ }^{*} \mathrm{p}<.05$. 


\section{Multilevel models}

Table 2 presents the results of the multilevel regression analyses. Model 1 is the null model. In Model 2, we added the individual-level variables. We found a significant correlation between the importance of YPCC for the project (from the perspectives of the YPCC themselves) and the outcome scale, controlling for age, sex and burden of their chronic conditions. YPCC who found themselves more important for the project scored higher on the outcome scale $(0.232, p<0.01)$. How much YPCC did in the project (from their perspectives) was not significantly associated with the outcome scale $(0.077, p=0.17)$. The total proportional reduction in unexplained variance in Model 2 compared to the null model (Model 1$)$ is $1-(0.276+0.076) /(0.119+0.323)$ or $20.4 \%$.

In Models 3a-3c, we added the project-level variables. The project-level variables degree of involvement $(-0.04, p=0.53)$, involvement as co-deciders $(0.08, p=0.66)$ and involvement from idea development $(0.03, p=0.89)$, as assessed by project coordinators, did not have a significant association with the outcome scale.

\section{Discussion}

The aim of the current study was to quantitatively explore how PPI of YPCC and the way it is organized is related to outcomes of research and implementation projects in health and social care. Using multilevel modelling techniques, we have studied the impact of PPI among 146 YPCC involved in seventeen different projects.

An important finding is that the self-perceived importance of YPCC for a project is positively related to the project outcomes they experience. This is in line with studies suggesting that YPCC experience personal growth and development, when they consider their role in a project meaningful and valuable.11,22,24,25 For example, Rich et al. have argued that 'empowering teens to influence change in the hospital brings the added benefit of their acquiring greater responsibility and increasing their confidence. ${ }^{25}$ Flicker has noted that 'feeling like a necessary part of "something"' can help their self-esteem. ${ }^{11}$

We did not find an association between the reports of YPCC about how much they did in a project and project outcomes they experience. This implies that the number of activities is less relevant for achieving impact than the meaningfulness of PPI. This notion is supported by the finding that the extent to which YPCC were involved, reported on the project level, is not related to project outcomes. Previous studies have also indicated that PPI activities should not necessarily be as much as possible. ${ }^{11,15}$ Of greater importance is the match between PPI activities, YPCC and projects. Lightfoot and Sloper have argued that 'different methods suit different people' and 'different methods suit different purposes.'12 Involvement activities should be negotiable rather than striving for as much involvement as possible. ${ }^{12,15}$ Helpful here is the suggestion of Franks to create 'pockets' of involvement 
by discussing with young people the parts of a project they would like to undertake and the parts they prefer researchers to undertake. ${ }^{26}$ This enables young people to take ownership of specific phases or facets of a project that are meaningful to them.

Related to this, is the finding that co-deciding, as reported by the project coordinators, is not related to the outcomes of a project. It may not be the amount of influence given to YPCC that makes a difference. In PPI with young people and with users of health services in general, researchers have argued that levels of influence are not hierarchical; more influence is not superior to less influence. ${ }^{19,20}$ In some cases, asking for advice may lead to the best results, while, in other cases, co-deciding may be preferred. The 'ideal' level of influence depends on the wishes and needs of YPCC and on the content of the project. A recent review has pointed out that real team work depends on listening, taking YPCC seriously and discussing issues that matter to them. ${ }^{17}$

Studies have stressed the importance of involving YPCC from the start of a project. ${ }^{5,12,21}$ We have examined whether involvement in idea development does improve project outcomes, but this was not the case in our sample. However, this does not necessarily mean that early involvement is not beneficial for the impact. Our sample also included projects in which YPCC were not involved in idea development but did play a role in an early phase, for example, writing a project proposal or setting up a project. A more general comparison of projects that involved them in the preparation phase to projects that involved them in later phases, for example, in the execution or dissemination phase, may provide a more complete picture.

Our study provides insight into the relation between the way PPI with YPCC is organized and its impact. An interesting next step would be to investigate more in depth the relation between different PPI approaches and impact among different groups of YPCC. Previous studies have suggested that the best way to involve young people may depend on their characteristics and social background. ${ }^{16}$ Special efforts should be made to learn more about the involvement of 'hard-to-reach' groups, such as young people with comprehension and communication limitations. ${ }^{27}$ Although examples of their involvement are available, ${ }^{\text {e.g. } 14,21,28}$ they are currently underrepresented in research on PPI. ${ }^{27}$ Increasing our understanding of how YPCC with different characteristics and backgrounds can be involved can contribute to more inclusive involvement of those who are less frequently heard next to the more usual suspects.

\section{Strengths and limitations}

To our knowledge, this study is the first to explore the impact of PPI with YPCC using quantitative multilevel modelling techniques. The findings are considered explorative, as they are based on a small sample of projects. However, they also provide unique quantitative insights in an area of research, in which virtually all findings are derived from 
qualitative methods. Moreover, even in a larger sample, it is unlikely that we would have found an association between the PPI variables on the project level and project outcomes, because coefficients were close to 0 and $p$ values were very high.

Another limitation of the study is that YPCC were only involved in pilot testing the questionnaire. Involving them in the interpretation of the findings could have provided more insights into questions posed by the data and areas for future research. This would therefore be a suggestion for future research. Furthermore, we invited all YPCC who were involved in projects in any way to fill out the questionnaire and also those who played a passive role, for example, receivers of an intervention or users of a tool created in the projects. During the study, it became clear that some YPCC were not able to define whether they played a PPI role or a passive role. Ideally, we would have made a clear distinction, as this would have allowed us to investigate whether PPI contributes to project outcomes for those passively involved, for example, receiving the intervention or using the tool. Also, there is a risk of common method bias in the data we used. ${ }^{29}$ Among YPCC, we have collected data on the predictor variables and the outcome variable simultaneously, using the same method, that is, the questionnaire, which may have inflated the estimates of the relationship between those variables. However, the correlation between both variables was relatively low $(r=0.39)$.

Finally, the findings of the current study are based on data from YPCC who were involved in projects within a Dutch participatory program, and we have compared projects that involved YPCC to at least some degree. Results may thus not apply to other settings and other countries. However, the findings are derived from diverse projects in various settings involving YPCC with various chronic conditions, which improves generalizability. Future research should compare the outcomes of participatory and non-participatory projects to learn more about impact.

\section{Conclusion}

The current study provides quantitative evidence concerning the impact of PPI in projects on the YPCC involved. A substantial part of the variation in project outcomes is due to differences between projects. Some of this variation can be explained by the positive relation between the self-perceived importance of YPCC for a project and project outcomes they experience. No relation with project outcomes was found for the other PPI variables. It is suggested that the meaningfulness of PPI is more important than the number of activities and the amount of influence given to young people. We do, however, strongly recommend conducting more research that critically examines the impact of PPI. The current study was the first quantitative exploration, but we need more critical measures to learn about effective ways of working together. These measures are also needed to convince a broad public of the validity and relevance of PPI. 


\section{Funding}

The project is funded by FondsNutsOhra, Amsterdam. 


\section{References}

1. Lum A, Wakefield CE, Donnan B, et al. Understanding the school experiences of children and adolescents with serious chronic illness: A systematic meta-review. Child Care Health Dev. 2017;43(5):645-662. doi:10.1111/cch.12475

2. Sattoe JNT, Hilberink SR, Van Staa A, Bal R. Lagging behind or not? Four distinctive social participation patterns among young adults with chronic conditions. J Adolescent Health 2014;54(4):397-403. doi:10.1016/j.jadohealth.2013.09.017

3. Chappell P. How Zulu-speaking youth with physical and visual disabilities understand love and relationships in constructing their sexual identities. Cult Health Sex.2014;16(9):1156-1168. doi:10.1080/13691058.2014.933878

4. Schalkers I, Dedding C, Bunders JF. '[I would like] a place to be alone, other than the toilet': Children's perspectives on paediatric hospital care in the Netherlands. Health Expect. 2015;18(6):2066-2078. Doi:10.1111/hex.12174

5. Castensoe-Seidenfaden P, Reventlov Husted G, Teilmann G, Hommel E, Olsen BS, Kensing F. Designing a self-management app for young people with type 1 diabetes: Methodological challenges, experiences, and recommendations. JMIR Mhealth Uhealth. 2017;5(10):e124. doi:10.2196/mhealth.8137

6. Coyne I, Prizeman G, Sheehan A, Malone H, While AE. An e-health intervention to support the transition of young people with long-term illnesses to adult healthcare services: Design and early use. Patient Educ Couns. 2016;99(9):1496-1504. doi:10.1016/j.pec.2016.06.005

7. Sattoe JNT, Jedeloo S, Van Staa, A. Effective peer-to-peer support for young people with endstage renal disease: A mixed methods evaluation of Camp Cool. BMC Nephrol. 2013;14(1):279. doi:10.1186/1471-2369-14-279.

8. Hart R. Children's participation: From tokenism to citizenship. Florence: UNICEF; 1992.

9. INVOLVE. What is public involvement in research? Accessed April, 2019. https://www.invo.org.uk/find-out-more/what-is-public-involvement-in-research-2/

10. Chappell P, Rule P, Dlamini M, Nkala N. Troubling power dynamics: Youth with disabilities as coresearchers in sexuality research in South Africa. Childhood. 2014;21(3):385-399. doi:10.1177/0907568214525427

11. Flicker $\mathrm{S}$. Who benefits from community-based participatory research? A case study of the positive youth project. Health Educ Behav. 2006;35(1):70-86. doi:10.1177/1090198105285927

12. Lightfoot J, Sloper P. Having a say in health: Involving young people with a chronic illness or physical disability in local health services development. Child Soc. 2003;17(4):277-290. doi:10.1002/CHI.748

13. Kramer J, Barth $Y$, Curtis $K$, et al. Involving youth with disabilities in the development and evaluation of a new advocacy training: Project TEAM. Disabil Rehabil. 2013;35(7):614-622. doi:10.3109/09638288.2012.705218

14. Stevenson M. Participatory data analysis alongside co-researchers who have Down syndrome. $J$ App/ Res Intellect Disabil. 2014;27(1):23-33. doi:10.1111/jar.12080

15. Van Staa A, Jedeloo S, Latour JM, Trappenburg MJ. Exciting but exhausting: Experiences with participatory research with chronically ill adolescents. Health Expect. 2010;13(1):95-107. doi:10.1111/j.1369-7625.2009.00574.x 
16. Brady LM, Preston J. How do we know what works? Evaluating data on the extent and impact of young people's involvement in English health research. Research for All. 2020;4(2):194-206. doi:10.14324/RFA.04.2.05

17. Schelven F van, Boeije $H$, Mariën $V$, Rademakers J. Patient and public involvement of young people with a chronic condition in projects in health and social care: A scoping review. Health Expect. 2020;23(4):789-801. doi:10.1111/hex.13069

18. Rosen-Reynoso M, Kusminsky M, Gragoudas $S$, et al. Youth-based participatory research: Lessons learned from a transition research study. Pediatrics. 2010;126(S3):S177-S182. doi:10.1542/peds.2010-1466N

19. Hart R. Stepping back from "the ladder": Reflections on a model of participatory work with children. In: Reid A, Bruun B, Nikel J, Simovska V, eds. Participation and Learning: Perspectives on Education and the Environment, Health and Sustainability. Springer; 2008:19-31.

20. Tritter JQ, McCallum A. The snakes and ladders of user involvement: Moving beyond Arnstein. Health Policy. 2006;76(2):156-168. doi:10.1016/j.healthpol.2005.05.008

21. Marshall Z, Nixon $S$, Nepveux D, et al. Navigating risks and professional roles: Research with lesbian, gay, bisexual, trans, and queer young people with intellectual disabilities. $J$ Empir Res Hum Res Ethics. 2012;7(4):20-33. doi:10.1525/jer.2012.7.4.20

22. Van Schelven F, Boeije H, Inhulsen MI, Sattoe JNT, Rademakers J. "We know what we are talking about ": Experiences of young people with a chronic condition involved in a participatory youth panel and their perceived impact. Child Care Pract. 2019;27(2):191-207. doi:10.1080/13575279.2019.1680529

23. Leyland AH, Groenewegen PP. Multilevel analysis for public health and health services research: Health in context. Cham: Springer; 2020.

24. Franklin A, Sloper P. Supporting the participation of disabled children and young people in decision-making. Child Soc. 2009;23:3-15. doi:10.1111/j.1099-0860.2007.00131.x

25. Rich C, Goncalves A, Guardiani M, O'Donnell E, Strzelecki J. Teen advisory committee: Lessons learned by adolescents, facilitators and hospital staff. Pediatr Nurs. 2014;40(6):289-296.

26. Franks M. Pockets of participation: Revisiting child-centred participation research. Child Soc. 2011;25(1):15-25. Doi:10.1111/j.1099-0860.2009.00258.x

27. Clavering E, McLaughlin J. Children's participation in health research: From objects to agents? Child Care Health Dev. 2010;36(5):603-611. doi:10.1111/j.1365-2214.2010.01094.x

28. Bruce SM, Parker AT. Young deafblind adults in action: Becoming self-determined change agents through advocacy. Am Ann Deaf. 2012;157(1):16-26. doi:10.1353/aad.2012.1607

29. Jordan PJ, Troth AC. Common method bias in applied settings: The dilemma of researching in organizations. Aust J Manag. 2019;45(1):3-14. doi:10.1177/0312896219871976 



\section{Chapter 6}

Perspectives of young people with a chronic condition and professionals on meaningful impact: a Q methodology study

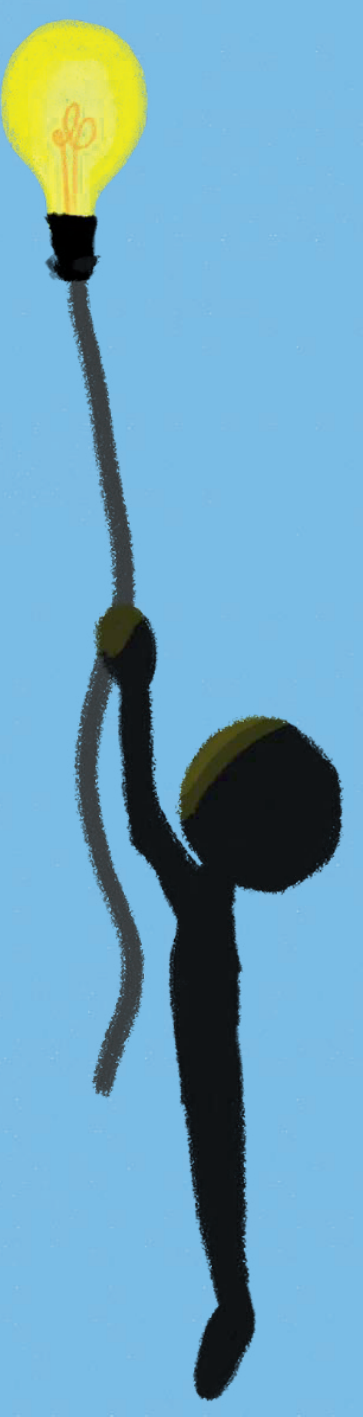

Revised version accepted for publication: Schelven F van, Boeije H, Rademakers J. Evaluating meaningful impact of Patient and Public Involvement: A Q methodology study among researchers and young people with a chronic condition. Health Expectations. 


\begin{abstract}
Introduction. Although Patient and Public Involvement (PPI) of young people with a chronic condition (YPCC) is gaining increasing attention, evidence of impact is lacking. This is partly due to a poor understanding of what meaningful impact entails. This study aims to gain an in-depth understanding of researchers' and YPCC's perspectives on meaningful impact.
\end{abstract}

Methods. A Q methodology study was conducted among 26 researchers and 20 YPCC with experience in PPI. Participants ranked statements about impact (e.g. 'YPCC obtain new knowledge and skills'), based on their agreement with them. They reflected on their rankings ( $Q$ sorts) in interviews. Factor analysis was conducted to identify similar patterns in the individual $\mathrm{Q}$ sorts. The interviews were used to determine and interpret the final factor solution. The resulting factors represent distinct perspectives on meaningful impact.

Results. Four distinct perspectives on meaningful impact of PPI were identified. Two were predominantly based on the $\mathrm{Q}$ sorts of researchers, e.g. improving research quality and facilitating dialogue and understanding, and two on the Q sorts of YPCC, e.g. achieving equality and inclusivity and doing justice to YPCC's rights. The factors were defined by 37 Q sorts (80\%); 9 Q sorts did not load significantly on any of the factors.

Conclusion. The results accentuate that researchers and YPCC can have different ideas about meaningful impact of PPI. The retrieved perspectives can serve as an aid in discussing these different views and formulating operational indicators of impact.

Patient or Public Contribution. An experience expert was involved in the early phases of this study. She helped formulating the statements and recruiting YPCC. 


\section{Introduction}

Young people with a chronic condition (YPCC) generally have a passive role in research. They are invited to participate in questionnaires and interviews. There is, however, growing consensus that YPCC should be actively involved in research that concerns them. This is also termed 'Patient and Public Involvement', or PPI. Hart defined PPI of young people as 'the process of sharing decisions which affect one's life and the life of the community in which one lives'. ${ }^{1}$ INVOLVE - the former PPI advisory group of the British National Institute for Health Research, now replaced by the Centre for Engagement and Dissemination - has devised a general and more practical definition, stating that PPI is about research being carried out 'with' or 'by' members of the public, rather than 'to', 'about' or 'for' them. ${ }^{2}$

Many researchers and YPCC are currently struggling how to do PPI in research. ${ }^{3}$ PPI can take many forms, with YPCC being involved in various ways and in several stages of different types of research. ${ }^{4,5}$ The literature on PPI of YPCC provides a plethora of examples, from intensive partnerships with a few $\mathrm{YPCC}^{6-8}$ to consultations with advisory panels., ${ }^{9,10}$ The flexibility of PPI makes it possible to adapt it to the research and the people involved. ${ }^{11} \mathrm{At}$ the same time, it complicates PPI practice, since there is no 'blueprint' for doing it right. 5,12 PPI with YPCC is further complicated by the tendency to view YPCC as vulnerable and inexperienced and to underestimate their competence as decision makers. ${ }^{1,3,6,12}$ This exacerbates the general issue of power imbalances in PPI. ${ }^{3}$

In recent years, there has been a rising demand for demonstrating the impact of PPI. The literature on PPI of YPCC shows that impact can take many forms. 4,5,11,13 It is suggested that PPI can increase the relevance and quality of research. YPCC are able to provide new insights from their lived experience, which can improve, for example, research design, ${ }^{14,15}$ data collection ${ }^{6,14}$ and dissemination of results. ${ }^{14,16}$ PPI is also believed to have a positive impact on the personal development of the YPCC involved, since they learn new skills and obtain more self-confidence. ${ }^{14,17}$ Among researchers, PPI can increase their commitment to research ${ }^{16}$ and evoke feelings of inspiration and pride. ${ }^{14}$ Finally, it is suggested that PPI can enhance the position of all YPCC in society, by promoting their rights to be heard and supporting inclusivity. ${ }^{14,18}$

Demonstrating the impact of PPI of YPCC can help resolve some of the complexities of PPI. ${ }^{5}$ It provides insight into the achievements of PPI. In addition, demonstrating impact in relation to specific PPI approaches can improve our understanding of the PPI approaches that are most likely to realize these achievements. Following the words of Staniszewska and colleagues: 'it requires evidence to inform best practice'. ${ }^{19}$ However, best practice can solely be informed by evidence that is robust and of high quality. Researchers in the field of PPI are currently struggling to find ways to conduct robust evaluations of PPI of YPCC. Several literature reviews - published in a time frame of sixteen years - have shown that the current 
evidence base on PPI of YPCC and its impact is weak. 4,11,20 The past decades, limited progress has been made to change this. ${ }^{4}$

This limited progress is partly the result of a poor understanding of what meaningful impact exactly entails. ${ }^{21}$ In a previous study, it was found that researchers and YPCC find it difficult to specify the impact they achieved beyond general descriptions. ${ }^{22} \mathrm{~A}$ more detailed understanding of impact can extend our knowledge about the difference PPI can make and what approaches work. The aim of the current study is therefore to systematically and extensively study the perspectives of researchers and YPCC on meaningful impact. The following research question will be addressed: What is considered meaningful impact of PPI in research, from the perspective of researchers and YPCC?

\section{Materials \& methods}

\section{Design}

Q methodology combines qualitative and quantitative techniques to systematically study the ways people think about a certain topic. ${ }^{23-25}$ In Q methodology, between 40 to 60 participants are presented with a sample of 20 to 100 statements, which they rank order onto a grid. After this, they are asked to reflect on the choices they made. Factor analysis is then conducted to reveal patterns of similarity in the way statements were sorted by respondents. Different from conventional factor analysis, individual rankings - not the different statements - are taken as variables. The resulting factors represent groups of individuals with similar perspectives. Participants' reflections on their rankings are used to interpret and describe the factors.

$Q$ methodology was chosen, since it is very suitable to answer our research question. It can be used to systematically study perspectives and compare their similarities and differences. $^{24,25}$ Another strength is that it prompts participants to carefully weigh the importance of different statements, as the method forces them to make a choice. ${ }^{24,26} \mathrm{~A}$ third reason to choose $\mathrm{Q}$ methodology is that it combines the strengths of quantitative and qualitative research. The factors retrieved in quantitative analyses are given meaning by using participants' reflections on their sorting of statements. ${ }^{24,25}$

\section{Participants}

The participants in the study were researchers and YPCC aged 15 to 30 years. Participants were required to have at least some experience with PPI of YPCC. Researchers were recruited through the authors' networks in the academic field. YPCC were recruited through the network of the experience expert involved in this study (an adolescent with a chronic condition) and an announcement placed on the website of JongPIT, a Dutch foundation for and led by YPCC. Snowballing was applied to get in contact with additional researchers and YPCC. 
In the current study, 50 participants sorted the $\mathrm{Q}$ sample and were interviewed. However, four participants were removed from the analysis. During data collection, it became clear that one researcher and one YPCC had not fully understood the sorting task. Two YPCC were not familiar with PPI. Consequently, the final sample consisted of 46 participants: 20 YPCC and 26 researchers. All researchers and YPCC were Dutch and therefore mostly had experience with PPI in the Netherlands. There were two exceptions: one Dutch researcher conducted research in Denmark and another in Canada. Researchers were not reimbursed for their participation in the study, YPCC received a gift card.

\section{Data collection}

Statements were collected about different types of impact, such us 'Young people obtain new knowledge and skills' and 'PPI contributes to a society in which everyone can participate'. A recently conducted literature review was used as primary input to formulate statements, ${ }^{4}$ by scanning the data on reported motivations and benefits of PPI. This was performed by the first author. In the process, she already merged some statements that were very similar. This resulted in a list of 39 statements, which was discussed by all authors and the experience expert. In an iterative process, it was decided to remove some additional statements to eliminate repetition. In addition, statements were clarified and shortened to improve comprehensibility. The final selection (the $Q$ sample) consisted of 33 statements (Table 2).

Participants were asked to rank order the $\mathrm{Q}$ sample, using a $Q$ sort table (Figure 1). Due to the situation with COVID-19, they were invited to do this digitally. Participants were sent a link to the ranking exercise, which was programmed using VQMethod. ${ }^{27}$ The ranking exercise started with an overview of all 33 statements. First, they were asked to sort the statements guided by the question 'What are your motivations for doing PPI?' (agree, neutral, disagree). The second step was to rank all statements in the $\mathrm{Q}$ sort table. Based on the first sorting exercise, participants were instructed to rank the statements based on how much they agreed with them. The more they agreed with a statement, the more they placed it to the right of the $\mathrm{Q}$ sort table. The more they disagreed with a statement, the more they placed it on the left. The statements they agreed or disagreed with most were placed at the extreme right (+4) and left (-4). After finishing the $\mathrm{Q}$ sort table, participants were asked to fill out some short questions about their background and previous experience with PPI of YPCC ('little', 'some' or 'much'). 


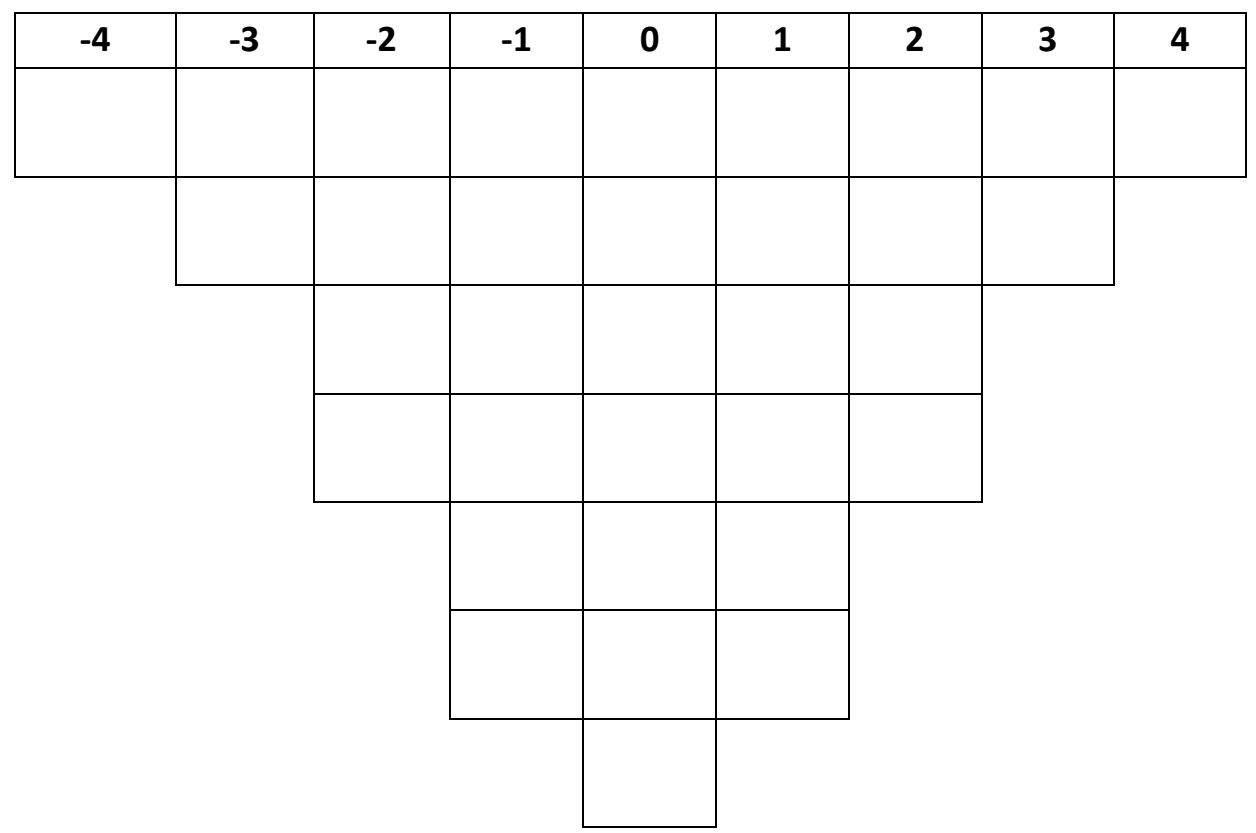

Figure 1. Q sort table

After the ranking exercise, telephone interviews or video calls were conducted with participants to reflect on their individual ranking of statements. Participants answered questions about the two or three statements they placed at the extreme right $(+3$ and +4$)$ and left ( -3 and -4$)$ sides. Some additional questions about successful PPI and impact were asked to make sure all relevant topics regarding meaningful impact were addressed (Box 1). All interviews lasted a maximum of three-quarters of an hour. They were audio-taped and transcribed.

Box 1. Interview guide

1. Can you tell me something about your experiences with PPI?

2. Before this interview you did a sorting task. How did this go? How did you make choices?

3. You sorted ... as the statement you agreed with very much / the most. Why did you consider this statement important?

4. You sorted ... as the statement you agreed with very little / the least. Why did you consider this statement not important?

5. What does successful PPI mean to you? What is meaningful impact? 


\section{Analysis and interpretation}

The individual rankings of statements - also termed $Q$ sorts - were analysed using principal component analysis, followed by Varimax rotation. Analyses were conducted in Stata 15.0, using qfactor. ${ }^{28}$ The selection of a factor solution was based on both quantitative and qualitative criteria. ${ }^{23,29}$ Some statistical features were examined. For example, only factors with an eigenvalue in excess of 1.00 were selected. Another requirement was that at least two $\mathrm{Q}$ sorts must load upon each factor. Ideally, the percentage of explained variance in the chosen factor solution is $35-40 \%$ or higher. ${ }^{29}$ In our analyses, factor solutions with 2 to 7 factors met these requirements.

Since factors should be interpretable and represent coherent and comprehensible narratives, the final factor solution was based on the qualitative interviews. ${ }^{29}$ As a part of $Q$ methodology, the views expressed during the interviews were compared with the idealised $\mathrm{Q}$ sort of each factor, the composite sorts. In a composite sort, 'the $\mathrm{Q}$ sorts of all participants who define a given factor are merged together to yield a single (factor exemplifying) $Q$ sort'. ${ }^{23}$ The choice for the final factor solution was based on the extent to which composite sorts were consistent with the qualitative reflections of those whose $\mathrm{Q}$ sorts define each factor.

Interpretation of the factor solution is based on the expressed views and elaborations in the interviews and the relative placement of all statements within each composite sort. Particular attention is paid to characterising and distinguishing statements. Characterising statements are statements on or near the extremities of the $Q$ sort table $(+4,+3,-3$ and 4). Distinguishing statements are statements that are placed on significantly different positions in the Q sort tables of different composite sorts.

Interviews were analysed in MaxQDA. The statements of the ranking exercise were translated into codes. All fragments reflecting on specific statements were coded. This resulted in an overview of how participants interpreted different statements and how they reflected on them. Based on this, it could be determined what participants provided similar interpretations and reflections and thus represented a similar perspective on impact.

\section{Results}

\section{Description of participants}

Table 1 provides an oversight of the study participants. On average, YPCC were 23 years old (range 17-29). Their experience with PPI varied from little or some (50\%) to much (50\%). The researchers who participated were on average 39 years (range 22-63) of age. Their experience in doing research varied, with interns, PhD students, postdocs, senior researchers and professors taking part in the study. They had little or some (62\%) or much (38\%) experience with PPI of YPCC. 
Table 1. Study participants

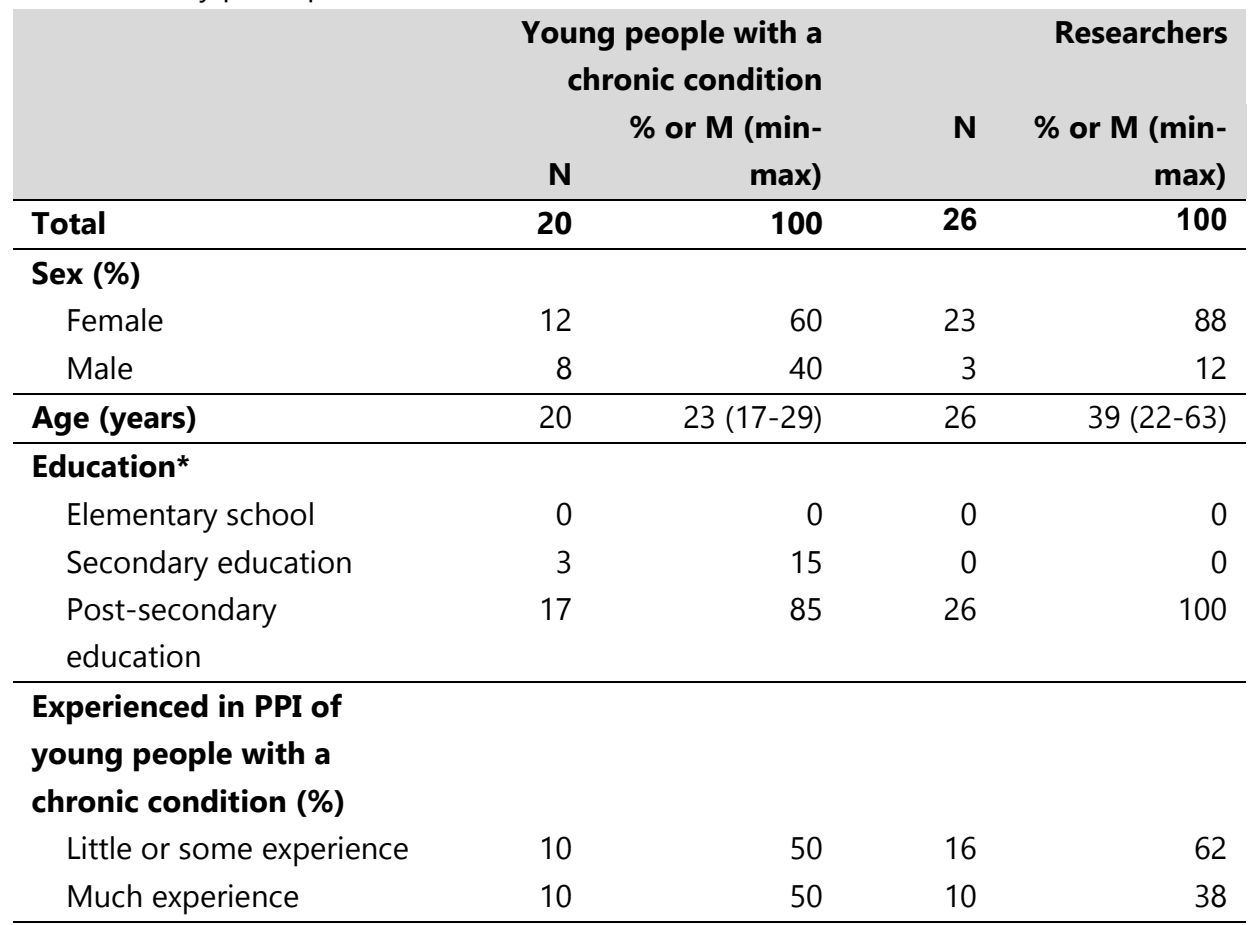

* Highest education currently enrolled in or completed

\section{Perspectives on meaningful impact}

Four factors and composite sorts were extracted from the data, that is, four distinct perspectives on meaningful impact of involving YPCC in research. These factors were defined by $37 \mathrm{Q}$ sorts (80\%); 9 Q sorts did not load significantly on any of the factors. Table 2 indicates the position of each statement in the composite sorts. 


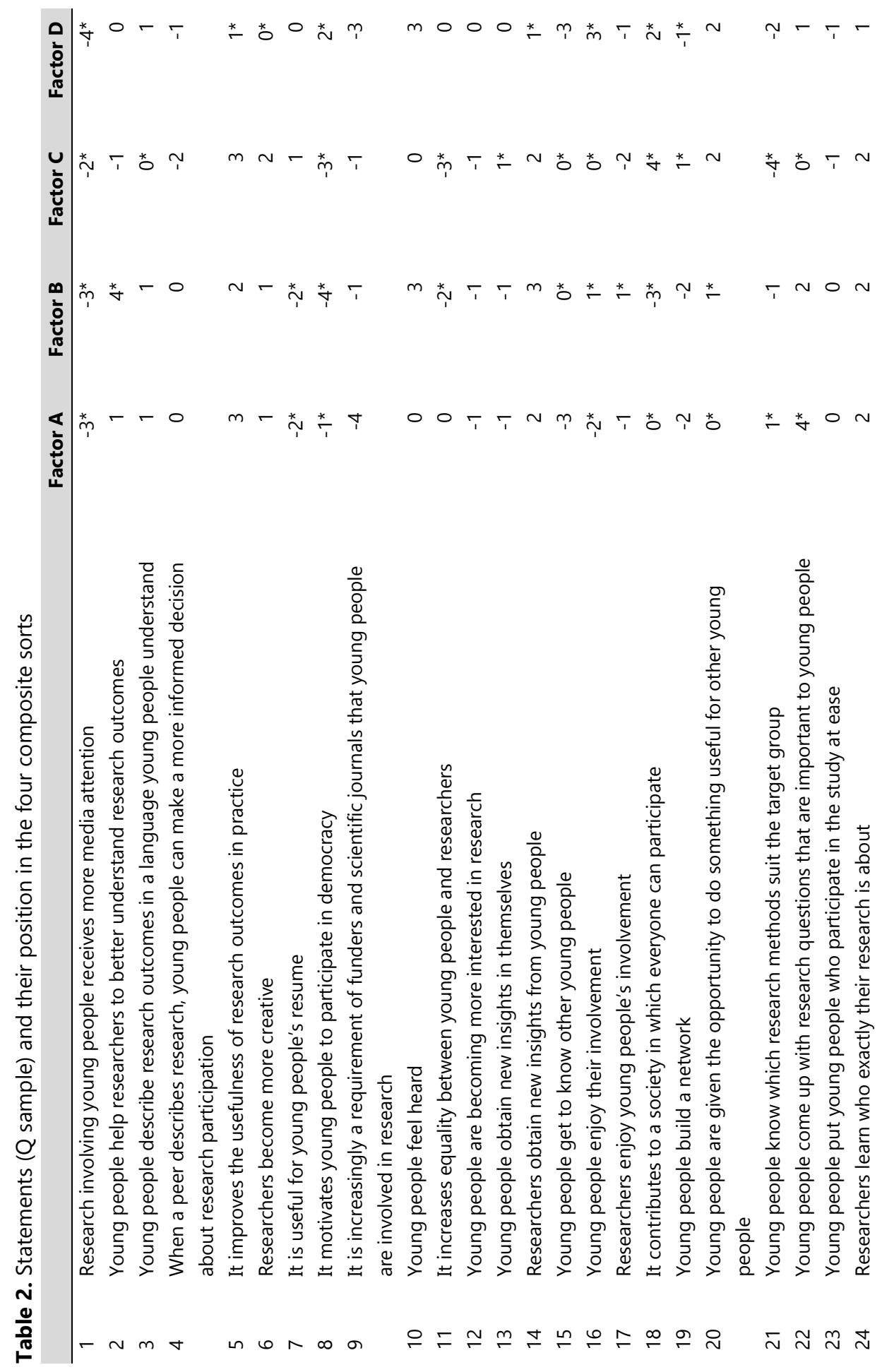




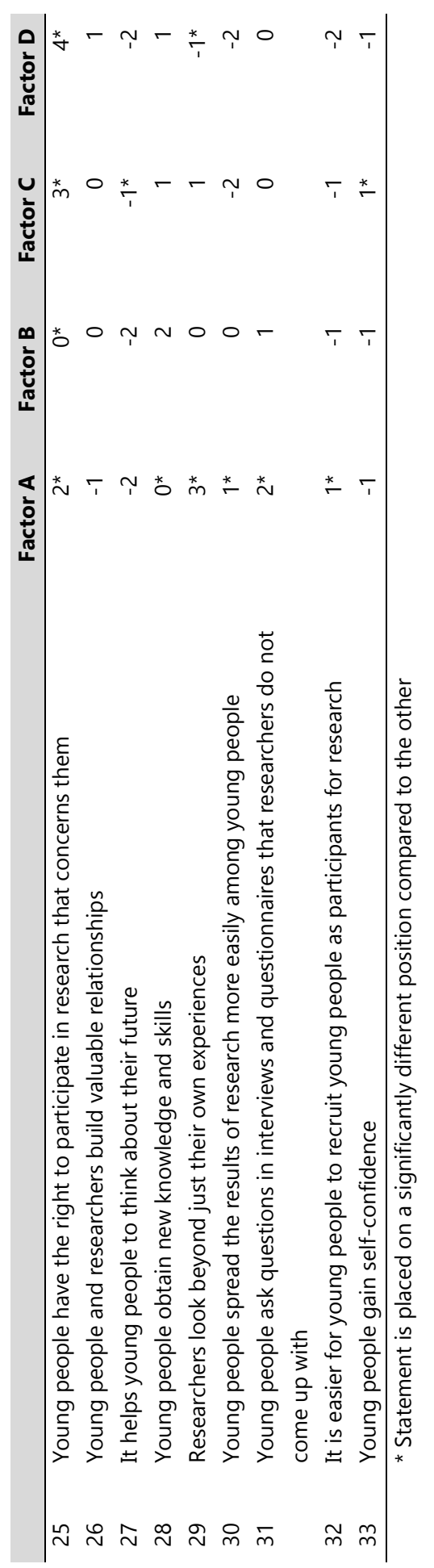


Below, the factors are described in more detail. Each factor description starts with general information about statistics and what participants loaded on this factor. Next, the factor interpretation is provided. In text, we have used parentheses to provide details about statements and their position in the composite sorts. For example, $(5 ;+3)$ means that statement 5 was positioned at +3 in the composite sort.

\section{Factor A: PPI improves the quality of research}

General information. The $\mathrm{Q}$ sorts of twelve participants significantly load on Factor A. It explains $19 \%$ of the study variance and has an eigenvalue of 14.8 . Eleven of the participants are researchers and one is a YPCC.

Factor interpretation. The quality of research is central to Factor A. PPI improves the quality of research by helping researchers to look beyond their own experiences $(29:+3)$. As one researcher explained, 'researchers focus on the details of their research, but can sometimes lose the bigger picture, what they are doing it for'. The benefits for research can take many forms. Most importantly, YPCC come up with research questions that matter to YPCC (22: $+4)$. This can improve the relevance of research and prevent a 'mismatch' between what is studied and what should be studied according to YPCC to improve their quality of life. Furthermore, YPCC ask questions in interviews and questionnaires that researchers do not come up with themselves $(31:+3)$. They can also help recruiting other YPCC as research participants $(32:+1)$ and they know which research methods are suitable for YPCC $(21:+1)$. At the end of a research project, they help disseminating research outcomes $(30:+1)$. Given these benefits, PPI can eventually increase the usefulness of research in practice $(5:+3)$. A researcher explains: 'Knowledge becomes more useful, because it is more in line with their experiences and the questions they have. It can be integrated more easily into practice, because it arises from practice.' Since their PPI can contribute to better research addressing their issues and questions, YPCC have a right to be involved in research concerning them $(25:+2)$. One researcher who conducts research in a hospital stated: 'we have a moral obligation to involve young people, because all of us can actually contribute to the improvement of health care'. Although PPI can also have individual benefits for the YPCC who are involved in research, this is not an aim. For example, it can improve YPCC's knowledge and skills (28: 0), contribute to their resume (7: -2) or provide them with new insights about themselves $(13 ;-1)$. These are, however, mainly 'side-effects'.

\section{Factor B: PPI facilitates dialogue and understanding}

General information. Factor B has eleven significantly loading $Q$ sorts of participants and explains $15 \%$ of the study variance. It has an eigenvalue of 5.0. Eight participants are researchers, three are YPCC.

Factor interpretation. Factor B focuses on engaging in a dialogue and improving researchers' understanding of YPCC's reality. Discourses between YPCC and researchers can 
help researchers to better understand research outcomes $(2:+4)$. One young person with a chronic condition states: 'It is hard for researchers to understand how we think. They are not the same age and they have not been through the things we have been through. We can help them understand'. It is therefore imperative to make sure YPCC are and feel heard $(10:+3)$. 'It helps to see through their eyes and to understand what they wish for, find and think, and what is going on in their lives'. Engaging in a dialogue with YPCC can provide researchers with a lot of new insights $(14:+3)$. This can help 'placing research outcomes in context' and eventually 'improve research quality'. It does, however, seldom lead to changes on societal level. The aim of PPI is not to motivate YPCC to participate in democracy (8: -4) or to contribute to an inclusive society $(18:-3)$. One researcher says about this: 'Although they may grow as a citizen or a human being, that is still a long way off'. Benefits for YPCC, such as building a resume (7: -2) and obtaining a network (19: -2), are seen as 'side-effects'. Equality between YPCC and researchers is not necessarily an aim (11: -2). 'It is about different roles. YPCC bring unique knowledge and experiences to the table. I wouldn't talk about equality or inequality, just different perspectives'.

\section{Factor C: PPI contributes to an equal and inclusive society}

General information. Six $\mathrm{Q}$ sorts of participants significantly load on Factor C. It explains $11 \%$ of the study variance and has an eigenvalue of 3.1. Five participants are YPCC, one is a researcher.

Factor interpretation. Central to Factor $C$ is equality and inclusivity. PPI contributes to a society in which everyone can participate $(18 ;+4)$ and is therefore a right of all YPCC $(25$ : $+3)$. YPCC can contribute to the usefulness of research in practice $(5:+3)$. 'And when research is useful in practice, you can really achieve something'. PPI enables YPCC to do something valuable for other YPCC who are in a similar situation $(20 ;+2)$. PPI also contributes to an inclusive society, since it propagates the message of 'equality' and 'inclusivity'. One young person stated: 'It is important that everyone can participate, despite their limitations. You should focus on the things you can do. When you involve young people in research, they can show that a lot is possible'. In line with this, PPI can contribute to the personal growth of YPCC. They can obtain new insights about themselves $(13:+1)$, become more self-confident $(33:+1)$ and build a network $(19:+1)$. One young person describes: 'Rewards for PPI can also be that you can put something on your resume or that you learn new things. I think this may be even more valuable than that I would receive money or whatever'. Although PPI should contribute to a more inclusive and equal society, YPCC and researchers are not equal in research processes (11:s -3). Researchers are experienced in doing research and bear more responsibilities. Therefore, they have the final say in decisions related to the research. 'Researchers are still far above young people. In my experience, young people are mostly there to provide input'. 
Factor D: YPCC have a right to make their voices heard

General information. Factor D has eight significantly loading $Q$ sorts of participants and it explains $11 \%$ of the study variance. It has an eigenvalue of 2.6 . Seven participants are YPCC, one is researcher.

Factor interpretation. Factor D focuses on the right YPCC have to make their opinions heard. YPCC have the right to be involved in research that concerns them $(25:+4)$. One young person explains: 'Young people have relatively little to say. They don't really feel taken seriously in society and politics. And if they are involved in research and taken seriously, then that is at least a start'. Hearing YPCC's voices in research $(10:+3)$ is a first step towards playing a more active role in the democracy $(8:+2)$. When YPCC are provided with real opportunities to express themselves, research involvement is a fun experience, as was stated by this researcher: 'It should be fun, make them enthusiastic and give them energy. They are participating, because they have something to say to the world'. PPI provides opportunities to do something useful for others $(20:+2)$ and to contribute to an inclusive society $(18:+2)$. On a smaller scale, PPI can contribute to the usefulness of research results $(5:+1)$, provide researchers with new insights $(14:+1)$ or improve research quality, for example, by coming up with important research questions $(22:+1)$. However, these are definitely not aims. PPI is above all a right and the focus should be on providing YPCC with sufficient space to make their opinions heard rather than improving the research as such.

\section{Discussion}

The current study examined the perspectives of researchers and YPCC on meaningful impact of PPI in research. The insights offer valuable opportunities for improving the evaluation of PPI of YPCC. This enables progression in a field that has shown limited progress in the past decades.

Using Q methodology, four distinct perspectives on meaningful impact were identified: (A) improving research quality, (B) facilitating dialogue and understanding, (C) contributing to equality and inclusivity and (D) doing justice to YPCC's rights. The perspectives show both differences and similarities. Distinctive in perspective $A$ is the focus on improving how research is designed and conducted. Conducting research that will improve the lives of YPCC is considered the most important type of impact, from this perspective. In perspective $B$, the highest value is placed on an improved understanding of research outcomes and formulating the right conclusions and implications. Similar in perspectives $A$ and $B$ is the emphasis on improving the usefulness of research. $A$ more inclusive society is the most important type of impact in perspective $C$. In contrast to perspectives $A$ and $B$, the personal development of the YPCC involved in research is also an aim. Perspective D distinguishes itself by placing the right of YPCC to be involved above all other impact. 
The findings demonstrate that researchers and YPCC generally have different perspectives on meaningful impact of PPI. We are aware that Q methodology is not particularly suited to make claims about the division of perspectives among different groups. As Watts and Stenner explained, $Q$ methodology is less about 'who said what about $X$ ' than 'what is currently being said about $X^{\prime} .^{23}$ It is, however, remarkable that perspectives $A$ (improving research quality) and $B$ (facilitating dialogue and understanding) are predominantly based on the $\mathrm{Q}$ sorts of researchers and perspectives $C$ (contributing to equality and inclusivity) and D (doing justice to YPCC's rights) on the Q sorts of YPCC. This finding highlights the importance of taking into account all perspectives in evaluations of PPI.

The findings also show there is a difference between meaningful impact researchers and YPCC strive for and secondary impact. It is important to make this distinction in PPI evaluations to improve critical reflection. This can be done by predetermining indicators of meaningful impact. However, we noticed during data collection that many participants were not used to define what impact matters most to them. A similar experience was reported by Cook et al. ${ }^{21}$ The retrieved perspectives can therefore serve as an aid in specifying meaningful impact in PPI evaluations. An important note to make here is that the perspectives are not meant for categorizing researchers and YPCC into different groups. They are the result of various merged $\mathrm{Q}$ sorts and qualitative interpretation and therefore not all researchers and YPCC may completely identify with them. Rather, the perspectives should be used to create awareness that meaningful impact can mean different things for each individual.

The perspectives and statements can also serve as an aid for operationalising meaningful impact into measurable indicators. Generally it is considered very difficult to quantify PPI impact. ${ }^{30}$ However, many types of impact can be operationalised based on the statements used in this study. For example, indicators could focus on the extent to which YPCC consider the research question important (statement 22), the extent to which researchers obtained new insights (statement 14), the new knowledge and skills obtained by being involved (statement 28) and the extent to which YPCC felt they were able to exercise their right to have a say in matters (statement 25). Some types of impact are more difficult to quantify, such as a more inclusive society (statement 18). For these types of impact more flexible and creative operationalisations are needed that describe them the best way possible. For example, measuring a more inclusive society may be approached by asking the YPCC involved or those using the study results in practice about their perspectives on the achievement of this impact.

One of the retrieved perspectives focuses on PPI as a right of YPCC. It is sometimes suggested that impact evaluations are not useful in this context, since the focus is on YPCC exercising their rights rather than on impact. ${ }^{5,31}$ However, in line with Staley, we argue that impact evaluations can always provide relevant feedback on the success of a PPI approach 
and the achievements of its aims. ${ }^{5}$ Staley emphasized that understanding PPI as a right can give patients 'a seat at the table', whereas impact evaluations can improve PPI approaches to ensure they can actually exercise their rights. Although less explicit, those who are doing PPI based on moral reasons also strive for impact. They wish for PPI to increase YPCC's opportunities to have a say in matters that affect them.

We also noticed during the interviews that questions about impact were answered with caution and many side notes. Especially researchers feared that impact would become a condition for doing PPI. We would propose, however, to look at impact evaluations as a learning mechanism and a way to obtain insight into the best ways to do it. ${ }^{5}$ Following Lundy's line of reasoning, imperfect PPI is not the end but rather the beginning of a learning process. ${ }^{32}$ When PPI does not result in the desired impact, much can be learnt from critical reflection on questions such as 'why not?' and 'what can we do differently next time?'.

\section{PPI in the current study}

An experience expert was involved in the current study. Our collaboration was shaped based on what Franks called 'Pockets of PPI'. ${ }^{33}$ We divided the study in different parts and discussed in what parts the experience expert wished to be involved. Due to COVID-19 and the nature of her chronic condition (a hearing impairment), our collaboration took place via email. We worked together this way with this experience expert before, so we were confident this would work again. The experience expert received reimbursements for her involvement.

The experience expert provided input on the statements for the sorting task. She suggested to add 'YPCC feel heard'. This appeared to be a relevant addition, since many study participants rated this statement as important. Based on the suggestions of the experience expert, we also reformulated statements. For example, the statement 'YPCC are given the opportunity to do something useful for others' was changed to 'YPCC are given the opportunity to do something useful for other YPCC'. The experience expert also helped recruiting YPCC as study participants via her network.

We also invited the experience expert to be involved in the analyses of the study and help to determine the factor solution. We sent her interview transcripts, so she could help us with the interpretation. However, after sending the transcripts, she stopped responding to her emails. We sent her three reminders over a period of two months and waited for her response. Then, we chose to continue our work, due to approaching deadlines. To make sure the perspectives of young people with a chronic condition were also included in the final stages of the study, we informally discussed our findings with some experience experts who were involved in another research project.

A lesson we learnt from this experience is that we should find new ways to involve YPCC who cannot communicate verbally. We considered email a good way, since we had good 
experiences previously. However, email also creates distance and we fear this may have resulted in a lack of commitment. Also, we had limited alternatives to contacting the experience expert, after losing contact. This is unfortunate, since the initial contact between us and the experience expert was pleasant and resulted in relevant improvements.

\section{Strengths and limitations}

To our knowledge, this is the first study that has studied impact of PPI in so much detail. Q methodology enabled us to systematically study perspectives and compare their similarities and differences. An important strength of this method was that it forced participants to choose what impact matters most to them. This motivated them to carefully weigh their motivations in a way they had not done before.

Due to the situation with COVID-19, we were forced to conduct the study online. Although the programme VQMethod ${ }^{27}$ was very suitable for doing the sorting task online, it is considered a limitation that participants could not complete the sorting tasks in the presence of the researchers. This resulted in the exclusion of a few participants who did not fully understand the sorting task. Also, it would have been valuable to hear their thoughts and considerations during the sorting tasks rather than retrospectively during the interviews. Another limitation is that recruiting participants through the networks of the authors may have resulted in some selection bias. However, by applying snowballing it was ensured that researchers and YPCC outside the networks were also reached. Finally, it may have been valuable to discuss the sorting tasks in focus groups rather than interviews to enrich our understanding of overlap and differences between arguments for doing PPI. The interviews, however, enabled us to discuss more in-depth with all participants what motivated them.

The current study provides extensive insight into perspectives on meaningful impact of researchers and YPCC. It would be interesting for future studies to explore these perspectives among different age groups, such as children, adults and elderly, since it is conceivable that desired impact may differ according to age.

\section{Conclusions}

The past decades, limited progress has been made in evaluating the impact of PPI with YPCC. The current study aims to change this by clarifying the concept of meaningful impact. Using Q methodology, four distinct perspectives on meaningful impact were identified among researchers and YPCC: improving research quality, facilitating dialogue and understanding, achieving equality and inclusivity and doing justice to YPCC's rights. Researchers and YPCC generally have different perspectives on meaningful impact. Evaluations should therefore take into account the perspectives of everyone involved in a PPI process. This study also highlights the importance of predetermining indicators for meaningful impact in PPI evaluations. The perspectives retrieved in this study can serve as a starting point for this and for operationalising them into measurable indicators. 


\section{References}

1. Hart R. Children's participation: From tokenism to citizenship. Florence: UNICEF; 1992.

2. INVOLVE. What is public involvement in research? Accessed July 23, 2020. https://www.invo.org.uk/find-out-more/what-is-public-involvement-in-research-2/

3. Brady LM, Preston J. How do we know what works? Evaluating data on the extent and impact of young people's involvement in English health research. Research for All. 2020;4(2):194-206. doi:10.14324/RFA.04.2.05

4. Schelven F van, Boeije H, Mariën V, Rademakers J. Patient and public involvement of young people with a chronic condition in projects in health and social care: A scoping review. Health Expect. 2020;23(4):789-801. doi:10.1111/hex.13069

5. Staley K. 'Is it worth doing?' Measuring the impact of patient and public involvement in research. Res Involv Engagem. 2015;1(1):1-10. doi:10.1186/s40900-015-0008-5

6. Chappell P, Rule P, Dlamini M, Nkala N. Troubling power dynamics: Youth with disabilities as coresearchers in sexuality research in South Africa. Childhood. 2014;21(3):385-399. doi:10.1177/0907568214525427

7. Stevenson M. Participatory data analysis alongside co-researchers who have Down syndrome. $J$ Appl Res Intellect Disabil. 2014;27(1):23-33. doi:10.1111/jar.12080

8. Graham N, Mandy A, Clarke C, Morriss-Roberts C. Using children and young people as advocates to inform research design. Brit J Occup Ther. 2017;80(11):684-688. doi:10.1177/0308022617725491

9. Van Schelven F, Boeije H, Inhulsen MI, Sattoe JNT, Rademakers J. "We know what we are talking about ": Experiences of young people with a chronic condition involved in a participatory youth panel and their perceived impact. Child Care Pract. 2019;27(2):191-207. doi:10.1080/13575279.2019.1680529

10. Marshall Z, Nixon S, Nepveux D, et al. Navigating risks and professional roles: Research with lesbian, gay, bisexual, trans, and queer young people with intellectual disabilities. $J$ Empir Res Hum Res Ethics. 2012;7(4):20-33. doi:10.1525/jer.2012.7.4.20

11. Bailey $S$, Boddy $K$, Briscoe $S$, Morris $C$. Involving disabled children and young people as partners in research: A systematic review. Child Care Health Dev. 2015;41(4):505-514. doi:10.1111/cch.12197

12. Dedding C. Delen in macht en onmacht: Kindparticipatie in de (alledaagse) diabeteszorg. [PhD thesis]. Amsterdam: University of Amsterdam; 2009.

13. Brett J, Staniszewska S, Mockford C, et al. A systematic review of the impact of patient and public involvement on service users, researchers and communities. Patient. 2014;7(4):387-395. doi:10.1007/s40271-014-0065-0

14. Flicker S. Who benefits from community-based participatory research? A case study of the positive youth project. Health Educ Behav. 2006;35(1):70-86. doi:10.1177/1090198105285927

15. Powers $L E$, Garner $T$, Valnes B, et al. Building a successful adult life: Findings from youth-directed research. Exceptionality. 2007;15(1):45-56. doi:10.1080/09362830709336925

16. Van Staa A, Jedeloo S, Latour JM, Trappenburg MJ. Exciting but exhausting: Experiences with participatory research with chronically ill adolescents. Health Expect. 2010;13(1):95-107. doi:10.1111/j.1369-7625.2009.00574.x

17. Franklin A, Sloper P. Supporting the participation of disabled children and young people in decision-making. Child Soc. 2009;23:3-15. doi:10.1111/j.1099-0860.2007.00131.x 
18. Bruce SM, Parker AT. Young deafblind adults in action: Becoming self-determined change agents through advocacy. Am Ann Deaf. 2012;157(1):16-26. doi:10.1353/aad.2012.1607

19. Staniszewska S, Herron-Marx S, Mockford C. Measuring the impact of patient and public involvement: The need for an evidence base. Int J Qual Health C. 2008;20(6):373-374. doi:10.1093/intqhc/mzn044

20. Cavet J, Sloper P. Participation of disabled children in individual decisions about their lives and in public decisions about service development. Child Soc. 2004;18(4):278-290. doi:10.1002/CHI.803

21. Cook T, Boote J, Buckley N, Vougioukalou S, Wright M. Accessing participatory research impact and legacy: Developing the evidence base for participatory approaches in health research. Educ Action Res. 2017;25(4):473-488. doi:10.1080/09650792.2017.1326964

22. Schelven F van, Meulen E van der, Kroeze N, Ketelaar M, Boeije H. Patient and public involvement of young people with a chronic condition: Lessons learned and practical tips from a large participatory program. Res Involv Engagem. 2020;6(1):1-13. doi:10.1186/s40900-020-00234-1

23. Watts S, Stenner P. Doing Q methodology: Theory, method and interpretation. Qual Res Psychol. 2005;2(1):67-91. doi:10.1191/1478088705qp022oa

24. Cross RM. Exploring attitudes: The case for Q methodology. Health Educ Res. 2005;20(2):206-213. doi:10.1093/her/cyg121

25. Jedeloo S, Van Staa A. Q-methodologie, een werkelijke mix van kwalitatief en kwantitatief onderzoek? Kwalon. 2016;14(2):5-15. doi:10.5117/2009.014.002.002

26. Prasad R. Development of the HIV/AIDS Q-Sort Instrument to measure physician attitudes. Fam Med. 2001;33(10):772-778.

27. Nazariadli S. VQMethod. Published online 2018. https://www.vqmethod.com/

28. Akhtar-Danesh N. qfactor: A command for Q-methodology analysis. Stata J. 2018;18(2):432-446. doi:10.1177/1536867x1801800209

29. Mchugh N, Baker R, Biosca O, Donaldson C. Who knows best? A Q methodology study to explore perspectives of professional stakeholders and community participants on health in low-income communities. BMC Health Serv. 2019;19(1):1-13. doi:10.1186/s12913-019-3884-9

30. Staley K, Barron D. Learning as an outcome of involvement in research: what are the implications for practice, reporting and evaluation? Res Involv Engagem. 2019;5(1):1-9. doi:10.1186/s40900019-0147-1

31. Friesen $P$, Lignou $S$, Sheehan $M$, Singh I. Measuring the impact of participatory research in psychiatry: How the search for epistemic justifications obscures ethical considerations. Health Expect. 2021;24(S1):54-61. doi:10.1111/hex.12988

32. Lundy L. In defence of tokenism? Implementing children's right to participate in collective decision-making. Childhood. 2018;25(3):340-354. doi:10.1177/0907568218777292

33. Franks M. Pockets of participation: Revisiting child-centred participation research. Child Soc. 2011;25(1):15-25. Doi:10.1111/j.1099-0860.2009.00258.x 




\section{Chapter 7}

General discussion

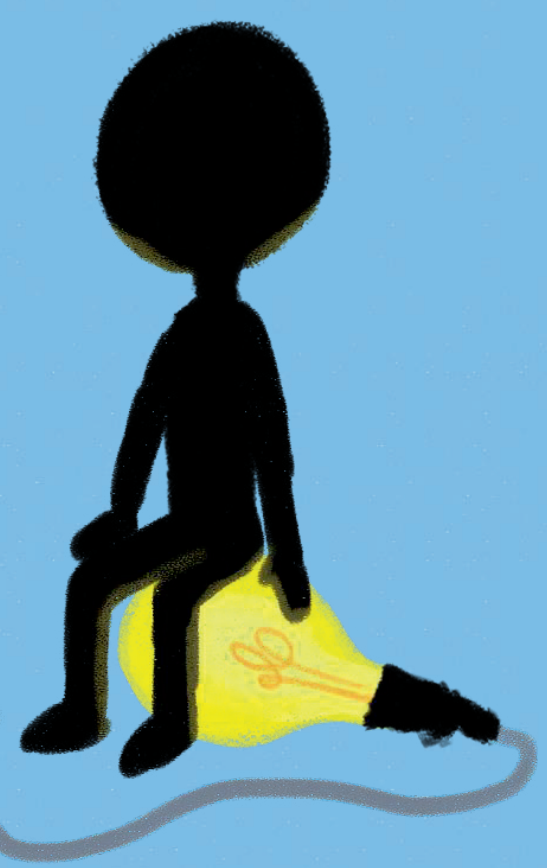


Worldwide, health service users are increasingly involved in research and innovation that concerns them. This is also termed Patient and Public Involvement, or PPI. Great expectations are raised about the impact of PPI. There is a widespread belief that it is an educational and enriching experience for all people involved and beneficial to the quality of projects. According to many, PPI does justice to the fundamental right of people to have a say in matters that affect them.

To date, most research on PPI focuses on adults. Relatively little is known about PPI of young health service users, such as young people with a chronic condition. There are still many questions about the ways they can be involved and the impact of their PPI. The objective of this thesis was therefore twofold: (1) to gain insight into the concept of PPI with young people with a chronic condition and possible shifts herein over time and (2) to strengthen the evidence base about the ways young people with a chronic condition can be involved in research and innovation projects in health and social care to achieve impact that is meaningful to them and to others. Three research questions were examined:

1. What developments in PPI of young people with a chronic condition can be seen in the existing literature over the past decades?

2. What factors hinder or facilitate (1) the process of PPI of young people with a chronic condition in research and innovation projects and (2) the impact of their PPI?

3. What is meaningful impact in the context of PPI of young people with a chronic condition in research and innovation projects, and how can this be evaluated?

The following paragraphs address and reflect upon the main findings of this thesis.

\section{Main findings}

\section{What developments in PPI of young people with a chronic condition can be seen in the existing literature over the past decades?}

To answer the first research question, a scoping review was conducted (chapter 2). This review addresses the developments in PPI of young people with a chronic condition between 2002 and 2017. The findings demonstrate that the attention for PPI of young people with a chronic condition has increased. Of the twenty-three studies included in the review, fifteen were published in the last decade. Next to this development, the scoping review describes the state of the art with regards to the terms and definitions used for PPI, its process and impact, and the quality of studies.

\section{Terms and definitions}

The scoping review shows great variation in the terms and definitions used for PPI. Studies refer to PPI with different words, such as participation, advocacy and emancipatory research. They provide different definitions for similar terms, and the other way around. 
However, there is also overlap between definitions. There is a general agreement that PPI is a collaborative process that enables young people with a chronic condition to have a say in matters that concern them. It is a continuum of activities providing the young people with different degrees of influence in various stages of a project. The variation in terms and definitions highlight the importance of studies including thorough descriptions of what is understood by PPI and how this is translated into activities.

\section{Process and impact}

The scoping review demonstrates there are various ways to involve young people with a chronic condition in projects. The included studies show that young people with a chronic condition can have different roles - with varying degrees of influence - in different stages of projects, such as recruitment, project design, data collection and analysis, and dissemination of project outcomes. Generally, it is agreed upon in the literature that there is not one 'right' way to do PPI.

Insight is also provided into important challenges within the process of PPI. For example, PPI can be time consuming for both young people with a chronic condition and professionals. Another challenge is related to representativeness and diversity, with studies suggesting that the young people involved are generally more outgoing, critical and confident than their non-involved peers. Changing power dynamics were also considered a challenge. In PPI, professionals and young people with a chronic condition work together as a team. Professionals let go of some of their control and enable young people with a chronic condition to make a difference. This can cause discomfort, especially when perspectives differ.

With regards to its outcomes, there is a general conviction that PPI leads to many forms of positive impact. Examples are provided of impact on the quality of projects, the personal development of young people with a chronic condition and the commitment of professionals to their work.

\section{Quality of studies}

The findings of the included studies are promising, but a quality assessment shows that most studies on PPI of young people with a chronic condition are of low quality. Four important shortcomings are identified. The first is inadequate reporting. Many studies insufficiently report how findings are derived, with some studies completely lacking a methods section. This hinders replication, critical appraisal and comparison of studies and thus learning about what works (and what not) in PPI of young people with a chronic condition. A second shortcoming is that systematic and objective methods are seldom applied to evaluate the process and impact of PPI. Most evidence concerns enthusiastic reports of professionals who reflect upon PPI processes they were part of themselves. Third, studies rarely address the perspectives of young people with a chronic condition. This is 
remarkable, as young people are a vital part of PPI processes. A fourth and final shortcoming is the lack of innovation in studies on PPI of young people with a chronic condition. Recently published studies report on similar topics as studies published over ten years ago. Follow-up studies applying innovative methods to build on previous work are seldom conducted.

\section{What factors hinder or facilitate (1) the process of PPI of young people with a chronic condition in research and innovation projects and (2) the impact of their PPI?}

To answer the second research question, this thesis monitored over thirty research and innovation projects that involved young people with a chronic condition. Both young people with a chronic condition (chapter 3 ) and professionals (chapter 4) were invited to reflect on the PPI in these projects. The chapters confirm that there are many different ways to do PPI. Examples are provided of young people being involved as members of project teams, through panels and advisory boards and through engaging sessions. The chapters also provide insight into some general factors that can facilitate or hinder the process and impact of PPI. Below, these factors are described in more detail; Box 1 provides a summary.

Box 1. Facilitating and hindering factors for the process and impact of PPI

\section{Facilitating}

The roles and responsibilities of young people with a chronic condition match their experiences and abilities

Roles and responsibilities are clear to young people with a chronic condition

Young people with a chronic condition are involved from an early stage of a project

Professionals listen to young people with a chronic condition, take them seriously and are willing to change their initial ideas

Young people with a chronic condition and professionals receive support, such as training, coaching or feedback
Hindering

The roles and responsibilities of young people with a chronic condition are too strenuous, difficult or tedious

There is a lack of communication about the roles and responsibilities of young people with a chronic condition

Professionals do not value the perspective of young people with a chronic condition and do not include them in decision making 
Sufficient time and resources are available

It is difficult to find young people with a chronic condition who are able and willing to be involved

\section{Match between PPI and young people with a chronic condition}

The findings in both chapters show variation in the degree of agency young people with a chronic condition have in projects. Examples are provided in which they receive information, give their opinion, provide (un)solicited advice or make decisions together with professionals or by themselves. Professionals noted that they did not necessarily provide young people with as much influence as possible in all stages of a project. A good match between PPI and the experiences and abilities of young people with a chronic condition is considered more important. PPI activities cannot be too strenuous, difficult or tedious, otherwise young people will not be able to follow-up on them or drop out. Both young people with a chronic condition and professionals suggested that involving young people in decisions about their involvement contributes to more effective PPI processes.

\section{Clarity about roles and responsibilities}

The importance of clearly determining roles and responsibilities of young people with a chronic condition in different stages of projects is voiced by both young people and professionals (chapters 3 and 4). Clarity helps them to understand what is expected from them and increases their commitment. A lack of transparency can cause disappointment and discomfort, as was experienced by young people who were a member of a youth panel (chapter 3). Due to a lack of communication about their roles and responsibilities, they did not understand why they were not always included in decision making and why there were differences between their roles and responsibilities and those of other panel members.

\section{Involvement from an early stage}

Especially professionals suggested that involving young people with a chronic condition from an early project stage contributes to a more effective PPI process (chapter 4). They provide examples of young people being involved in generating new project ideas, formulating research questions and writing project proposals. According to professionals, early involvement enables young people to influence the content and course of projects, before these are set in stone. Moreover, it facilitates collaboration as equals, since both parties are involved from the start. 


\section{Flexibility and an open mind among professionals}

In chapter 3, young people with a chronic condition indicated that their opportunities to make a difference in projects commonly depend on professionals and the value they place on their perspectives. Professionals are aware of this responsibility (chapter 4). They emphasized that they have to make time to listen attentively to the ideas of young people with a chronic condition and take them seriously. Moreover, they consider a willingness to change initial (ideas about) project plans fundamental for successful PPI.

\section{Support for young people and professionals}

The vulnerability of young people with a chronic condition sometimes limits possibilities for PPI, as they have to deal with lower energy levels, health issues and hospital stays (chapters 3 and 4). Support in the form of training and coaching can make PPI less strenuous, as it improves the match between PPI activities and the knowledge and skills of young people (chapter 4). Professionals can also benefit from training and coaching. Young people with a chronic condition emphasized that feedback on their input is another indispensable form of support (chapter 3). Feedback helps them to improve their future PPI efforts. It was found that personal development of young people with a chronic condition enables them to increase their impact, through a process termed 'professional socialization'. Through experience and support, young people become more familiar with PPI and decision making structures, which increases their ability to influence decision making.

\section{Recruitment}

The findings in chapter 3 and 4 demonstrate that it is difficult to find young people with a chronic condition who are willing to be involved. Young people with a chronic condition are often rather 'anonymous'. Some of them are not willing to do PPI, since they prefer not to concern themselves too much with their chronic condition. Professionals suggested that collaborating with patient or youth organizations and developing PPI activities that appeal to young people can facilitate recruitment (chapter 4). A relevant note here, is that different forms of PPI can appeal to different people. For example, chapter 3 shows that a formal panel predominantly attracted young people who are 20 years or older and highly educated. As a result, the panel lacked lower educated and younger people with a chronic condition.

\section{Availability of resources}

In chapter 4, professionals stated that PPI generally requires additional time and resources that need to be included in project proposals. A flexible project planning helps creating sufficient opportunities for dialogue between young people with a chronic condition and professionals without the pressure of approaching deadlines. Project budgeting also needs to include reimbursements for the young people who are involved. Reimbursements are 
not solely a way to appreciate their input, but can also increase commitment and clarify mutual expectations.

\section{What is meaningful impact in the context of PPI of young people with a chronic condition in research and innovation projects, and how can this be evaluated?}

To answer the third research question, a $\mathrm{Q}$ methodology study was conducted that provides in-depth insight into the concept of PPI impact (chapter 6). Also, young people with a chronic condition and professionals were invited to reflect on the impact of PPI in different projects (chapters 3 and 4). A quantitative study was conducted to explore the relation between PPI and a specific form of impact, i.e. on project outcomes (chapter 5).

\section{Concept of impact}

Chapter 6 provides in-depth insight in the concept of impact. The study focuses on PPI in research projects. It shows that it varies among individuals what is considered meaningful impact. Four distinct perspectives are identified. The first perspective focuses on improvements in the way research is designed and conducted. From this perspective, meaningful impact concentrates on changes in specific aspects of research, such as the extent to which young people with a chronic condition consider the research question important. The second perspective addresses an improved understanding among researchers of young people with a chronic condition and the world they live in. Here, professionals obtaining new insights is an example of meaningful impact. The third perspective focuses on the benefits for young people with a chronic condition involved in PPI and in general. Here, an example of meaningful impact is the extent to which young people with a chronic condition obtained new knowledge and skills from being involved. The fourth perspective values the right of young people with a chronic condition to be involved in research that concerns them above all other forms of impact. Here, meaningful impact could focus on whether young people with a chronic condition felt they were able to exercise their right.

\section{Realisation of impact}

The reflections of young people with a chronic condition and professionals demonstrate a firm belief in the positive impact of PPI. Young people with a chronic condition who were a member of the youth panel noted they had impact on different levels (chapter 3). On the individual level, they gained new knowledge through their PPI and became more confident. On the project level, they ensured that the content of projects were more in line with the needs of young people with a chronic condition. On a political level, they raised awareness of their issues through meetings with politicians and position papers. Professionals also described different forms of impact (chapter 4). They observed that the PPI of young people with a chronic condition improved the quality of projects, for example, by facilitating 
recruitment of participants, assessing the relevance of projects and helping to disseminate findings.

Although these reflections provide useful insights in the impact of PPI, critical examination shows that many notions on impact are hindsight contemplations and rarely substantiated by data. Apart from some concrete examples, professionals and young people with a chronic condition were often unable to specify impact beyond expectations or vague notions. To obtain more objective and concrete data about impact, a quantitative study was conducted (chapter 5).

The quantitative study explored the relation between PPI in research and innovation projects and the subsequent outcomes of these projects. Project outcomes were defined as the contribution of projects to the social position of young people with a chronic condition (as perceived by themselves) and addressed different life domains, i.e. care, school, work, sport and personal strength. The study demonstrated that PPI can indeed contribute to improved project outcomes. Young people with a chronic condition reported better project outcomes, when they considered their role in a project important. No relation was found between how much young people with a chronic condition did in a project (as perceived by themselves and by professionals) and project outcomes. Project outcomes were also not affected by the amount of influence provided to young people with a chronic condition. These findings suggest that the achievement of impact depends more on the meaningfulness of PPI than on the number of activities and the amount of influence young people have.

The quantitative study also did not demonstrate a relation between early involvement and an increased impact of PPI. In chapter 5, it is suggested that this is the result from the way early involvement was operationalized, i.e. as involvement in the idea development stage of a project. There are also other early stages of a project to which young people with a chronic condition can contribute, such as writing a project proposal or setting up a project, but these were not taken into account.

\section{Controversiality regarding impact}

In chapter 6, some controversiality regarding the measurement of PPI impact was noted. Virtually all young people with a chronic condition and professionals reported that they do PPI because of its expected impact. It would, therefore, be logical to monitor to what extent the desired impact is achieved. However, especially professionals answered questions about (the measurement of) impact with caution and many side notes. They feared that demonstrable impact would become a condition for doing PPI. According to them, not all impact can be easily demonstrated and some valuable forms of impact may thus be missed in evaluations, leading to wrong conclusions about the success of PPI. 


\section{Reflections on the findings}

\section{The evidence base}

The findings of this thesis demonstrate that the current evidence base on PPI of young people with a chronic condition is lacking quality. Some fundamental principles of good scientific research are often not met: reporting is inadequate, systematic and objective research methods are rarely applied and only a few studies build on previous work. Between 2002 and 2017, limited progress has been made in this respect. This is at odds with the increased interest in PPI of young people with a chronic condition. Mayo stated in 2001 that PPI entered the mainstream vocabulary, but the practice lagged behind its rhetoric. ${ }^{1}$ Two decades later, this still applies to PPI of young people with a chronic condition.

This limited progress can be partly explained by the activist background of PPI. As described in the introduction, PPI has its roots in the second half of the $20^{\text {th }}$ century, during which groups of health service users developed a collective voice and formed emancipatory groups that actively campaigned for the right to have a say in matters that affect them. ${ }^{2}$ Since 1989, the UNCRC established this right for young people with and without a chronic condition. ${ }^{3}$ Consequently, PPI is often conceptualized as an undertaking that is of intrinsic value: doing it is always 'good'. ${ }^{4}$ Following this line of reasoning, evaluation is not needed, leaving the evidence base behind. Next to this, the evaluation of PPI is difficult and timeconsuming. PPI is a complex activity and many factors affect its process and impact. ${ }^{5,6}$ It is - amongst other things - dependent on the people involved, the culture of the organizations involved, the resources available, the purpose of the PPI and the purpose and content of the research and innovation projects health service users are involved in. It requires substantial time and resources to precisely document these factors, track developments and monitor outcomes. Also, the literature is inconclusive about the best way to conduct robust evaluations of PPI while taking into account its complexities.

However, an improved evidence base is imperative to obtain more insight into the benefits of PPI and into what works (or not). ${ }^{7,8}$ The growing belief in its positive impact has led an increasing number of young people with a chronic condition and professionals to invest their time in PPI. In addition, funders of research and innovation in health and social care are increasingly mandating them to work together. ${ }^{9,10}$ At the same time, there is little high quality evidence available that demonstrates the actual realization of these expectations and the ways they can be realized. This thesis identifies four ways to improve the evidence base: (1) improved reporting, (2) application of more systematic and objective measures, (3) inclusion of both young people's and professionals' perspectives and (4) application of innovative methods to build on previous work. These principles were applied in all studies presented in this thesis. 


\section{Meaningful involvement}

This thesis demonstrates that the process and impact of PPI do not necessarily benefit from providing young people with a chronic condition with as much influence as possible in all stages of research and innovation projects. More important is the meaningfulness of PPI activities and the match between roles and responsibilities of young people with a chronic condition and their experiences and abilities. This conclusion is in line with studies suggesting that there is 'not one right method for PPI'. ${ }^{11-14}$ The best way may depend on various factors, such as the purpose of their PPI, the people involved and the content and form of the project they are involved in.

To ensure meaningful PPI that matches experiences and abilities, young people with a chronic condition and professionals ideally decide on PPI activities together. Young people know their needs and wishes regarding their involvement and how PPI activities fit into their daily lives. Professionals have ideas about the input they wish from young people with a chronic condition and are familiar with project planning and resources. In addition, chapter 3 and 4 of this thesis demonstrate that dialogue about PPI activities can help young people with a chronic condition to understand what is expected from them and what their contributions will be. Other studies have also suggested that continuous communication can help to create mutual awareness of assumptions, responsibilities and limitations within PPI processes and impact. ${ }^{15,16}$

Several models have been developed to discuss PPI activities within projects. A very influential model in PPI of young people is Hart's ladder of involvement. ${ }^{17}$ Based on the work of Arnstein, ${ }^{18}$ he illustrated that young people can be provided with different degrees of agency in projects. However, as described in the introduction, his ladder has been criticized for the hierarchy it implies, in which providing young people with more agency is always better. ${ }^{19-21}$ Tritter and McCallum considered it an oversimplification of reality. ${ }^{20}$ The findings of this thesis show that these criticisms are justified: more agency is not necessarily better and PPI is much more complex than the ladder suggests. Despite this, ladders like those of Arnstein and Hart were influential in the field and guided the development of many other models and tools.

Very useful tools based on the ladders are involvement matrices. Involvement matrices depict the roles of those involved per project phase (Figure 1). They can take many forms. An example is available of a document on which roles can be written down, digital or on paper. ${ }^{22}$ Others have transformed it into a game, in which pawns are placed on an involvement matrix game board. ${ }^{23}$ Different from a ladder, a matrix generally place roles next to each other, preventing hierarchical thinking about roles. In addition, it shows that the roles of those involved can differ per project phase. Although involvement matrices are 
still a simplification of reality, they have proven to be useful in discussing, clarifying and evaluating PPI in projects, both in this thesis and the literature. 22,23

Figure 1. Example of an involvement matrix, based on Smits et al. ${ }^{22}$

ROLE IN PROJECT

\begin{tabular}{ccccc} 
Listener & Co- & Advisor & Partner & Decision- \\
Is given & thinker & Gives & Works as & maker \\
information & Is asked & (un)solicited & an equal & Takes \\
& to give & advice & partner & initiative, \\
& opinion & & & (final) \\
& & & & decision \\
\hline
\end{tabular}

$\frac{5}{\frac{0}{4}}$

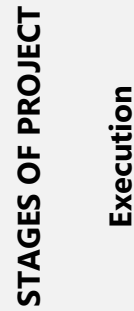

흘

\section{Power and dependency}

Despite the context dependency of PPI, it is also possible to identify some general factors that hinder or facilitate its process and impact. These factors address, for example, the timely involvement of young people with a chronic condition, the flexibility and open mind of professionals and the availability of support, time and resources.

Looking closely, it can be concluded that professionals have most influence on the factors identified in this thesis. It is up to them to involve young people with a chronic condition, to listen to and act upon their contributions, to provide the right support and to take care of practicalities such as budget and planning. This is the result of different positions. For 
most young people with a chronic condition, PPI is something they do on the side. They combine PPI with their daily lives and pursuits towards adulthood, such as living independently from their families, building their own social life and making school and career choices. ${ }^{24-26}$ For most professionals, PPI is part of their (paid) work. In virtually all research and innovation projects, professionals obtain funding and therefore bear responsibility for successful completion of projects. ${ }^{27,28}$

Due to these differences, professionals pose the question 'Would you work with me?' - the title of this thesis - more often than young people with a chronic condition. This creates a power imbalance in which professionals are responsible for the inclusion of young people with a chronic condition in decision making. The literature confirms that those who invite others to be involved generally decide who can be involved and who cannot, how much power is shared and what contributions are incorporated in decision making within projects. ${ }^{29,30}$ This leads to the paradoxical situation in which professionals have the power to decide for (young) health service users how and when they are involved in a process that revolves around values of sharing power. ${ }^{15,30}$ This discrepancy is not easily resolved. Young people with a chronic condition remain largely dependent on the extent to which professionals are willing to take on a less directive role and share their power. ${ }^{31}$

Despite this, Locock and colleagues noted that health service users cannot be seen as 'lacking agency and ultimately always under the thumb of [professionals]'. ${ }^{28} \mathrm{~A}$ gradual shift is taking place in which experiential knowledge is increasingly valued and thus powerful. In addition, endorsement of PPI by funders and scientific journals is constraining professionals' power to resist it. Chapter 3 of this thesis shows that policies mandating PPI can also increase the power of young people with a chronic condition. Due to these shifts, PPI of young health service users is now becoming increasingly indisputable.

\section{Evaluation of impact}

This thesis showed that young people with a chronic condition and professionals firmly believe that PPI improves the quality of projects and benefits those involved. This confirms the general conviction in the literature that PPI leads to many forms of positive impact. ${ }^{32,33}$ However, notions on impact are often based on (vague) expectations and hindsight contemplations. In addition, they are rarely substantiated by data. A similar finding was reported by Cook and colleagues, who noticed that professionals found it difficult to describe impact beyond the meaning PPI had for the health service users they had involved. ${ }^{34}$ To learn from previous experiences, more robust evaluation of impact is indispensable. This provides insight into whether PPI yields the desired achievements and contributes to our understanding of what works, for whom and in what circumstances. ${ }^{7,8}$ Next to this, it could help building the case for PPI, improve its overall recognition and protect continued funding. ${ }^{8}$ 
A first step towards more robust evaluation is a clearer specification of impact. As became clear in chapter 6 of this thesis, this helps making a distinction between impact that is actually aimed for and secondary impact. In virtually none of the current studies on PPI of young people with a chronic condition, it is predetermined what impact is aimed for. Rather, all impact is retrospectively labelled as an indicator for successful PPI. ${ }^{35}$ It is very likely that this has contributed to the predominantly positive results that are currently reported regarding PPI of young people with a chronic condition. The perspectives on meaningful impact identified in chapter 6 of this thesis are a valuable aid for young people with a chronic condition and professionals to specify the impact they desire.

Not only the specification, but also the measurement of impact is an issue in PPI. This thesis found a general hesitance among professionals to measure impact. The literature on PPI of health service users in general also describes this hesitance. Different reasons are provided. A first reason is that it is difficult to translate impact of PPI into measurable indicators. ${ }^{36}$ Another reason is the context-dependency of PPI, which makes it nearly impossible to compare PPI efforts in different projects. ${ }^{36,37}$ Also, PPI can have unexpected and unintended forms of impact which could be missed when focusing on measuring predetermined forms of impact. ${ }^{34,38}$ Some have argued that measurement of impact places too much emphasis on the (positive) outcomes of PPI and ignores negative forms of impact and important aspects of PPI processes. ${ }^{4,37}$ Remarkably, most of these reasons assume that impact should be measured using traditional, quantitative research methods, such as RCTs. ${ }^{36}$ They assume impact should always be operationalized into quantifiable indicators, such as the number of PPI activities and people involved. There are, however, an increasing number of qualitative or mixed methods approaches available that can take into account the complexities of PPI and the measurement of its impact. This thesis provides examples of methods that can be applied to evaluate PPI and its impact.

Some have raised fundamental objections against impact measurement, since they consider PPI an end in itself, not a means to an end. They consider the process of PPI most valuable, conceptualizing PPI as a social practice of dialogue and learning between researchers and the public. ${ }^{4,36}$ It is, however, a misconception that young people with a chronic condition and professionals invest their time in PPI just to do PPI. Chapter 6 demonstrates that they generally have other aims, such as improving the quality of projects, increasing mutual understanding, creating a more inclusive society and doing justice to young people's rights. Specifying and monitoring PPI aims gives direction to its processes. It prevents PPI from becoming a tick box exercise, in which PPI is done for the sake of PPI. ${ }^{39}$ Moreover, monitoring the progress in achieving these aims can be a valuable motivator for those involved. 


\section{Methodological considerations}

An important strength of this thesis is that diverse data collection methods are applied to obtain insight into PPI of young people with a chronic condition. Qualitative (chapter 4), quantitative (chapter 6) and mixed methods (chapters 5 and 7) studies address the perspectives of both professionals (chapters 5, 6 and 7) and young people with a chronic condition (chapters 4, 5, 6 and 7). The combination of multiple data collection methods makes it possible to study PPI of young people with a chronic condition from different angles and provides rich insights into factors that affect successful PPI and its impact. Another strength is the application of research methods that have not been used before in this field, such as multilevel analysis (chapter 6) and Q methodology (chapter 7). This contributes to a better understanding of some complex issues in PPI, such as measuring impact. A third strength is the PPI of young people with a chronic condition in the studies presented in this thesis. They were involved in various parts of different studies, by codeveloping or reviewing data collection methods (chapters 6 and 7), interpreting results (chapter 4) or co-writing (chapter 5). This helped to develop data collection methods that suit study participants and to reflect on our findings and place them in the right context. It also led to the formulation of practical tips that are relevant and understandable for young people with a chronic condition and professionals (chapter 4).

Some limitations of the studies presented in this thesis should be noted as well. The first concerns the generalizability of the findings. Most findings are based on the Care and Future Prospects program of the Dutch fund FNO and may therefore predominantly apply to this setting and the Dutch context. However, the program hosted a diversity of projects addressing various topics, such as school, work, sports and care, over a period of three years, which improves generalizability. Nevertheless, it would be valuable to conduct evaluations on PPI in other funding programs or calls that require PPI of young people with a chronic condition, especially since they are now increasing in numbers. Another limitation is that the studies in this thesis predominantly concern young people with a chronic condition aged 20 years or older and with a relatively high education level. All of them were able to communicate verbally, and most at a relatively high level. Younger people with a lower education level were very difficult to find. The findings of this thesis may therefore not completely apply to them.

\section{Implications for practice}

\section{PPI of young people with a chronic condition}

It is recommended to involve young people with a chronic condition in research and innovation projects that address their lives and wellbeing. According to the UNCRC, it is their fundamental right to have a say in matters that affect them. ${ }^{3}$ This thesis demonstrates that PPI can be a valuable means to do justice to this right. Many other forms of positive 
impact were also found. For example, PPI can benefit the young people with a chronic condition involved in projects, since they obtain new knowledge and skills and become more confident. Professionals do benefit by feeling more committed to their projects and obtaining a better understanding of young people with a chronic condition and their lives. PPI can also improve the quality of projects, since they are more in line with the needs and experiences of young people with a chronic condition.

\section{Sharing decisions about the PPI process}

This thesis shows that decisions about PPI, e.g. roles and responsibilities and support, are ideally made in consultation between young people with a chronic condition and professionals. This increases the match between PPI activities and the experiences and abilities of young people with a chronic condition. In addition, it can help young people with a chronic condition to understand what is expected from them and what their contributions will be. Useful tools and methods have been developed to aid in sharing decisions about PPI activities, such as involvement matrices. ${ }^{22,23}$ Also helpful is Franks' method of creating so-called 'pockets' of PPI. This helps discussing the parts of a project young people with a chronic condition would like to undertake and the parts they prefer professionals to undertake. ${ }^{40}$

\section{Creating the right conditions for PPI}

This thesis demonstrates that PPI is not something that comes naturally: it needs to be well prepared. Especially professionals bear a responsibility to create the right conditions for sharing decision making power within projects. They need to make sufficient time and resources available, timely involve young people with a chronic condition and provide adequate support. More importantly, they need to take on a less directive role than in traditional research and innovation projects. ${ }^{31}$ Young people with a chronic condition need to be committed to their involvement, make sure they are available and take their place. Naturally, this is a two-way street: commitment among professionals facilitates commitment among young people with a chronic condition, and the other way around. In chapter 4, practical tips are provided that can aid them in their collaboration.

\section{Evaluation of PPI and its impact}

To learn from previous experiences, robust evaluation of PPI is indispensable. This thesis demonstrates that clearly specifying meaningful impact in advance of PPI processes can facilitate critical evaluation, since it helps to make a distinction between impact that was actually aimed for and secondary impact. The perspectives identified in chapter 6 are a valuable aid for specifying the desired impact and translating this into measurable indicators. Indicators can be evaluated using methods that are adapted to their nature: some are best measured using quantitative methods, other require qualitative or mixed methods. Ideally, young people with a chronic condition and professionals reflect together 
on the achievement of the specified impact. It can also be valuable to invite an objective outsider.

\section{Implications for future research}

\section{High quality research}

There is a need for more high quality research on PPI of young people with a chronic condition. This research should apply the principles identified in chapter 3 of this thesis. First, it should clearly report what is meant by PPI and how it was evaluated. Useful tools have been developed to aid in this, such as the GRIPP-checklist. ${ }^{41}$ Second, research should be conducted systematically. The Public Involvement Impact Assessment Framework ${ }^{42}$ and Quality Involvement Framework ${ }^{43}$ can aid in this process. When evaluating PPI practice, it can be of added value to invite an objective outsider in conducting the study. Finally, research should learn from and build on previous work.

\section{Inclusion of different perspectives}

As is demonstrated in this thesis, research can solely provide a complete picture of PPI processes and impact, when all perspectives are taken into account. It should therefore address the experiences of both young people with a chronic condition and professionals involved in PPI practice.

\section{Enhancing diversity}

The studies in this thesis predominantly concern young people with a chronic condition who were aged 20 years or older, had a relatively high education level and were able to communicate verbally. More research should be conducted on PPI of hard-to-reach or hard-to-involve groups of young people with a chronic condition.

\section{Unfavourable impact}

This thesis predominantly focused on the positive impact of PPI. Future research should address potential forms of unfavourable impact as well. ${ }^{4}$ These forms of impact can also provide insight into the question of what works (and what not).

\section{Operationalisation of meaningful impact}

The perspectives that are identified in chapter 6 provide leads for the operationalisation of meaningful impact in PPI evaluation. Future research should build on this work and create valid operationalisations, both qualitative and quantitative. 


\section{References}

1. Mayo M. Children's and young people's participation in development in the South and in urban regeneration in the North. Prog Dev Stud. 2001;1(4):279-293. doi:10.1177/146499340100100401

2. Wilson $P$, Mathie E, Keenan J, et al. ReseArch with Patient and Public invOlvement: a RealisT evaluation: The RAPPORT study. Health Services and Delivery Research. 2015;3(38). doi: $10.3310 /$ hsdr03380

3. United Nations General Assembly. Convention on the Rights of Child, 1989.

4. Russell J, Fudge N, Greenhalgh T. The impact of public involvement in health research: what are we measuring? Why are we measuring it? Should we stop measuring it? Res Involv Engagem. 2020;6(63):1-8. doi:10.1186/s40900-020-00239-w

5. Staley K, Buckland SA, Hayes H, Tarpey M. 'The missing links': understanding how context and mechanism influence the impact of public involvement in research. Health Expect. 2014;17(6):755764. doi:10.1111/hex.12017

6. Mockford C, Staniszewska S, Griffiths F, Herron-Marx S. The impact of patient and public involvement on UK NHS health care: A systematic review. Int J Qual Health Care. 2012;24(1):2838. doi:10.1093/intqhc/mzr066

7. Staley K. 'Is it worth doing?' Measuring the impact of patient and public involvement in research. Res Involv Engagem. 2015;1(1):1-10. doi:10.1186/s40900-015-0008-5

8. Staniszewska S, Herron-Marx S, Mockford C. Measuring the impact of patient and public involvement: The need for an evidence base. Int J Qual Health C. 2008;20(6):373-374. doi:10.1093/intqhc/mzn044

9. FNO Zorg voor Kansen. Jongeren INC: Programmatekst 2020-2023. Published 2020. Accessed October 30, 2020. https://www.fnozorgvoorkansen.nl/wpcontent/uploads/2020/01/Publieksversie-Programmatekst-Jongeren-INC-26-nov.pdf.

10. ZonMw. Relevantiecriteria ZonMw. Published 2017. Accessed June 22, 2020. https://www.zonmw.nl/nl/subsidies/relevantiecriteria/.

11. Marshall Z, Nixon S, Nepveux D, et al. Navigating risks and professional roles: Research with lesbian, gay, bisexual, trans, and queer young people with intellectual disabilities. $J$ Empir Res Hum Res Ethics. 2012;7(4):20-33. doi:10.1525/jer.2012.7.4.20

12. Stevenson M. Participatory data analysis alongside co-researchers who have Down syndrome. J App/ Res Intellect Disabil. 2014;27(1):23-33. doi:10.1111/jar.12080

13. Lightfoot J, Sloper P. Having a say in health: involving young people with a chronic illness or physical disability in local health services development. Children \& Society. 2003;17(4). doi:10.1002/chi.748

14. Franklin A, Sloper P. Supporting the participation of disabled children and young people in decision-making. Child Soc. 2009;23:3-15. doi:10.1111/j.1099-0860.2007.00131.x

15. Arieli D, Friedman VJ, Agbaria K. The paradox of participation in action research. Action Res. 2009;7(3):263-290. doi:10.1177/1476750309336718

16. Wicks PG, Reason P. Initiating action research. Action Research. 2009;7(3):243-262. doi:10.1177/1476750309336715

17. Hart R. Children's participation: From tokenism to citizenship. Florence: UNICEF; 1992.

18. Arnstein S. A ladder of citizen participation. J Am I Planners. 1969;35(4):216-224. doi:10.1080/01944366908977225 
19. Dedding C. Delen in macht en onmacht: Kindparticipatie in de (alledaagse) diabeteszorg. [PhD thesis]. Amsterdam: University of Amsterdam; 2009.

20. Tritter JQ, McCallum A. The snakes and ladders of user involvement: Moving beyond Arnstein. Health Policy. 2006;76(2):156-168. doi:10.1016/j.healthpol.2005.05.008

21. Hart R. Stepping back from "the ladder": Reflections on a model of participatory work with children. In: Reid A, Bruun B, Nikel J, Simovska V, eds. Participation and Learning: Perspectives on Education and the Environment, Health and Sustainability. Springer; 2008:19-31.

22. Smits DW, van Meeteren K, Klem M, Alsem M, Ketelaar M. Designing a tool to support patient and public involvement in research projects: The Involvement Matrix. Res Involv Engagem. 2020;6(1):1-7. doi:10.1186/ s40900-020-00188-4

23. Moser A, Stoffers E, Melchior I, et al. Toolkit Patiëntenparticipatie in de Palliatieve Zorg: Onderzoeks-, Onderwijs- En Praktijkprojecten. Heerlen/Sittard: Lectoraat Autonomie en participatie van chronisch zieken Zuyd Hogeschool en Zorgbelang Limburg; 2018.

24. Waldboth V, Patch C, Mahrer-Imhof R, Metcalfe A. Living a normal life in an extraordinary way: A systematic review investigating experiences of families of young people's transition into adulthood when affected by a genetic and chronic childhood condition. Int I Nurs Stud. 2016;62:44-59. doi:10.1016/j.jjurstu.2016.07.007

25. Taylor RM, Gibson F, Franck LS. The experience of living with a chronic illness during adolescence: A critical review of the literature. J Clin Nurs. 2008;17(23):3083-3091. doi:10.1111/j.13652702.2008.02629.x

26. Sattoe J. Growing up with a chronic condition: Challenges for self-management and selfmanagement support. [PhD thesis]. Rotterdam: Erasmus University; 2015.

27. Fløtten KJØ, Guerreiro AIF, Simonelli I, Solevåg AL, Aujoulat I. Adolescent and young adult patients as co-researchers: A scoping review. Health Expect. 2021;24:1044-1055 doi:10.1111/hex.13266

28. Locock L, Boylan A-M, Snow R, Staniszewska S. The power of symbolic capital in patient and public involvement in health research. Health Expect. 2017;20(5):836-844. doi:10.1111/hex.12519

29. Cornwall A. Beneficiary Consumer Citizen: Perspectives on Participation for Poverty Reduction. Stockholm: Swedish International Development Cooperation Agency; 2002.

30. Woelders S. Power-full patient participation: Opening spaces for silenced knowledge. [PhD thesis]. Amsterdam: Vrije Universiteit Amsterdam; 2009.

31. Curtin M, Murtagh J. Participation of children and young people in research: Competence, power and representation. BrJ Occup Ther. 2007;70(2):67-72. doi:10.1177/ 030802260707000204

32. Bailey $S$, Boddy $K$, Briscoe $S$, Morris $C$. Involving disabled children and young people as partners in research: A systematic review. Child Care Health Dev. 2015;41(4):505-514. doi:10.1111/cch.12197

33. Brady LM, Preston J. How do we know what works? Evaluating data on the extent and impact of young people's involvement in English health research. Research for All. 2020;4(2):194-206. doi:10.14324/RFA.04.2.05

34. Cook T, Boote J, Buckley N, Vougioukalou S, Wright M. Accessing participatory research impact and legacy: Developing the evidence base for participatory approaches in health research. Educ Action Res. 2017;25(4):473-488. doi:10.1080/09650792.2017.1326964

35. Staniszewska S, Adebajo A, Barber R, et al. Developing the evidence base of patient and public involvement in health and social care research: the case for measuring impact. Int $J$ Consum Stud. 2011;35(6):628-632. doi:10.1111/j.1470-6431.2011.01020.x 
36. Staley K, Barron D. Learning as an outcome of involvement in research: what are the implications for practice, reporting and evaluation? Res Involv Engagem. 2019;5(1):1-9. doi:10.1186/s40900019-0147-1

37. Barber R, Boote JD, Parry GD, Cooper CL, Yeeles P, Cook S. Can the impact of public involvement on research be evaluated? A mixed methods study. Health Expect. 2012;15(3):229-241. doi:10.1111/j.1369-7625.2010.00660.x

38. Trickett EJ, Beehler S. Participatory action research and impact: an ecological ripples perspective. Educ Action Res. 2017;25(4):525-540. doi:10.1080/09650792.2017.1299025

39. Preston J, Stones SR, Davies H, Phillips B. How to involve children and young people in what is, after all, their research. Arch Dis Child. 2019;104(5):494-500. doi:10.1136/archdischild-2018315118

40. Franks M. Pockets of participation: Revisiting child-centred participation research. Child Soc. 2011;25(1):15-25. Doi:10.1111/j.1099-0860.2009.00258.x

41. Staniszewska S, Brett J, Mockford C, Barber R. The GRIPP-checklist: Strengthening the quality of patient and public involvement reporting in research. Int J Technol Assess Health Care. 2011;27(4):391-399. doi:10.1017/S0266462311000481

42. Collins M, Long R, Page A, Popay J, Lobban F. Using the Public Involvement Impact Assessment Framework to assess the impact of public involvement in a mental health research context: $A$ reflective case study. Health Expect. 2018;21(6):950-963. doi:10.1111/hex.12688

43. Morrow $E$, Ross $F$, Grocott $P$, Bennett J. A model and measure for quality service user involvement in health research. Int J Consum Stud. 2010;34(5):532-539. doi:10.1111/j.1470-6431.2010.00901.x 



\section{Impact}

\section{paragraph}


Worldwide, young people with a chronic condition are increasingly involved in research and innovation projects in health and social care that concern them. Great expectations are raised about the impact of this so-called Patient and Public Involvement (PPI). Consequently, more and more young people with a chronic condition and professionals are investing their time in PPI. However, it is unclear how different forms of impact can be achieved. In addition, there is limited high quality data available on the actual achievement of this impact. These issues were addressed in this thesis. This chapter reflects on the scientific and societal impact of this thesis and the dissemination of its findings.

\section{Scientific impact}

This thesis has scientific relevance, as it adds knowledge to an important field that made limited progress in the past decades. First, it demonstrates how the quality of research on PPI of young people with a chronic condition can be improved. The current scientific evidence base would benefit from improved reporting, the application of more systematic and objective measures, the inclusion of both young people's and professionals' perspectives and the application of innovative methods to build on previous work. Second, this thesis monitored over thirty projects that involved young people with a chronic condition to learn about factors that can hinder or facilitate PPI. The current evidence base is predominantly based on reports about PPI in a single project. The overarching analysis of PPI processes in many different projects led to solid evidence regarding the best ways to work together with young people with a chronic condition. Third, this thesis adds insights that are valuable to the continuous scientific debate about the impact of PPI. Many questions exist about whether impact should be measured and, if so, how it should be measured. This thesis demonstrates that impact measurements are always of value, regardless of the reasons for doing PPI. In addition, it provides extensive insight in the definition of impact and how it can be operationalized and measured. Researchers can use these insights to improve PPI evaluations and enhance the evidence base about the difference PPI can make and the approaches that work best to achieve different forms of impact.

Although the findings of this thesis primarily apply to PPI of young people with a chronic condition, they also have merit for PPI of other health service users. For example, the findings regarding impact can create awareness among scientific researchers that impact means something different to different stakeholders. They also contain the general message that measuring impact is very suitable to learn about the achievement of the desired impact and what works. In addition, the evaluation methods used in this thesis can serve as an example for the evaluation of PPI in general. 


\section{Societal impact}

This thesis can facilitate the wider implementation of PPI of young people with a chronic condition. It addresses different ways of involving young people with a chronic condition in projects. In chapter 4, lessons learned and practical tips are provided on how to organize PPI and how to deal with some common issues, such as sharing power, reimbursing the young people involved and making time for PPI. These lessons can aid inexperienced young people with a chronic condition and professionals, such as researchers, health care providers and policy makers, to shape their collaboration and achieve their aims. They are also valuable to those who already do PPI, but struggle with specific challenges or wish to improve their collaboration.

Further implementation of PPI of young people with a chronic condition can also lead to wider societal impact. First, it helps to improve the quality of research and innovation, as these are more in line with the needs and wishes of young people with a chronic condition. This can lead to improvements in the care services they use and eventually enhance their quality of life and participation in society. Second, it does justice to the right of young people to be heard in matters that concern them. It facilitates the use of their talents and encourages them to take part in society as an active and democratic citizen. Third, it improves the way professionals are doing their job and increases their commitment, as they obtain a better understanding of young people with a chronic condition and their lives.

\section{Dissemination of findings}

Various channels were used to disseminate the findings of this thesis to young people with a chronic condition, researchers, policy makers, health care providers and other stakeholders. All the articles in this thesis were published (or accepted for publication) in international, peer-reviewed journals. Three of these articles are accessible free of charge, since they are published open access. All articles are available through the Nivel repository. The articles were generally quickly accepted for publication, suggesting a general need for research on this topic. The findings of this thesis were presented at national and international conferences, such as the International Conference on Integrated Care 2020 and the 2019 CareDays 'Science for citizens - Citizens for science' in the Netherlands.

The above mentioned channels predominantly reach researchers. Other channels were used to disseminate the findings to a broader group of stakeholders, such as young people with a chronic condition, policy makers and health care providers. Workshops were organized for them, for example at the Dutch conference 'Krachtpatsers' by FNO. In addition, the findings of the studies reporting on data retrieved from the Care and Future Prospects program are also available in Dutch, in the report 'Overkoepelend Evaluatieonderzoek: Programma Zorg én Perspectief'. Together with young people with a chronic condition, this 
report was also translated into a youth friendly booklet. The practical tips described in chapter 4 of this thesis were disseminated among young people with a chronic condition and professionals in the Netherlands through an accessible and appealing infographic. 


Summary 
The involvement of young people with a chronic condition in decisions related to health and social care is receiving increasing attention. After the ratification of the United Nations Convention on the Rights of the Child (UNCRC) in 1989, the awareness that young people have a right to have a say in matters that affect them accelerated. From that time onwards, research and innovation in the field of health and social care has increasingly been carried out with young people with a chronic condition, rather than solely for them. The UNCRC is now ratified by almost all countries in the world, with the Netherlands being among one of the first.

Chapter 1 of this thesis describes the background on working together with health service users in research and innovation projects. This is also called Patient and Public Involvement (PPI). The past decades, PPI gained increasing momentum. There are several arguments for this. From a moral point of view, involvement in decisions that will (eventually) affect people's lives is a fundamental right. In addition, there is a belief that PPI will ultimately lead to better research and innovation projects. From an educational point of view, PPI is an educational and enriching experience for all involved.

To date, most research on PPI focuses on adult health service users. Relatively little is known about PPI of younger health service users, such as young people with a chronic condition. Many questions continue to exist about the ways they can be involved in research and innovation projects and about the impact of their involvement. Therefore, this thesis aimed to answer the following questions:

1. What developments in PPI of young people with a chronic condition can be seen in the existing literature over the past decades?

2. What factors hinder or facilitate (1) the process of PPI of young people with a chronic condition in research and innovation projects and (2) the impact of their PPI?

3. What is meaningful impact in the context of PPI of young people with a chronic condition in research and innovation projects, and how can this be evaluated?

\section{Main findings}

Chapter 2 describes the developments in the existing literature on PPI of young people with a chronic condition. Literature searches were conducted in the scientific databases of Cinahl, Embase, PsycINFO, PubMed and Scopus. Studies were included, when they described PPI of young people with a chronic condition, contained empirical data, were written in English and were published after 1990. Twenty-three studies out of 4993 initial hits met the inclusion criteria. The literature review showed that the attention for PPI of young people with a chronic condition has increased. Of the twenty-three included studies, fifteen were published in the last decade. Furthermore, the literature review provided insight into the process and impact of PPI of young people with a chronic condition. The 
included studies showed that there are many different ways to involve young people with a chronic condition in research and innovation projects. Challenges were reported as well, such as the time that PPI costs, the lack of diversity of the young people involved and the changes in power relations. All studies emphasized that PPI has a positive impact, for example, on the quality of projects and on the people involved. Although this sounds promising, the literature review also showed that most studies on PPI of young people with a chronic condition are of low quality. Four major shortcomings were identified: (1) studies do not adequately report where findings come from; (2) systematic and objective methods are rarely used to evaluate PPI; (3) studies rarely address the perspectives of young people; and (4) studies seldomly build on previous research. To move the field forward and to address the reported challenges in PPI, it is important that future research addresses these shortcomings.

Chapter 3 addresses the experiences of young people with a chronic condition with PPI through a panel. For three years, a youth panel was followed. This panel was a structural part of a program of the Dutch fund FNO, called Care and Future Prospects (Box 1). The aim of Care and Future Prospects was to promote the social position of young people with a chronic condition in the Netherlands. During the program, six focus groups with four to eleven panel members were conducted. The results showed that panel members took part in multiple projects and activities, such as assessing project applications, evaluating the progress of projects and organizing a political lobby. They were enthusiastic about their role in the panel. The structural nature of the panel enabled them to achieve personal growth and professionalization of their PPI. Consequently, panel members experienced an increasing impact on the program and separate projects, and on national politics. The main conclusion of this chapter was therefore that a structural form of PPI, such as a youth panel, is suitable to facilitate meaningful PPI of young people with a chronic condition. An important side note, however, is that the panel predominantly attracted young people who were in their twenties and highly educated and appeared to be less appealing to lower educated and younger people with a chronic condition.

\section{Box 1. The Care and Future Prospects program}

Chapters 3, 4 and 5 describe studies for which data were collected in the Care and Future Prospects program of $\mathrm{FNO}$, a fund that stimulates and supports initiatives that improve the opportunities of vulnerable people. In the Care and Future Prospects program, FNO funded 45 research and innovation projects to improve the position of young people with a chronic condition in five areas: care, school, work, sport and personal strength. Output from these projects was, for example, an instrument to improve selfmanagement, a method to facilitate the transition to adult care and a digital platform 
about performing physical activity with a disability. PPI of young people with a chronic condition was an important element of the Care and Future Prospects program. A panel was set up, consisting of young people with various chronic conditions, such as rheumatism, diabetes and acquired brain injury. Tasks of this panel were to inform the program, the 45 projects hosted within the program and the national politics about the experiences of young people with a chronic condition and to advise on possible solutions. Within the program, for example, it played a significant role in the assessment of project applications. Project teams that received funding were formally obliged to involve one panel member that was assigned to them. In addition to the youth panel, project teams were also asked to involve individual young people with a relevant chronic condition. For example, projects about young people with rheumatism were asked to collaborate with young people with rheumatism. Project teams were allowed to decide for themselves - preferably in consultation with the young people - how they would shape the PPI in their project.

In addition to the involvement of the youth panel, the Care and Future Prospects program stimulated the involvement of individual young people with a chronic condition in the separate research and innovation projects they hosted (Box 1). Chapter 4 illustrates the lessons learned from the PPI of these young people. Various data sources were used for this. All individual young people involved in a project were invited to complete a questionnaire. All project coordinators were asked or obliged to write project reports and to fill out an Involvement Matrix (a table in which the roles of young people in specific phases of a project can be specified). Five projects were extensively studied in a case study. Together, the different data sources contained information about PPI in 33 projects. For most projects, information from more than one data source was available. Combining the findings from all data sources resulted in valuable lessons about PPI of young people with a chronic condition. The lessons were divided into six themes, including practicalities, involvement from the start, roles and responsibilities, support, flexibility and evaluation of process and outcomes. The lessons emphasized that meaningful PPI requires effort, time and resources from both young people and professionals, from start to finish. It is important to continuously discuss roles and responsibilities and whether they (still) align with everyone's wishes and needs. The chapter provides practical examples of challenges that young people and professionals encountered in PPI and tips on how to deal with them.

Chapter 5 also addresses the involvement of individual young people with a chronic condition in the separate research and innovation projects in the Care and Future Prospects program (Box 1). It explored the impact of PPI on project outcomes, using quantitative methods. Three hypotheses were tested: to increase the impact of PPI, young people should (1) be provided with as much influence as possible by being involved as (co-)deciders, (2) be involved in as many activities as possible within a project and (3) be involved from the 
very beginning of a project. Project coordinators filled out project reports with questions about PPI, i.e. to what extent were young people with a chronic condition involved, were they involved as co-deciders and were they involved in developing the project idea. Young people with a chronic condition filled out questionnaires with questions about their involvement, i.e. the number of PPI activities and the self-perceived importance for the project. They also answered questions about project outcomes. These addressed, for example, the extent to which a project had contributed to their self-confidence, independence and participation in school, work and sport. Based on these questions, an overarching scale for project outcomes was developed. Multilevel analyses were performed on the data, which concerned seventeen reports from project coordinators and 146 questionnaires from young people with a chronic condition. None of the hypotheses were confirmed by the results: it did not matter for project outcomes whether or not young people were involved as (co-)decision makers, whether they were involved in as many activities as possible within a project and whether they were involved from the very beginning of a project. A positive relation was, however, found between self-perceived importance of young people for a project and the project results they experience. The chapter therefore suggests that organizing meaningful PPI activities is more important for achieving impact than the number of activities and the amount of influence provided to young people.

Chapter 6 provides in-depth insight into the perspectives of young people with a chronic condition and researcher on meaningful impact of PPI in research. A Q methodology study was conducted among 20 young people and 26 researchers with experience in PPI. This method combines qualitative and quantitative techniques to systematically study the ways people think about a certain topic. Participants ranked statements about impact, based on their agreement with them. A table in the form of an inverted pyramid was employed, which allowed them to put some statements on the far right (most agree) or left (least agree) and many statements in the middle (neutral). Statements addressed the types of impact that can be achieved with PPI (e.g. "Young people gain new knowledge and skills"). In interviews, participants reflected on their rankings. Factor analysis was performed to identify patterns in the way participants ranked the statements. The interviews were used to determine and interpret the final factor solution. Four factors, representing four distinct perspectives on meaningful impact of PPI were identified: improving the quality of research, facilitating dialogue and understanding, achieving equality and inclusivity and doing justice to the rights of young people with a chronic condition. The first two perspectives were mainly based on rankings of researchers, the last two on those of young people. The findings also showed that there is a distinction between meaningful impact that young people and researchers actually strive for and (unexpected) secondary impact. Secondary impact concerns the forms of impact that do not directly contribute to the aims that young people and professionals had with their collaboration. The findings in this chapter have important 
implications for measuring impact. It is important to include all perspectives in impact evaluations and to discuss the desired impact in advance of PPI processes. The retrieved perspectives can serve as an aid in discussing different viewpoints on meaningful impact and in formulating operational indicators for meaningful impact.

\section{Discussion and conclusion}

Chapter $\mathbf{7}$ is the concluding chapter, in which the main findings are addressed and reflected upon. It also describes practical implications and recommendations for future research. In this chapter, it is discussed that the scientific evidence base for PPI of young people with a chronic condition is of low quality. As a result, there is insufficient insight into what works in PPI, in which context and which form of PPI has the most impact.

The systematic study of more than thirty research and innovation projects involving young people with a chronic condition provided important insights into the ways in which young people with a chronic condition and professionals can work together. It was found that PPI can take many forms. Examples are provided of young people being involved as members of project teams, through panels and advisory boards and through engaging sessions. There is not one right method. This thesis also identified some general factors that facilitate or hinder PPI of young people with a chronic condition. It is, for example, important that the roles and responsibilities of young people are clear and match their experience and skills. Ideally, young people and professionals determine together how they shape PPI. Fundamental to a successful PPI process is also that professionals take young people with a chronic condition seriously and act on their input. Other facilitating factors are involving young people from an early stage, providing them with support and making sufficient time and resources available. An important hindering factor in PPI is the vulnerability and difficult recruitment of young people with a chronic condition.

Finally, this thesis showed that young people with a chronic condition and professionals are convinced that PPI leads to many forms of positive impact. However, many notions on impact were vague, hindsight contemplations which were not substantiated by data. An important way forward is for young people with a chronic condition and professionals to predetermine what they wish to achieve with PPI. Are they doing it to improve the quality of projects, to achieve more mutual understanding, to create a more inclusive society or to do justice to young people's rights? A clear specification of the desired impact helps focusing measurements on impact that matters to those involved. It is important to realize that these measurements do not necessarily have to be performed using traditional, research methods. An increasing number of qualitative and mixed methods are now available that can take into account the complexities of PPI. 




\section{Nederlandse samenvatting}




\section{'Je kan niet voor een doelgroep werken zonder de doelgroep te betrekken. Dat is de grootste fout die altijd wordt gemaakt, dat er over jongeren gesproken wordt en niet met ze.'}

Dit is een uitspraak van een jonge vrouw met een chronische aandoening die zich actief inzet voor het welzijn van leeftijdsgenoten met een chronische aandoening. Het illustreert een belangrijke reden waarom het betrekken van jongeren met een chronische aandoening in beslissingen in de sociale en gezondheidszorg steeds meer aandacht krijgt. Na de ratificatie van het Verdrag van de Rechten van het Kind van de Verenigde Naties in 1989 nam het bewustzijn toe dat jongeren het recht hebben om inspraak te hebben in zaken die over hen gaan. Sindsdien worden onderzoeks- en innovatieprojecten in de zorg steeds vaker met jongeren met een chronische aandoening gedaan, in plaats van alleen voor hen. Het verdrag is nu geratificeerd in bijna alle landen in de wereld, met Nederlands als één van de eersten.

In hoofdstuk 1 van dit proefschrift wordt de achtergrond van het samenwerken met zorggebruikers in onderzoeks- en innovatieprojecten beschreven, ook wel Patient and Public Involvement (PPI) genoemd. De afgelopen decennia heeft PPI om verschillende redenen steeds meer momentum gekregen. Vanuit moreel oogpunt is betrokkenheid bij beslissingen die (uiteindelijk) het leven van mensen zullen beïnvloeden een fundamenteel recht. Daarnaast bestaat de overtuiging dat PPI uiteindelijk tot betere onderzoeks- en innovatieprojecten leidt. Vanuit educatief oogpunt is PPI een leerzame en verrijkende ervaring voor alle betrokkenen.

Tot op heden richt het meeste onderzoek over PPI zich op volwassen zorggebruikers. Relatief weinig is bekend over PPI van jonge zorggebruikers, zoals jongeren met een chronische aandoening. Er zijn nog veel vragen over de manieren waarop zij betrokken kunnen worden bij onderzoeks- en innovatieprojecten en over de impact van hun betrokkenheid. De volgende vragen stonden daarom centraal in het proefschrift:

1. Welke ontwikkelingen in PPI van jongeren met een chronische aandoeningen zijn zichtbaar in de literatuur van de afgelopen decennia?

2. Welke factoren belemmeren of faciliteren (1) het proces van PPI van jongeren met een chronische aandoening in onderzoeks- en innovatieprojecten en (2) de impact van hun PPI?

3. Wat is betekenisvolle impact in de context van PPI van jongeren met een chronische aandoening in onderzoeks- en innovatieprojecten, en hoe kan dit geëvalueerd worden? 


\section{Belangrijkste bevindingen}

Hoofdstuk 2 beschrijft de ontwikkelingen in de bestaande literatuur over PPI van jongeren met een chronische aandoening. Er is naar literatuur gezocht in de wetenschappelijke databases van Cinahl, Embase, PsycINFO, PubMed en Scopus. Studies werden geïncludeerd, wanneer ze PPI van jongeren met een chronische aandoening beschreven, empirische data bevatten, geschreven waren in het Engels en gepubliceerd waren na 1990. De zoektocht in de databases leverde 4993 studies op, waarvan er 23 voldeden aan de criteria. Het literatuuronderzoek liet zien dat de aandacht voor PPI van jongeren met een chronische aandoening is toegenomen. Van de 23 geïncludeerde studies, zijn 15 in het afgelopen decennium gepubliceerd. Daarnaast gaf het literatuuronderzoek inzicht in de bestaande kennis over het proces en de impact van PPI van jongeren met een chronische aandoening. De geïncludeerde studies lieten zien dat jongeren met een chronische aandoening op veel verschillende manieren betrokken kunnen worden bij onderzoeks- en innovatieprojecten. Er werden ook uitdagingen gerapporteerd, zoals de tijd die PPI kost, het gebrek aan diversiteit van de betrokken jongeren en de veranderingen in machtsverhoudingen. Alle studies benadrukten dat PPI positieve impact heeft, bijvoorbeeld op de kwaliteit van projecten en op de betrokkenen. Hoewel dit veelbelovend klinkt, liet het literatuuronderzoek ook zien dat de meeste studies over PPI van jongeren met een chronische aandoening van lage kwaliteit zijn. Vier belangrijke tekortkomingen werden geïdentificeerd: (1) studies rapporteren onvoldoende waar bevindingen vandaan komen; (2) er worden zelden systematische en objectieve methoden toegepast om PPI te evalueren;

(3) studies gaan zelden in op de perspectieven van jongeren; en (4) studies bouwen beperkt voort op eerder onderzoek. Om het veld verder te brengen en oplossingen te vinden voor de gerapporteerde uitdagingen in PPI, is het belangrijk dat toekomstig onderzoek deze tekortkomingen aanpakt.

Hoofdstuk 3 gaat over de ervaringen van jongeren met een chronische aandoening met PPI via een jongerenpanel. Voor het onderzoek is drie jaar lang een jongerenpanel gevolgd dat structureel onderdeel was van een programma van het fonds FNO, genaamd Zorg én Perspectief (Box 1). Dit programma beoogde de maatschappelijke positie van jongeren met een chronische aandoening in Nederland te bevorderen. Tijdens de duur van Zorg én Perspectief zijn zes focusgroepen gehouden, waaraan steeds vier tot elf leden van het jongerenpanel meededen. De panelleden hadden verschillende taken, zoals het beoordelen van projectaanvragen in het programma, het evalueren van de voortgang van gehonoreerde projecten en het organiseren van een politieke lobby. Ze waren enthousiast over hun rol in het panel. Het structurele karakter van het panel stelde hen in staat om persoonlijke groei en professionalisering van hun PPI te realiseren. Panelleden merkten daardoor een toenemende impact op het programma, de afzonderlijke projecten en de landelijke politiek. De belangrijkste conclusie van dit hoofdstuk is daarom dat een 
structurele vorm van PPI, zoals een jongerenpanel, geschikt is om betekenisvolle PPI van jongeren met een chronische aandoening mogelijk te maken. Een belangrijke kanttekening is echter dat het panel vooral uit twintigers en hoogopgeleiden bestond en minder aantrekkelijk leek voor lager opgeleide jongeren en tieners.

\section{Box 1. Het programma Zorg én Perspectief}

Hoofdstuk 3, 4 en 5 beschrijven studies waarvoor data verzameld is in het programma Zorg én Perspectief van FNO, een fonds dat initiatieven stimuleert en ondersteunt die de kansen van kwetsbare mensen vergroten. In het programma Zorg én Perspectief financierde FNO 45 onderzoeks- en innovatieprojecten om de positie van jongeren met een chronische aandoening te verbeteren op vijf terreinen: zorg, school, werk, sport en persoonlijke kracht. Output van deze projecten was bijvoorbeeld een instrument om zelfmanagement te verbeteren, een onderbouwde methode om de overgang naar volwassenenzorg te vergemakkelijken en een digitaal platform over sporten met een beperking.

PPI van jongeren met een chronische aandoening was een belangrijk element van het programma Zorg én Perspectief. Een panel werd opgezet, bestaande uit jongeren met verschillende chronische aandoeningen, zoals reuma, diabetes en niet-aangeboren hersenletsel. Taken van dit panel waren om het programma, de 45 projecten binnen het programma en de landelijke politiek te informeren over de ervaringen van jongeren met chronische aandoeningen en te adviseren over mogelijke oplossingen. Zo speelde het binnen het programma een belangrijke rol bij de beoordeling van projectaanvragen. Aan elk gehonoreerd project werd een panel toegewezen dat betrokken was bij de opzet, uitvoering en implementatie. Daarnaast werden projecten gevraagd - en later verplicht - om ook individuele jongeren erbij te betrekken met een chronische aandoening die relevant was voor het project. Zo werd aan projecten over jongeren met reuma gevraagd om samen te werken met jongeren met reuma. Projectteams mochten zelf beslissen liefst in overleg met de jongeren - hoe ze de PPI in hun project vorm zouden geven.

Naast de betrokkenheid van het jongerenpanel, stimuleerde Zorg én Perspectief de betrokkenheid van individuele jongeren met een chronische aandoening bij de afzonderlijke onderzoeks- en innovatieprojecten die zij financierden (Box 1). Hoofdstuk 4 beschrijft de geleerde lessen van de betrokkenheid van deze jongeren. Hiervoor is gebruik gemaakt van verschillende databronnen. Alle individuele jongeren die betrokken waren bij een project werden uitgenodigd om hierover een vragenlijst in te vullen. Alle projectleiders werden gevraagd dan wel verplicht om projectrapportages aan te leveren en een Participatiematrix in te vullen (een tabel waarin men kan aangeven welke rollen jongeren hebben in welke fasen van een project). Daarnaast zijn vijf projecten uitgebreid bestudeerd 
in een case study. Tezamen bevatten de verschillende databronnen informatie over PPI in 33 projecten, waarbij voor de meeste projecten meer dan één databron beschikbaar was. Het combineren van de bevindingen resulteerde in waardevolle lessen over PPI van jongeren met een chronische aandoening. De lessen zijn onderverdeeld in zes thema's, waaronder praktische zaken, betrekken vanaf het begin, rollen en verantwoordelijkheden, ondersteuning, flexibiliteit en evaluatie van proces en resultaten. De lessen onderstrepen dat betekenisvolle PPI inspanning, tijd en middelen vraagt van zowel jongeren als professionals, van begin tot eind. Het is belangrijk om continu te overleggen over rollen en verantwoordelijkheden en de aansluiting bij ieders wensen en behoeften. Het hoofdstuk geeft praktische voorbeelden van problemen die jongeren en professionals in PPI tegenkwamen en hoe ze hiermee omgingen. De lessen zijn daarnaast samen met jongeren vertaald naar praktische tips.

Hoofdstuk 5 gaat ook over de betrokkenheid van individuele jongeren met een chronische aandoening bij de afzonderlijke onderzoeks- en innovatieprojecten in Zorg én Perspectief (Box 1). Hierin wordt de impact van PPI op de uitkomsten van projecten onderzocht met behulp van kwantitatieve methoden. Drie hypotheses werden getoetst: om de impact van PPI te vergroten moeten jongeren (1) zo veel mogelijk invloed krijgen door betrokken te zijn als (mede)beslissers, (2) in zoveel mogelijk activiteiten binnen een project betrokken zijn en (3) betrokken zijn vanaf het eerste begin van een project. Om deze hypotheses te toetsen is gebruik gemaakt van projectrapportages, waarin projectleiders vragen beantwoordden over de mate waarin jongeren bij hun project betrokken waren, of zij hebben meebeslist tijdens de duur van het project en of ze waren betrokken bij de ontwikkeling van het projectidee. Daarnaast is gebruik gemaakt van vragenlijsten, waarin jongeren vragen invulden over het aantal activiteiten waarbij zij betrokken waren en de mate waarin zij ervaarden belangrijk te zijn voor het project. Ook beantwoordden jongeren vragen over projectuitkomsten. Deze gingen bijvoorbeeld over de mate waarin een project had bijgedragen aan hun zelfvertrouwen, onafhankelijkheid en participatie in school, werk en sport. Op basis van deze vragen is één overkoepelende schaal voor projectuitkomsten ontwikkeld. Multilevelanalyses zijn uitgevoerd op de data uit zeventien rapportages van projectleiders en 146 vragenlijsten van jongeren. Geen van de hypotheses werd bevestigd door de resultaten: het makkte voor projectuitkomsten niet uit of jongeren wel of niet betrokken waren als (mede)beslissers, of zij in zoveel mogelijk activiteiten binnen een project betrokken waren en of zij betrokken waren vanaf het eerste begin van een project. Wel werd een positieve relatie gevonden tussen de mate waarin jongeren zichzelf belangrijk vonden voor een project en de projectresultaten die zij ervaren. Het hoofdstuk suggereert daarom dat het organiseren van betekenisvolle PPI activiteiten belangrijker is voor bet bereiken van impact dan het aantal activiteiten en de hoeveelheid invloed die aan jongeren wordt gegeven. 
Hoofdstuk 6 geeft uitgebreid inzicht in de perspectieven van onderzoekers en jongeren met een chronische aandoening op betekenisvolle impact van PPI in onderzoek. Hiervoor is een $\mathrm{Q}$ methodologiestudie uitgevoerd onder 26 onderzoekers en 20 jongeren met ervaring in PPI. Deze methode combineert kwalitatieve en kwantitatieve technieken om systematisch te onderzoeken hoe mensen over een bepaald onderwerp denken. Deelnemers rangschikten uitspraken over impact op basis van de mate waarin hun eigen gevoelens en ideeën ermee overeenstemden. Dat deden ze in een tabel in de vorm van een omgekeerde piramide, waarbij ze enkele uitspraken aan de uiterst rechter- (meest mee eens) of linkerkant (minst mee eens) konden zetten en veel uitspraken in het midden (neutraal). Uitspraken gingen in op de soorten impact die met PPI kunnen worden gerealiseerd (bijvoorbeeld 'Jongeren krijgen nieuwe kennis en vaardigheden'). In interviews reflecteerden deelnemers op hun rangschikkingen. Factoranalyse is uitgevoerd om patronen te identificeren in de manier waarop deelnemers de uitspraken hadden gerangschikt. De interviews zijn gebruikt om de uiteindelijke factoroplossing te bepalen en te interpreteren. Vier factoren, die vier verschillende perspectieven op betekenisvolle impact vertegenwoordigen, werden geïdentificeerd: het verbeteren van de kwaliteit van het onderzoek, het faciliteren van een dialoog en begrip, het bereiken van gelijkheid en inclusiviteit en het recht doen aan de rechten van jongeren met een chronische aandoening. De eerste twee perspectieven zijn voornamelijk gebaseerd op rangschikkingen van onderzoekers, de laatste twee op die van jongeren. Daarnaast lieten de bevindingen zien dat er een onderscheid bestaat tussen betekenisvolle impact waar jongeren en onderzoekers daadwerkelijk naar streven en (onverwachtse) neveneffecten. Neveneffecten zijn vormen van impact die niet direct bijdragen aan de doelen die jongeren en professionals hadden met hun samenwerking. De bevindingen in dit hoofdstuk hebben belangrijke implicaties voor het meten van impact. Het is van belang om alle perspectieven mee te nemen in impact evaluaties en om van tevoren na te denken over de nagestreefde impact. De beschreven perspectieven kunnen als hulpmiddel dienen bij het bespreken van verschillende standpunten over betekenisvolle impact en bij het formuleren van operationele indicatoren voor betekenisvolle impact.

\section{Discussie en conclusie}

Hoofdstuk $\mathbf{7}$ is het afsluitende hoofdstuk, waarin de belangrijkste bevindingen en reflecties daarop worden gepresenteerd. Ook worden aanbevelingen gedaan voor de praktijk en toekomstig onderzoek. In het hoofdstuk wordt bediscussieerd dat de wetenschappelijke onderbouwing voor PPI van jongeren met een chronische aandoening van onvoldoende kwaliteit is. Daardoor is er onvoldoende zicht op wat werkt voor hen in PPI, in welke context en welke vorm van PPI het meeste impact heeft.

De systematische studie van tientallen onderzoeks- en innovatieprojecten waarin jongeren met een chronische aandoening waren betrokken leverde een aantal belangrijke inzichten 
op over de manieren waarop jongeren en professionals kunnen samenwerken. Zo blijkt dat verschillende vormen werken. Er worden voorbeelden gegeven van jongeren die betrokken zijn als lid van projectteams, via panels en adviesraden en door deelname aan georganiseerde sessies. Er is niet één goede manier. Dit proefschrift identificeerde ook een aantal algemene factoren die PPI kunnen faciliteren of belemmeren. Zo is het belangrijk dat de rollen en verantwoordelijkheden van jongeren duidelijk zijn en aansluiten bij hun ervaring en kunde. Idealiter bepalen jongeren en professionals samen hoe zij PPI vormgeven. Fundamenteel voor succesvolle PPI is ook dat professionals jongeren serieus nemen en iets doen met hun inbreng. Andere faciliterende factoren zijn het vroegtijdig betrekken van jongeren, het bieden van ondersteuning en het vrijmaken van voldoende tijd en middelen. Een belangrijke belemmerende factor voor PPI is de kwetsbaarheid en moeizame werving van jongeren met een chronische aandoening.

Tot slot bleek uit dit proefschrift dat jongeren met een chronische aandoening en professionals overtuigd zijn dat PPI positieve impact heeft. Veel uitspraken over impact waren echter vage en achteraf reflecties die niet onderbouwd werden met data. Een belangrijke stap vooruit is dat jongeren met een chronische aandoening en professionals vooraf bepalen wat ze met PPI willen bereiken. Doen ze het om de kwaliteit van projecten te verbeteren, meer wederzijds begrip te krijgen, een meer inclusieve samenleving te creëren of recht te doen aan de rechten van jongeren? Een duidelijke specificatie van de gewenste impact helpt om metingen te richten op impact die er echt toe doet voor betrokkenen. Het is belangrijk om te bedenken dat deze metingen niet per definitie uitgevoerd hoeven te worden met behulp van traditionele, kwantitatieve onderzoeksmethoden. $\mathrm{Er}$ is een toenemend aantal kwalitatieve of gemengde methoden beschikbaar die rekening kunnen houden met de complexiteit van PPI. 



\section{Dankwoord}


Samen kom je verder dan alleen. Dat maakt de vraag 'Would you work with me?' zo belangrijk. Ik bedank iedereen die met mij heeft gewerkt aan dit proefschrift: door mee te denken of 'gewoon' door er te zijn.

Allereerst bedank ik mijn promotor Jany Rademakers en copromotor Hennie Boeije. Zonder jullie was dit proefschrift er niet geweest. Jullie kritische commentaren hebben mij geholpen om iets te maken waar ik trots op ben. Ik heb ontzettend veel van jullie geleerd. Jany, bedankt voor je scherpe blik en vertrouwen. Bijzonder dat ik de eerste promovenda mag zijn met jou als promotor! Hennie, wat werken wij fijn samen. Jouw creativiteit inspireerde me om onderzoeken met en voor jongeren op inventieve manieren uit te voeren. Bedankt voor de ruimte om zelf te ontdekken en proberen. En voor je gezelligheid in de vorm van gebakjes, flamingofoto's en lessen over Klimt!

Ik bedank graag de beoordelingscommissie die de tijd heeft genomen om mijn proefschrift te lezen en beoordelen: Prof. dr. A.J.H.M. Beurskens, prof. dr. G.E. Nagelhout, dr. C. Dedding en dr. H.M. van de Bovenkamp.

Debora, wat fijn dat je zo geholpen hebt met de opmaak van de tekst in dit proefschrift. Het is heel mooi geworden!

Mijn dank gaat ook uit naar alle jongeren die op verschillende manieren meewerkten aan de onderzoeken in dit proefschrift en daarbuiten. Ik blijf me verwonderen dat jullie mij zo willen meenemen in jullie levensverhalen. Jullie leverden niet alleen een waardevolle bijdrage aan de onderzoeken, maar ook aan mijn ontwikkeling als onderzoeker en mens. Ik hoop dat ik ook iets voor jullie heb kunnen betekenen. De jongeren uit het voormalige Jongerenpanel van FNO - nu JongPIT - wil ik nog even in het bijzonder noemen. Jullie hebben meer dan eens meegedacht en -gewerkt aan de onderzoeken. Jullie drive om te werken aan een betere toekomst voor jongeren met een chronische aandoening is bewonderingswaardig.

Dit proefschrift schreef ik bij het Nivel. Alle lieve collega's en oud-collega's maakten het tot een fijne plek om te werken. In het bijzonder bedank ik de mensen uit het themagebied CHR: Hennie, Juliane, Hille, Marieke, Rune, Ellen, Mariska, Jill, Emiel en Annette. We doen met $z$ 'n allen prachtig onderzoek, en het is nog gezellig ook! Ook mijn kamergenootjes uit 1.12 mogen niet vergeten worden. De dagelijks wandelingen en koffierondjes om 10 uur en 15 uur zijn onmisbaar geworden. Marjon, wat heb jij bijgedragen aan de Kwaliteit2020! van dit proefschrift. Dat is absoluut geen Onzin1234! Wanneer Gaanweweer6! wat drinken? Aukelien, met jou kon ik goed filosoferen over patiëntparticipatie. Marlon, top dat wij elkaar gevonden hebben als kletsmaatje voor een prachtig tv-programma. Lisa en Laura, veel dank voor jullie gezelligheid en het meermaals corrigeren van de Engelse teksten! 
Dit dankwoord is niet compleet zonder de buren uit 1.13. Kim en Marieke, we hebben elkaars proefschriften vanaf het begin meegemaakt. Elke overwinning en tegenslag is uitgebreid besproken. De wijntjes na een gepubliceerd artikel waren steeds een klein feestje. We moeten er nog een hoop inhalen: wanneer hebben jullie tijd?

Veel dank ook aan mijn lieve familie en vrienden. Ik kan jullie niet allemaal apart noemen, maar ik ben blij dat jullie er zijn!

Lieve meiden uit J.C. Callisto, ik twijfel er niet aan dat jullie meteen naar deze bladzijdes zijn gevlogen. Cockie zei al: 'het dankwoord is toch wel het leukste deel'. Bedankt voor alle etentjes, weekendjes en spelletjesavonden. En voor het fijne lotgenotencontact met alle promoverende meiden. Sorry Sas, Died en Lies, als het gesprek voor de zoveelste keer over promoveren ging. We maken het straks goed met een hoop feestjes! Naar de maan!

Erin en Gideon, wat ben ik blij dat jullie in Amersfoort wonen! Onze wekelijkse etentjes veranderden jullie appartement in ons tweede thuis, inclusief twee peetkatten. Bedankt voor de goede gesprekken de afgelopen jaren. Maar nog veel meer bedankt voor de leuke dingen die we samen hebben meegemaakt en die afleiding boden van de serieuze dingen in het leven. Wat heb ik gelachen tijdens Memphis Maniacs, onze darttoernooien en ons weekend in Drenthe. Een feest is niet compleet zonder jullie (en Erin's verkleedkist). Onze vriendschap is mij heel dierbaar.

Lieve mama, jij leerde mij dat je alles kunt bereiken, als je er maar voor gaat. De instelling 'ik heb het nog nooit gedaan, dus ik denk dat ik het wel kan' heeft mij meer dan eens over de drempel getrokken om iets nieuws te proberen. Ook in dit proefschrift. Bedankt voor alle knuffels, kaartjes en speciaalbiertjes op de juiste momenten. Ik weet dat jij er altijd voor mij zult zijn.

Lieve papa, er zijn weinig mensen die zo trots kunnen kijken als jij. Bedankt dat je er bent en dat je in mij gelooft. Je hebt een speciaal lijntje naar mijn hart, zoals jij dat altijd zegt. Lieve Brenda, ik ben blij dat jij er bent. Bedankt voor je genegenheid, zorgen en interesse in wat ik doe. Anouk en Babette, wat fijn dat wij het zo gezellig hebben met elkaar. Het kwartet Riny, Tiny, Fred en Ed is niet meer weg te denken. Dat we nog een hoop polonaises mogen maken, samen met Roeland, Dylan en kleine Lewis!

Lieve Floor, jij bent mijn zusje en allerbeste maatje. Ik vind onze sterke band heel bijzonder. Dat jij de omslag van dit boekje hebt gemaakt maakt me nog trotser op het proefschrift. Ik kan altijd op jou rekenen, voor een goed gesprek of voor een knettergekke danssessie. Bedankt, klein smurfje!

Lieve Frank, wat ben ik gek op jou! Jij hebt dit hele proefschrift aan mijn zijde gestaan. Voor een deel zelfs letterlijk: door de pandemie werkten we zij-aan-zij aan één bureau. Ik heb 
wel eens gegrapt dat jij een eigen 'ondankswoord' zou krijgen, omdat je te hard belde, te luidruchtig je boterham at of me te veel afleidde met filmpjes. Maar dat lag misschien ook wel een beetje aan mij (dat heb je nu zwart op wit haha). Jij leert mij om niet alleen naar de grote doelen te rennen, maar om ook stil te staan en te genieten van de kleine dingen. Bedankt voor alle micro-avonturen die we samen aangaan. Binnenkort is het tijd voor ons grootste avontuur dusver: een half jaar Europa verkennen met onze eigen bus. Ik kan niet wachten!

Femke 


About the author 
Femke van Schelven was born on the 1st of March 1994 in Diemen, the Netherlands. She completed secondary school at Stedelijk Gymnasium Arnhem. In 2015, she obtained a bachelor's degree in Health and Society with honors at Wageningen University and Research. During her bachelor course, she was enrolled in courses about young people, growing up and risk behaviors at Utrecht University for one semester. Inspired by her interest in the developmental tasks of young people, she chose to enroll in a Master's in Youth Studies at Utrecht University. In 2016, she obtained her Master's degree with honors. From 2016 to 2018, Femke worked as a researcher at I\&O Research. She worked at the departments Citizen and government ('Burger \& bestuur') and Work, care and youth ('Werk, zorg \& jongeren'). She conducted various studies on citizen involvement, care provided by municipalities and substance use among young people. In March 2018, she started working as a researcher at Nivel, the Netherlands Institute for Health Services Research. She conducted various studies on care and participation of (young) people with a chronic condition. She was attached as an external PhD candidate to the department of Family Medicine of Maastricht University. 


List of publications 


\section{Publications in international journals}

Boeije H, Leemrijse C, Schelven F van. 'I cannot be missed yet': A qualitative study among relatives of people with an intellectual disability about future care planning during COVID19. Submitted.

Schelven F van, Boeije H, Inhulsen MB, Sattoe J, Rademakers J. (2019). 'We know what we are talking about': Experiences of young people with a chronic condition involved in a participatory youth panel and their perceived impact. Child Care Pract. 2019;27(2):191-207. doi:10.1080/13575279.2019.1680529

Schelven F van, Boeije H, Mariën V, Rademakers J. Patient and Public Involvement of young people with a chronic condition in projects in health and social care: A scoping review. Health Expect. 2020;23(4):789-801. doi:10.1111/hex.13069

Schelven F van, Boeije $H$, Rademakers J. Evaluating meaningful impact of Patient and Public Involvement: A Q methodology study among researchers and young people with a chronic condition. Accepted for publication in Health Expect.

Schelven F van, Meulen E van der, Kroeze N, Ketelaar M, Boeije H. Patient and public involvement of young people with a chronic condition: lessons learned and practical tips from a large participatory program. Res Involv Engagem. 2020;6(59):1-13. doi:10.1186/s40900-020-00234-1

Schelven F van, Groenewegen P, Spreeuwenberg P, Rademakers J, Boeije H. Exploring the impact of patient and public involvement of young people with a chronic condition: A multilevel analysis. Child Care Health Dev. 2021;47(2):349-356. doi:10.1111/cch.12847

Zonneveld E, Schelven F van, Boeije H. Effects of the COVID-19 pandemic on quality of life among relatives of individuals with intellectual disabilities: A longitudinal study. Submitted.

\section{Publications in national journals}

Boeije $H$, Leemrijse $C$, Schelven F van. 'Wat als ik het niet meer kan?' Een kwalitatief onderzoek onder naasten van mensen met een beperking en een intensieve zorg en ondersteuningsbehoefte. Under revision.

Menting J, Scheffer M, Spreeuwenberg P, Schelven F van. Positieve beoordeling van de zorg weinig veranderd tijdens de coronapandemie, maar nog altijd ruimte voor verbetering. Accepted for publication in TSG. 


\section{Reports and factsheets}

Boeije $H$, Heijmans $M$, Schelven F van, Kappen $H$, Inhulsen MB, Sattoe J. Overkoepelend evaluatieonderzoek: Programma Zorg én Perspectief. Utrecht: Nivel; 2019.

Boeije $\mathrm{H}$, Leemrijse $\mathrm{C}$, Schelven F van, Putter I de. Jongeren met hersenletsel op weg naar werk: Onderbouwing, optimalisering en verbreding van de Class. Utrecht: Nivel; 2019.

Boeije $\mathrm{H}$, Schelven F van, Verkaik R. Naasten van mensen met een verstandelijke beperking over hun zorgen en wensen voor de aanpak van corona. Utrecht: Nivel; 2020.

Boeije $\mathrm{H}$, Schelven F van. Een hart onder de riem: adviezen en tips voor en door naasten van mensen met een verstandelijke beperking. Utrecht: Nivel; 2020.

Boeije $\mathrm{H}$, Schelven F van, Verkaik R. Gevolgen van coronamaatregelen voor naasten van mensen met een verstandelijke beperking. Onderzoek naar kwaliteit van leven tijdens de tweede golf. Utrecht: Nivel; 2021.

Knapen J, Grosscurt R, Schelven F van, Boeije H. Het werkt anders: Handreiking om arbeidsparticipatie van mensen met een visuele of auditieve beperking te bevorderen. Utrecht: Nivel; 2020.

Menting J, Schelven F van, Grosscurt R, Spreeuwenberg P, Heijmans M. Zorgmonitor 2019. Ontwikkelingen in de zorg voor mensen met een chronische ziekte 2005-2018. Utrecht: Nivel; 2019.

Menting J. Schelven F van, Boeije H. Gevolgen van de coronapandemie voor gezondheid, behandeling en zelfmanagement van mensen met een chronische ziekte. Utrecht: Nivel; 2020.

Schelven F van, Meulen E van der, Wessels E, Boeije $\mathrm{H}$. Behandellast bij jongeren met een chronische aandoening: Begeleidende kennisbundel bij gesprekstool voor jongeren en zorgverleners. Utrecht: Nivel; 2021.

Schelven, F. van, Verkaik, R. \& Boeije, H. Kwaliteit van leven van naasten van mensen met een verstandelijke beperking tijdens de coronacrisis. Utrecht: Nivel; 2020.

Springvloet L, Schelven F van, Kroezen M, Luijkx J, Brug A ten, Putten A van der, Embregts $\mathrm{P}$, Boeije $\mathrm{H}$. Kwaliteit van leven van naasten van mensen met een beperking. Utrecht: Nivel; 2020. 
Verkaik R, Schelven F van, Boeije $\mathrm{H}$. Zorgen en zwaaien: over de ervaringen van naasten van mensen met een verstandelijke beperking met wonen, bezoek en zorg tijdens corona. Utrecht: Nivel; 2020.

\section{Other published materials}

Tool Bodymap maken: hulpmiddel bij het praten over behandellast. Available at: https://www.nivel.nl/nl/tool-bodymap-maken-hulpmiddel-bij-het-praten-overbehandellast

\section{Conference contributions}

Overkoepelend evaluatieonderzoek Zorg én Perspectief. Oral presentation at FNO Krachtpatsers Congres. Amersfoort, the Netherlands; 2019.

"We know what we are talking about": Experiences with a participatory panel of young people with a chronic condition. Oral presentation at CareDays (Science for citizens Citizens for science). Eindhoven, the Netherlands; 2019.

Involving young people with a chronic condition in participatory research and implementation projects: What is the impact? Oral presentation at International Conference on Integrated Care. Virtual conference; 2020.

Kwaliteit van leven van naasten van mensen met een beperking: Wat brengen ze naar voren en hoe kunnen ze worden ondersteund? Oral presentation at Congres Volwaardig Leven. Virtual conference; 2020.

Quality of life of family members of people with an intellectual disability before and during COVID-19. Oral presentation at IASSIDD conference. Virtual conference; 2021. 

